

PIATE I. 


\section{HEDGES AND EVERGREENS.}

A COMPLETE MANUAL

FOR THE

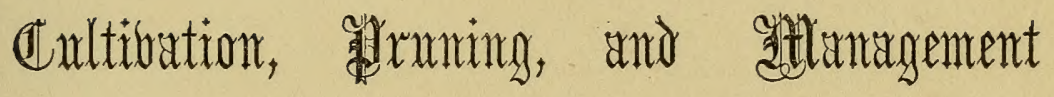

OF

ALL PLANTS SUITABLE FOR AMERICAN HEDGING;

ESPECIALLY THE

MACLURA, OR OSAGE ORANGE.

FULLY ILLUSTRATED WITH ENGRAVINGS OF PLANTS, IMPLEMENTS, AND PROCESSES.

TO WHICH IS ADDED,

\section{A TREATISE ON EVERGREENS;}

THEIR DIFFERENT VARIETIES-THEIR PROPAGATION, TRANSPLANTING, AND CULTURE IN THE CNITED STATES.

JOHN A. WARDER, M.D.,

EDITOR OF WESTERN HORTICULTURAL REVIEW, PRESIDENT OF THE CINOINNATI HORTICULTURAL SOCIETY, ETC.

Tew Xor :

A. O. MOORE, AGRICULTURAL BOOK PUBLISHER, 140 FULTON STREET. 
Entered, according to Act of Congress, in the year 1858, BY A. O. MOORE,

In the Clerk's Office of the District Court for the Southern District of New York. 


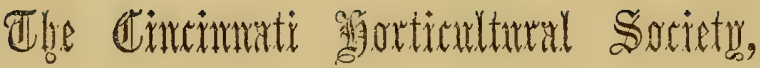

As to the Sohool of Developient of Mr Krowledge of Hontioultural, Pomological, amd Rural AfFairs, THIS LITTLE VOLUNE IS RËSPECTFULLY INBCRIBED, BY THE AUTHOR.

Cincinnati, 1858. 



\section{P R E F A C E.}

To the readers of this Essay on Hedging, I have a few words of advice and explanation to submit. The subject is one of immense importance to the future of this country, inasmuch as it is an efficient arm of the great agricultural interest. The people of these United States have settled the question of distinct inclosures, whether wisely or otherwise, in the affirmative. Fences of some kind being one of the recognized institutions of our country, and the majority of our best farms being destitute of rock for walls, and being rapidly divested of timber for wooden fences, foreign materials, whether of boards or iron, present themselves as candidates for public favor: and I here beg to offer that agreeable alternative-the useful, the economical, the practical, and at the same time, the ornamental, LiveFence or Hedge.

The reasons for presenting myself in this manner before my brother farmers are:- First, the great 
importance of the subject to the country, and the desire to have the matter properly understood. Secondly, the apprehension that many persons throughout the land are laboring under incorrect notions upon the subject of Hedging. Thirdly, that the directions for the modes of procedure are often deficient in practical detail, and not only very contradictory, but scattered through the evanescent journals of the day, and rarely accessible to the agricultural reader. Fourthly, that many of the ephemeral productions which attempt to instruct the young hedger are fallacious and erroneous, and are therefore likely not only to mislead the uninitiated, but also to bring discredit upon the whole subject. Fifthly and lastlyfor you must think me already well fortified with reasons-my friends urged me to the discharge of this duty, and I willingly perform the labor.

This important part of the preface being disposed of, it may be further stated, that though I have never laid claim to the distinguished honor of being: the "Father of the Maclura Hedge," I have always been an admirer of Live-Fences-have for years repeatedly written and spoken upon this topic for the agriculturists of my country-and, moreover, have planted and tended a good deal of Hedge, and expect to continue so doing; and yet, though an earnest advocate for this kind of fence, am perfectly 
disinterested, having never sold a hedge-plant in my life, and expecting, while I have a rod to plant, that I shall continue a purchaser.

I should here acknowledge my obligations to those authors from whose pages and writings $I$ have now or heretofore drawn more or less extensively, in making up the compendium of opinions about to be set forth. The boast of originality is not one of my weaknesses; for so singular a sponge is the human mind, and so treacherous is the memory, that we never can know as to the originality of aught beyond the bare record of an observation - whether the deductions we have consequently made, be really our own, or whether we may not have absorbed them from another, at some forgotten period, is all guesswork; and too often we see men, like Mr. Grenning, in Talpa, who have coldly received our suggestions in past days, presenting them boldly as their own at some future period. With regard to certain principles in hedging, which early attracted my attention so forcibly as to induce their distinct exposition, this remark has been rendered feelingly true by many a $\mathrm{Mr}$. Greening, who at first even forcibly combated and rejected the propositions, which they now, I am glad to know, bring forward triumphantly as unquestionable truths; and for which they are unwilling to admit any paternity but their own. 
In the preparation of this work, I have been unwilling to trust entirely to my own personal observations; although, having enjoyed very extended opportunities for seeing what others have done in many parts of our country, and having been familiar with hedges from my infancy, and an operator for some years past upon my own grounds, I might be considered a competent witness. I have therefore consulted all the authorities at command, among which my indebtedness should be acknowledged to the several State Agricultural Societies' valuable Reports, to JoHnson's "Farmer's Encyclopedia," to McMahon's "Gardener," to the "Patent Office Reports," to the "Manual" of E. SAYERS, to the "Encyclopedias," to "CoLMan's Reports," to The Western Agriculturist, to The Western Farmer and Gardener, and to various Agricultural Periodicals-among which, those most frequently instructive in this department of Rural Economy are: The Prairie Furmer, of Illinois; The Cultivator, and The Farmer, of Ohio ; and The Horticulturist. Also especially to the "Prize-Essays" of C. R. Overman, of Illinois, and of Jas. McGrew, of Ohio; besides several shorter articles issued by those engaged in the sale of plants and seed. To the authors of all of which I tender my sincere thanks, trusting that if they should happen to recognize their sentiments in these pages, set forth without the credit 
they may think due unto themselves, they will consider this a sufficient acknowledgment, and be satisfied that my attempts to diffuse valuable information will also extend their useful efforts to a wider circle.

That all may strive for the diffusion of useful knowledge, is the desire of

Aston, Sunset Avenue,

THE AUTHOR.

North Bend, 0. 1857. $\}$ 



\section{TABLE OF CONTENTS.}

\section{PART I. - HEDGE MANUAL.}

CHAPTER I.

General Introduction-History of Hedging-Reasons for Hedging-Economy-Influence on Climate-Morality.........

CHAPTER II.

Selection of Hedge Plants-Hedges for various purposes .......

CHAPTER III.

Selection of Plants, continued-the Shelter, Screen, Barrier, and

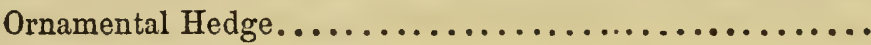

CHAPTER IV.

The Maclura Hedge-Why it has Failed-Seed, Sprouting, Planting, Taking up the Plants, Sorting, Wintering, Puddling,

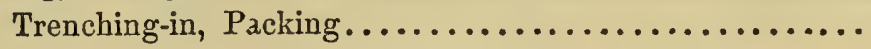

CHAPTER V.

Hedge-Making-How to do it-Preparation of the Hedge-RowSetting the Plants-Distance-Culture the First Year-Shall the Hedge be Trimmed ?........................

CHAPTER VI.

Hedge-Making, continued-Second Year-Replanting-CultureTrimming-Third Year-Culture, Mulching, Finishing up, and Seeding-Implements - Shape of the Hedge.......... 
CHAPTER VII.

Fourth and Future Years-the Perfect Hedge-the FinalityPAGE

Root-Pruning-the Comparative Cost-Climatic EffectsCorrecting Defective Hedges....................

\section{CHAPTER VIII.}

Objectors Answered-False Methods-European Plans unfit for Us. .

\section{CHAPTER IX.}

The Philosophy of Pruning-Summer and Winter Trimming-

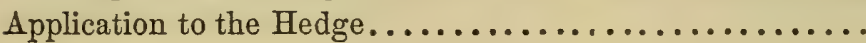

\section{CHAPTER $\mathrm{X}$.}

Jurisprudence of Fences - the Laws of Maine, Massachusetts, New Hampshire, Vermont, Connecticut, New York, Nerw Jersey, Pennsylvania, Delaware, Virginia, Maryland, North Carolina, South Carolina, Georgia, Alabama, Florida, Mississippi, Louisiana, Missouri, Tennessee, Kentucky, Ohio, Indiana, Illinois, Iowa, Wisconsin, Michigan, Texas, California-Remarks-Advice-Proposition-English Usage...........

\section{A P P E N D X.}

Resolution of Ohio State Agricultural Society-Communication of James McGrew-Statement of A. H. Ernst-Communication from D. Landreth-Letter from Prof. J. B. Turner-Letter from Daniel Gano-Letter from Sleeper \& Lindly.........

\section{PART II.-EVERGREENS.}

INTRODUCTION.

Evergreens-Ornament-Economy - Transplanting - Time for

Planting-Pruning....................... 223-229

Evergreen Hedges......................... 240

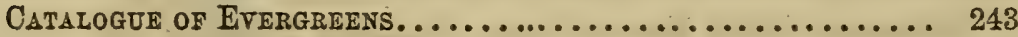

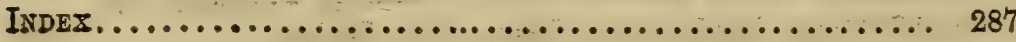




\section{IIST OF PIATES.}

PLATE I. Pinus pinaster (Frontispiece).

II. Cratcegus oxycanthus-Buckthorn.

III. Laurus nobilus-Noble Laurel.

Crastcegus crus-galti-Cockspur.

IV. Gleditschia triacanthos-Honey-Locust.

V. Maclura auriantica-Osage Orange.

VI. Pinus laricio-Larch-Pine (FroNTISPIECE to "EVERGREENs").

VII. Pinus sylvestris-Scotch Pine.

VIII. Abies excelsa-Norway Spruce.

IX. Abies alba-the White Spruce Fir.

Abies Smithiana-Himalayan Spruce Fir.

X. Picea balsamifera-Balm of Gilead, Silver Fir.

Abies Douglasii-Douglas Spruce Fir.

XI. Picea pectinata-European Silver Fir.

XII. Magnolia grandiflora.

Magnolia glauca.

\section{LIST OF ENGRÄVINGS IN TEXT.}

II.

III. Growth of Second Summer, . . . . . . . . . 85

IV. "Third " . . . . . . . . . 90

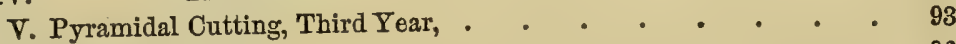

VI. Slashing-Knives, . • . . • • • • • • . 96

VII. Perfect Hedge, • • c • • c • • • • . 104

VIII. Hedge trained in Lattice Form, . • . • • . . . 127

IX. Looping Plan of Hedge, $\quad$ • • • • • • • • • 128

$\mathrm{X}$. End-View of Badly-trimmed Hedge, . . . . . . . 129

XI. Net-Work Hedge, . • • • • • . • • • • 188

XII. Ilex aquifolium, . • . • . . . . . . . 273

XIII. Ilex opaca, • • • • • • • • • • • • • 274

XIV. Rhododendron catarobiense, . . . . . . . . . 277

XV. Kalmia latifolia, . • • • • • • • • • • 278 



\section{H E D G I G .}

CHAPTER I.

General Introduction-History-Reasons for Hedging-Economy -Beadtr-Shelter-Protection-Effect on Climate-Morality.

Lrve-Fences, or-as they are commonly calledHEDGES, are a means of inclosure that belongs to an advanced state of civilization: hence we rarely find them in a new country; unless we except such portions of our Western prairies as have been suddenly populated by a people highly advanced in agricultural progress, and, in this respect, very different from the usual character of the early pioneers, who were obliged slowly to conquer the red man, and the unbroken forests of other regions.

We do not always find this kind of inclosure, however, as an attendant upon the highest state of agriculture; for there may be circumstances under which hedging would not be advisable. As a general proposition, where the farms are very small, and need to be much subdivided into small fields, the hedge occupies too large a proportion of the soil. Thus, in France, in Belgium, in parts of Great Britain, and in some other countries, where the highest culture prevails, 
we find that the people are content to hold their fields in common, or with only a pathway between their several allotments of land. In most parts of the world, however-high civilization to the contrary-we find man's selfish nature disposes him to fence out intruders: and our venerable ancestors in Great Britain, having always understood the ethics of meum and turum, have for centuries been careful to inclose their possessions; and, as other material for fencing was scarce in the cultivated portions of the country, hedges were generally adopted, and are the most common means of subdivision: we, their descendants, equally regard our individuality; and our people have universally desired to preserve their own property inclosed from intrusion, whether by erecting the cumbrous zig-zag worm-fence, or some other wooden structure, or-in those portions of the country where stones abound - by piling them up in substantial walls, centennial works, defying the tooth of Time.

In some portions of our Western country, essentially agricultural, and where the grain-growing interest largely preponderates over the grazing and stockraising, it is now seriously proposed to enact laws providing for the inclosure of all domestic animals, in order to avoid the expense of fencing in the extensive grain-fields; in this, the grain-growers of Northern Illinois are but imitating the French, Belgians, and other nations in countries where fencing materials are no longer attainable. In some parts of Illinois, I believe, already such a custom or law prevails-every farmer being obliged to keep his stock within his own inclosures. In the neighborhood of many of our 
Eastern cities, also, where the highest culture exists, the fences are mere formalities, and the gates at the entrances of splendid lawns and parks, that contain the most beautiful plantations, are frequently left open for months together-so entirely safe are they from the trespasses of cattle in the roads.

In the Western Agriculturist - an excellent compendium, issued under the direction of the Hamilton County Agricultural Society, in 1830 - under the article "Fences," some passages occur which show, that even then the expense and inefficiency of fences were severely felt, and legislation was called for. The writer quotes one of the most scientific farmers of the county, to the following effect: "Without fear of contradiction from our experienced farmers, I pronounce this to be the leak which prevents the filling up of our cup of bliss: as things are managed in the Western country, it is worse than a leak; it is a sore, a blotch, the source of perpetual discontent, the 'fretting leprosy' of the land. Tell us how this is to be cured, and your book shall be immortal-'semper honos, nomenque tuum, laudesque manebunt.' * * * The mode of inclosing, as here practiced, and the urgent necessity there is for the strongest fortifications, in consequence of the barbarous practice of suffering stock of all kinds to run at large, keeps the farmer poor, and groveling, and ignorant, and creates more rustic quarrels than any other thing-whisky not excepted." The writer then urges the necessity of penal enactments against the running at large of all kinds of stock. His suggestions have had little effect upon our law-makers. More than a 
quarter of a century has elapsed, and the same state of things exists: except that my excellent neighbor has fortified himself by erecting some of the best walls and fences anywhere to be seen; and he has contracted for a maclura hedge on one of his boundarylines.

For the most of us farmers and planters in this wicked world, then, it is found necessary to erect barriers against our neighbors-and thus it has been from remote antiquity. Nor are hedges a modern invention: in the Bible we read of the vineyard being hedged about; Homer tells us that the old Liaërtes was planting a hedge, when his son Ulysses returned from the Trojan War. The old Latin writers tell us of thorns used for making live-fences; hawthorn hedges were used in Italy in the fourteenth century, and in England they have been used since the times of the Romans. Indeed, the hedge is one of the most interesting features of the European landscape, and is a fruitful topic for the poet-who here finds, in its shade, its flowers, and fruit, as well as in the gentle florets, and animated birds which are fed and protected by it, so many rural sights and sounds wherewith to embellish and enliven his verse.

The advantages and the necessity for this kind of inclosure will depend upon the character and condition of the country. Where timber of good quality abounds, or where easy access may be had by water or railroads to a lumber region, or where stone is an incumbrance to the soil, these materials may be preferred for fencing; so, also, where small farms and limited inclosures prevail, live-fences may not be 
desirable; but, wherever the ruthless axe has produced its havoc among the primeval forest growth, upon a fertile soil, which is kept under the tillage of the plow, with no mountain-ridges near, as a reserve for forest growths, the scarcity of timber soon becomes very apparent: so, also, on our naked, treeless prairies-the green oceans of the West-those boundless savannahs, which stretch from one side of the horizon to the other, the want of timber renders the introduction of live-fences a matter of great moment. Our fellow-citizens in Mllinois fully appreciate this boon to their prairie country, and are striving, by means of the Maclura, to inclose the country that lies open, ready cleared, before them.

It being conceded that, with our mixed agriculture, we must have inclosures, the important question arises, Of what shall they be made? I shall not insist upon the use of hedging where the farms are supplied with these appliances, or where the farmers have secured other legislative provision for their protection from encroachment; and yet even to those the hedge may be presented farorably, on account of other qualities that are well worthy of consideration. Among these, their beauty, their protection and shelter, as well as their happy effect upon the temperature and moisture of the climate of a country, may all be urged as arguments in favor of some sort of live-fences.

Economy.-It is a common saying, that if you touch an American's pocket, you may expect to reach his soul. Here, then, the advocate of hedges may hope to make an impression; for, surely, this kind of inclosure has fair claims to be ranked as the cheapest of all 
fences. Hedges are not now thought to require one or two large ditches to protect them; neither is it found necessary, as heretofore, to fence the fences. A little time is requisite to be sure, but not so much with our present hedge-plants as with those formerly used; and when once made, there is only a trifling annual expense requisite to maintain the hedge in good order-nobody knows how long. E. Sayers, in his manual, asserts, that on land of tolerable fertility, the labor and expense of perfecting a system of hedges would not be greater than to keep our ordinary inclosures in good order, for the time required to construct them. When completed, this heavy item in every farmer's account would be expunged. Further details of the cost will be given in another place; for there is an abundance of testimony to the economy of hedging.

Beauty.-All writers and travellers tell us of this beautiful feature of the landscape in various parts of the Old World, where hedges abound; those who have visited the cultivated piains of France and Belgium, on the other hand, complain of the monotony of the scene, where no lines of green separate the different fields; and the universal testimony of European travellers in our own country is, that the worm-fences are uncouth and cumbrous, and that there is a consequent want of finish in the appearance of the landscape. How exceedingly happy would be the effect produced by these lines of green-especially on an uneven surface, where they would rise and fall in easy and natural curves-may be imagined by those who have had the opportunity of observing, even in a 
limited degree, well-grown and well-trimmed livefences.

For protection, nothing in the way of inclosure, from the yawning ditch to the sharp picketed iron fence, or the high wall, can equal the perfect livehedge. When properly constructed, it is absolutely impassable to man and boy, to boar or bison, to fox or rabbit, and should scarcely afford shelter to mouse or snake: as to pigs and poultry, they will neither penetrate nor fly over a hedge that has been well made; and they will for ever remain in profound ignorance of what is transpiring in the outer regions.

Shelter from the elements, as well as from prying eyes, is frequently a desideratum to be obtained from a screen of living green, and will be appreciated by those who, upon a wintry day, have found themselves upon the sunny side of a row of cedars or other evergreens. Shelter from the cold winds is often a matter of great importance to the gardener: this may be much better obtained from an evergreen hedge than from a board-fence, even though it be close ; and certainly, the former is the more agreeable object to contemplate.

The landscape gardener well understands the value of screens to shut out disagreeable objects, or to give a sense of protection from the idle gaze of strangers. For this purpose, a peculiar sort of hedge is required, which may act as a protecting barrier, or otherwiseaccording to the taste and objects of the planter.

Climate, Temperature, and Hygrometricity.-Under the previous head, allusion was made to the influence upon temperature that is produced by a close ever- 
green hedge; it is believed also that the mean temperature of a whole country, especially an open champaign country, would be very considerably modified, were its surface intersected with common hedges, dividing it into twenty-acre fields. This has been urged with considerable force by the able editor of The Prairie Farmer, as an inducement to plant hedges in the West. The happy influence of a hedge in protecting fields of grain from the cutting effects of the wintry blasts have been noticed by every farmer.

Other equally important climatic results have been observed-which may be called the hygrometric. In a high wind, as is well known, evaporation progresses more rapidly than in a gentle breeze, or in a calm. When, therefore, tender young crops are exposed, they will often suffer from the rapid evaporation that is caused by a strong current of air; but if an obstruction can be presented that will reduce the force of the current, we shall also diminish the evaporation. This may be done to a great extent by hedging, so as materially to modify the climate; and as our country has a decided tendency to aridity, important results may ensue from the observance of any means that lie in our power to regulate this. The barrenness of the great Western plains of our continent is said to depend more upon their aridity, and the constant evaporation caused by the winds that sweep over their surface, than upon any deficiency in the soil. It has been suggested, that the first step toward the settlement of such a country would be, to plant belts of trees of the hardiest drought-enduring kinds-such as Ailanthus, Catalpa, \&c. 
M. Kelly, a very intelligent nurseryman of Cincinnati, called my attention to this subject, and has happily carried out the principle upon his grounds. He plants in such a manner as to have close rows of evergreens, at distances of fifty feet, that shall come on in succession, as those of larger growth are removed. These he finds sufficient to reduce the current of air in a storm, with a velocity of fifty miles an hour, to that of a gentle breeze, or five miles an hour. This applies to the surface only; but that is the very point at which he wishes to protect the young vegetation from the effects of violent evaporation.

The editor of The Prairie Farmer has given some suggestions on this subject. He thinks the preservation and extension of forest growth, and the division of the prairies into twenty-acre lots, by the dense hedges of maclura, would be equivalent to four or five degrees of latitude sonth during the growing season, and to half that in Winter. This is an off-hand estimate of the effect on climate, yet it is not beyond the known probability. The beauty of hedges - when contrasted with wooden fences-is too obvious for further argument.

These are some of the valuable results of hedging, independentof the common questions of efficiency and economy : they may appear trivial, and possibly may be considered fallacious, but I believe they are important, and real; and have therefore presented them in this part of the essay.

Morality.-In the words of one of my neighbors, quoted on a previous page, the immorality of our common system of fencing, and its cause-the free 
range of everybody's hungry kine, and other stockwas well set forth. May it not be shown, that if perfect hedges were generally introduced, a great improvement in the morals of the community would necessarily ensue? I shall take the affirmative of this question. The fruitful source of disagreements among: neighbors would be removed. The troublesome animals that are turned out to make their own living upon the highways, and which are constantly encroaching upon private property, that board and rail fences will not protect, would soon die of starvation, and our troubles would have an end. Other more accountable beings often trespass upon us, to gratify their appetites at our expense, and though the law does not consider them guilty of stealing, there must be a wear and tear of their consciences, that is as unhealthy to them as their acts are unprofitable to us, the occupants of the soil. If, therefore, these breaches of propriety can be prevented by the construction of good hedges, the act may fairly be set down as a contribution to the morality of the community. 


\section{CHAPTER II.}

Selection of the Plants-Dependent upon tue Object in TiewProtection and Defence.

The choice of the plants, with which to construct our hedges, will depend upon the soil, situation, and climate; and also upon the especial object the planter may have in view. If, as is generally the case, he wishes to produce a barrier against depredation from without, and to prevent escape of his own animals from within, some plant must be selected that shall have the strength necessary to effect that object, with bushiness of habit, and a more or less thorny character. Hedges are often needed for shelter alone, or shelter combined with protection-in which case, a different sort of plant may be preferred: here the evergreens will often be selected, since they retain their foliage at a season when the shelter from biting winds is most needed. Very often, however, the landscape-gardener, or amateur planter, desires to make a hedge as a screen to some disagreeable object, or may wish to use this means of providing an ornament to the grounds under his care; in which case, he would make a very different selection of plants from those which would be preferred for a fence of protection.

When the subject of live-fences first attracted the 
attention of farmers in this country, our European predilections very naturally induced us to look to the English hawthorn (Cratogus oxycanthus), as the plant which would be most suitable for this purpose, and repeated attempts were made by the earliest planters, some of whom were entirely successful; others, and by far the greater number, failed in effecting the object, not so much from any inherent defect of the thorn, as from sheer neglect in its management, and often, too, where the operators professed to be expert English hedgers. Too generally, the hedge was allowed, in the course of a few years, to become an irregular row of tall bushes, which might make a shady lane, redolent of sweets in the blossoming Spring-time, and ornamented with rich clusters of coral berries, attractive to the birds in Winter, beautiful to the poet at either season, but of small value as a fence, and possessing little to attract the eye of the good farmer, as an ornamental protection to his crops; too often, indeed, requiring a wooden fence or a stone wall on either side, to make it at all protective.

There are, however, exceptions to this. In the United States, there are many handsome hedges of the English hawthorn, which are entirely effective; and in Ohio, Indiana, and Illinois, as well as in some of the older States, there are those who have been so entirely successful with this plant as to feel perfectly satisfied with it. The English thorn, in the first attempts in hedging, was most commonly planted, because it was readily and cheaply obtained by importation from England. Other plants had then to be 



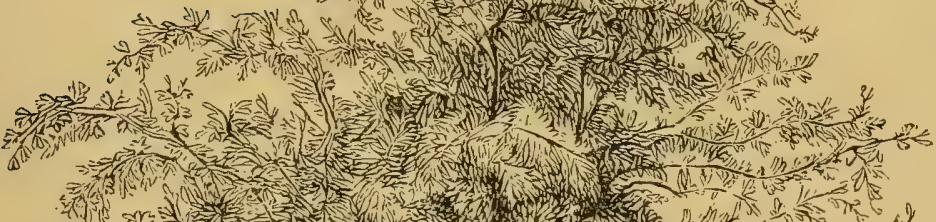

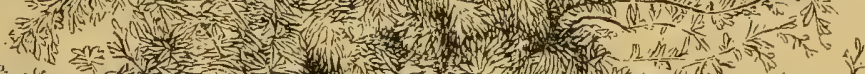

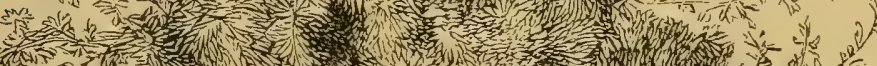

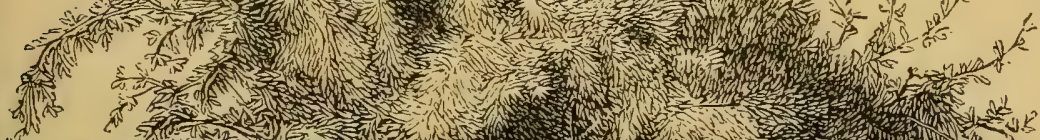

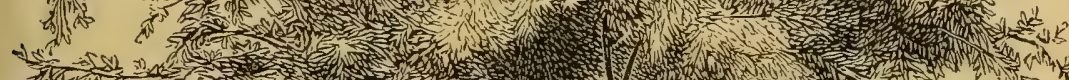
3

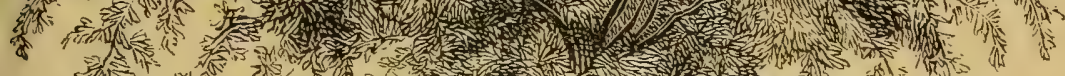

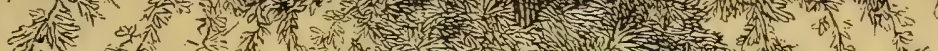

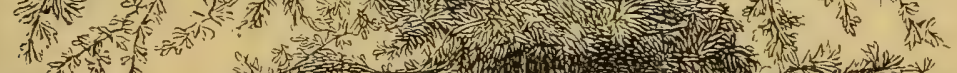

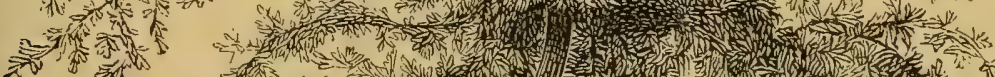

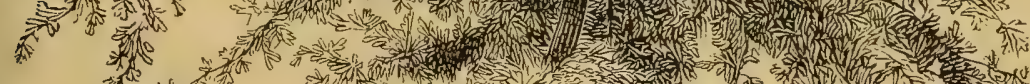

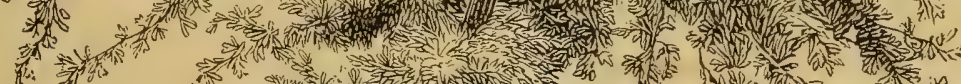
留

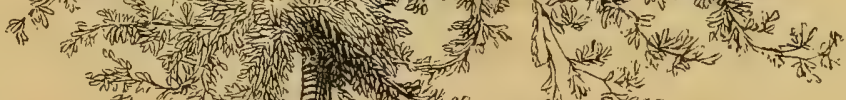
\%

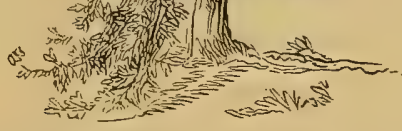

URATAGUS OXYCANTHUS.

Harothorn.-(SEE PAGE 24.) 



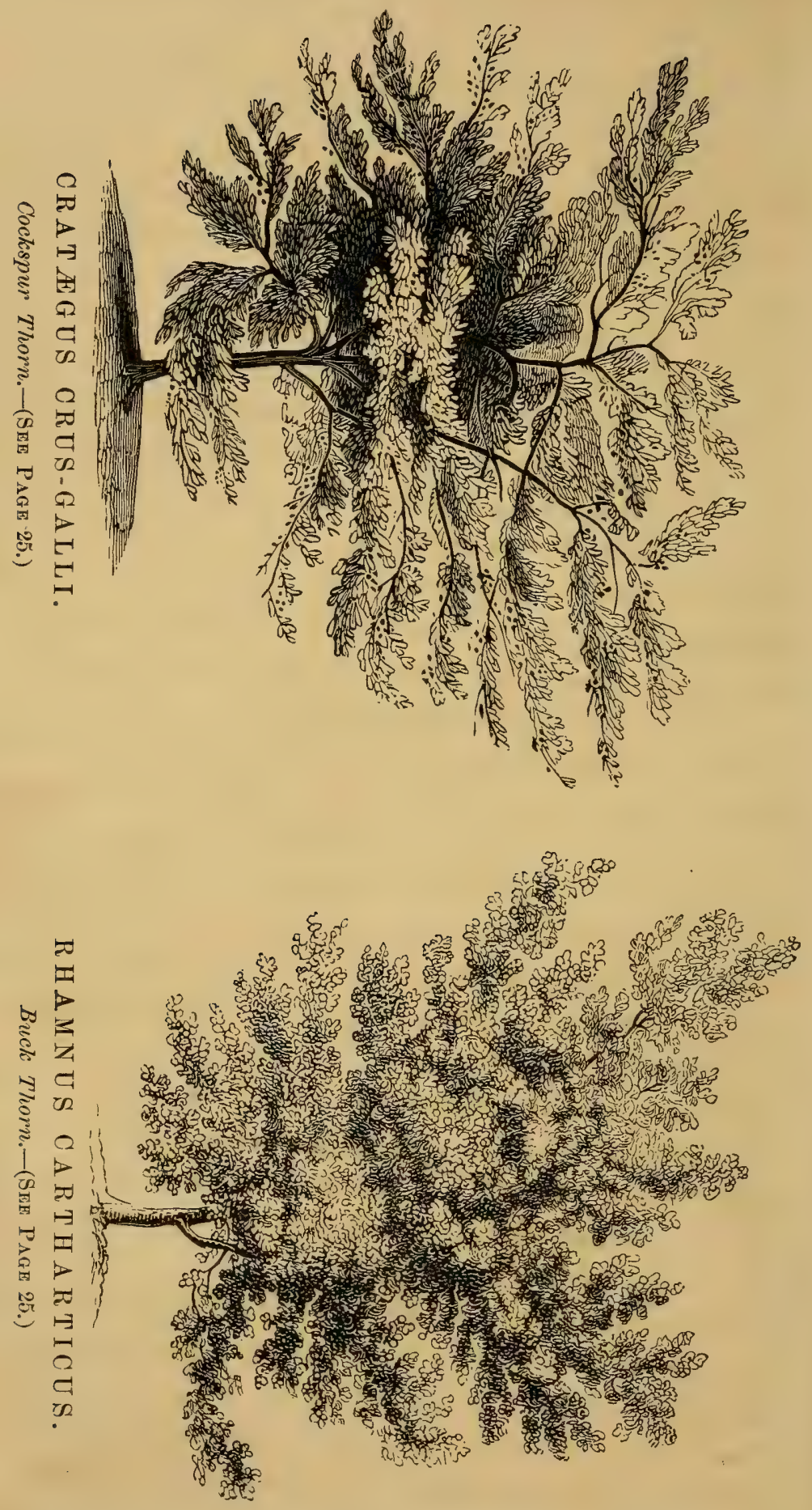
grown in this country, before the nurserymen were able to supply the demand, as they have since done, with this and other plants, in great abundance. The introduction of this thorn, and its improper treatment, have doubtless contributed much to the disfavor with which hedging is often viewed by many of our countrymen. For even those who have fortunately succeeded in erecting a protective barrier with the English hawthorn, whether by the laborious plashing and trimming, or by trimming alone, have found that the droughts of our summers caused the leaves to fall from this native of a cooler and more humid clime; and, after midsummer, there was little foliage, but a naked fence of dead-looking brush.

Similar objections apply with great force to many of our own thorns; but there may be some among this beautiful family which are not subject to the same defect: one is well known to be free from it, the Cockspur (Cratogus crusgalli), used extensively about Wilmington, Delaware--where there are some of the finest and best-grown farm-hedges that are to be found on our continent. This plant is a native of our Middle States, and is truly beautiful, with its deep green and highly-polished leaves, which are long and entire, or with a finely serrated margin: the thorns are very long, slender, and tough; so that it is well adapted to the purpose.

The Buckthorn (Rhamnus catharticus), indigenous to our country, as well as to Northern Europe and Asia, is a bushy plant, growing from ten to fifteen feet high, not very thorny, but having sharp stiff spurs, or side branches. It is very easily propagated 
by seeds, and is considerably used as a hedge-plant in the Northern States, for which purpose, on account of its hardiness, it is there especially adapted. In the Transactions of the Essex County Agricultural Society is an account of a very successful hedge, grown by Mr. Derby, of Salem, Mass. ; his first hedge had not lost a plant in thirty-three years, nor was it attacked by any insect.

The buckthorn sncceeds remarkably well, also, as far south as $39^{\circ}$ north latitude, where it retains its small, dark-green leaves until late in the Autumn. This plant bears clipping remarkably well, does not suffer from extreme cold, puts on its greenness early in the Spring, and is possessed of great vitalityso that it seldom suffers from transplanting. It is generally set in the hedge-row at about nine inches distance apart.

The native Crab Apple (Pyrus coronaria), has been planted for hedges with some success: it may be grown from seed, but is less vigorous than some other plants: it bears clipping very well, it is exquisitely beautiful when clothed with its very fragrant blossoms, that are the prettiest of all the apple flowers: but this plant is open to the objection made to most of its congeners of the thorn family-it is apt to lose its foliage after midsummer. The peculiar beauty of the wild crab being its dwarf tree habit, in which it sometimes assumes the most picturesque forms, it may be mingled with other plants with great advantage, where it is desirable to produce an effect, by training a little tree, here and there above the hedge, to break the monotony of the continuous line: for this purpose the crab has no equals. 


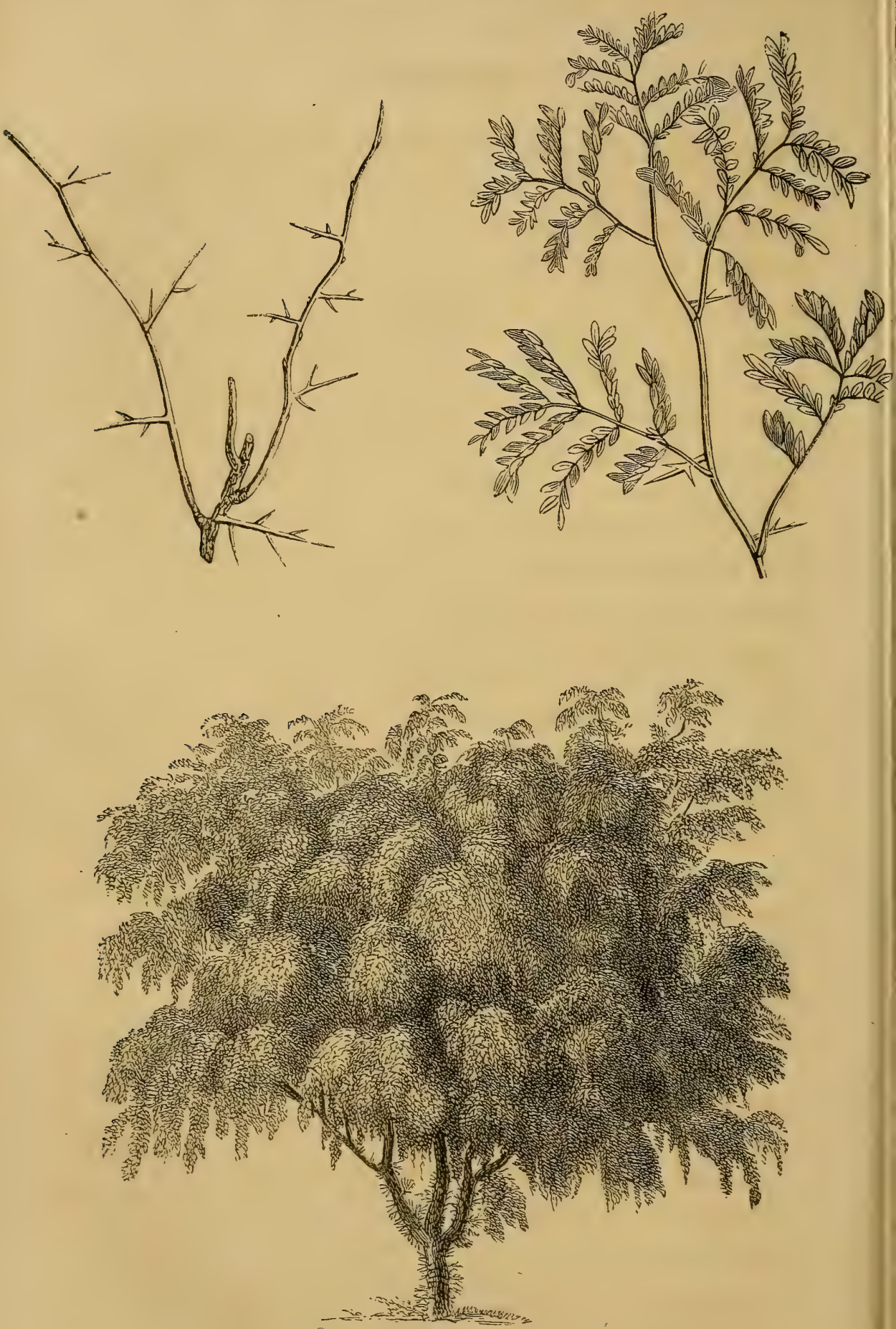

GLEDITSCHIA TRIA CANTHUS.

Honey Locust.-(SEe PAGE 27. 
The Honey-locust (Gleditschia triacanthos), is in our forests a large tree, draped in a most beautiful foliage, and armed with terrific thorns. The size attained by this tree in its native wilds would appear to disqualify it for the purpose of hedging; but its thorns and the peculiar tendency of its branches to form sturdy, short-jointed spray, when subjected to close pruning, make it a capital material from which to form an impregnable barrier upon the outside of farm inclosures: vineyards and orchards inclosed with the three-thorned acacia would need little guarding against depredators. My favorable ideas of this plant for our purpose have not been derived from many good specimen hedges, but from the round, impenetrable masses of thorns and spray that may be found in any of our closely-fed commons, where the cattle have browsed off the tender young shoots, as fast as they were produced.

Though a strong grower, and one that will require the most severe pruning to make a hedge, and though almost every writer and experimenter has condemned the honey-locust as unfit for a hedge-plant, my own observations of it, as seen in the commons and by the road-sides, have satisfied me that it is worthy of further trial as an outside fence: my reasons are, its easy propagation, its strong and rapid growth, its endurance of severe clipping, and its tendency, when cut-in, to produce a multitude of strong, short-jointed shoots, while the whole plant is covered with terrible thorns, that bid defiance to man and beast. Generally, the hedges that I have seen of this locust have failed from too close planting, by which means a large proportion 
of the plants were smothered; and then, from want of trimming, the result was very soon a row of trees. I shall plant three feet apart, beside a public road, and trim severely, as often as may seem needful, until the bush habit be established; nor ever allow a leader to grow a yard above the hedge-top: and by this course I shall expect to have an impenetrable hedge in two, or at most three, years from planting. Few hedgers have done their duty with this plant: they have crowded the hedge-row, and then neglected the needful severity in pruning. Every common will give us positive evidence in favor of this plant, as an offset to the failures of unphilosophic experimenters, who denounced it as unworthy further trial, because it would not make a hedge of its own free-will and accord, and in spite of their neglect.

Wm. Reid, of Elizabethtown, N. Y., who has been a very successful experimenter with various hedgeplants, considers the honey-locust the best for farm hedges. After twenty years' trial, he is satisfied that it is more easily kept, and better adapted for a farm-fence, than any other that has yet been used. When properly cut, it looks as well as any deciduous plant-as I can myself testify, from an inspection of his different hedges. The editor of The Hortisulturist prefers it to the maclura, because, he says, it does not sucker-in this no backwoodsman will concur; for we know that the gleditschia is very prone to sucker in plowed land; but we have never known a maclura to do so. The desideratum of a good defensive, and, at the same time, ornamental hedge, would seem to be supplied, says that editor, in the buckthorn and the honey-locust. 
A. H. Ernst, one of our oldest horticulturists, has had a good deal of experience in hedging, which, I know, will be acceptable as testimony in a work like this. On some points, however, we do not entirely agree. In a communication to the Western Horticultural Review, he gives the result of twenty-ive years' observation and experience, with the influence of climate on plants and hedging.

"Having, in my boyhood, in my own 'fatherland,' imbibed a strong love for the beautiful and graceful hedge, which there lines every roadside, no other stimulus than its recollection was required to prompt attention to it, at the first moment I became a landowner. Consulting the best authors, and such other experienced aids as I could command, I went to work with a corresponding zeal. My first experiment was with the privet or prim; of this I had nearly half a mile planted, which grew and flourished as beautifully and luxuriantly as the heart could wish, until it became necessary to bring it to a stationary point by the shears; it then became affected in spots with a blight, producing death: this spread, until my beautiful hedge, the admiration of every one who passed by, became a most unsightly and worthless affair.

"Next I attempted with several varieties of our native whitethorn, which I found indigenous on my land. These all grew finely while young; but in the process of forming the hedge, when it became necessary to bring it to a stationary point, by summer shearing, the leaves turned yellow, and dropping off, left the plants naked of foliage after midsummer; from these mischievous effects it has never recovered. 
"I also experimented on the honey-locust, the plants of which I raised from seed: these flourished beautifully; but after being planted in hedge-rows, and as they grew larger, they commenced dying out-satisfying me that it is not a plant which will bear crowding, or subjection to the hedge form.

"Then I planted the Washington thorn, and buckthorn: both grew beautifully-the former throwing up straight and vigorous stems after each Spring's cutting down, with but little disposition, however, to form laterals, or to fill up below. It continued thus to flourish until it became necessary to plash it; since which it is evidently becoming enfeebled, and shows symptoms of speedily sharing the fate of its predecessors. The buckthorn has, on the contrary, evinced a hardiness and ability to flourish under every treatment to which it has been subjected-recommending itself very strongly to my confidence, as being well adapted for hedging in our climate, though a northern plant. It is remarkable for spreading at the bottom, throwing out strong laterals, almost at right angles, near the ground; and is dwarfish in its habit of growth, but has no thorns, which makes it undesirable for an outside protector: still, it forms spurs which are stiff and pointed; so that with care in plashing it will make a capital fence, and certainly one of great beauty. The plants are easily raised from seed. I have seen the fruitless attempts to bring the black-locust, sweetbriar, and other native and foreign plants, into use for hedging.

"With due respect for the feelings of zealous advocates, I feel that I hazard nothing in saying, that 
as yet hedging for fencing and protection, in a practical point of view, is only in the process of experiment with us. We have been accustomed to look to Europe for lessons of instruction-a land in which almost every variety of tree is made to assume the hedge form with entire success-where the solar rays are far less intense and severe. To this source we have looked for instruction, and attempted to carry their practice into effect, withont duly considering the difference of climate. Plants, under their comparatively mild and more humid atmosphere, are sheared through the Summer, and exposed with perfect impunity. If the same treatment is applied to them here, and divested of foliage by the shears or hedge-hook, while under the influence of a partial suspension of vegetation, for want of necessary moisture in the earth during the excessive droughts which almost always occur after midsummer, and thus exposed to our brilliant sun's rays, the most pernicious effects on them will be the consequences, and it will not require many repetitions to cause disease and their destruction. That this is no visionary speculation, I need only name the fact, that the plants on which I have experimented are indigenous to our soil and climate, where, in their natural state, and isolated, they flourish most luxuriantly. I am well aware that almost all young woody deciduous plants will bear cutting down, no matter how low, so that it is not below the neck, and throw up a strong growth; but it is only safe do to this in the Spring; if repeated after June, it is at the imminent risk of the destruction of the plant. The more rampant its growth, the 
greater care is necessary not to check it up too suddenly and severely.

"While, however, I would inculcate caution to those who are inexperienced in hedging, against the evils of too much severity in pruning at the improper time, I give my full sanction to the necessity of so pruning as to secure a close and compact base. If a plant will not bear this treatment, it had better be discarded, for without such compactness a hedge is not worth the trouble of planting."

Various other plants have been applied to the purpose, in this country and in Europe; some of which will be considered under the heads to which they appropriately belong: but, for a fence of defence, the first in importance, and that which has pre-eminent qualities, is the Maclura, Bodark (Bois d'arc) or Osage Orange, a native of Arkansas and Texas, but admirably adapted to our climate, growing luxuriantly, and withstanding our Winter very well. The Maclura claims our attention as a hedge-plant, on account of its beautiful bright green and shining foliage, which is retained until late in the Autumn, as well as for its vigorous growth, and the admirable manner in which it bears the clippings necessary to make a good hedge.

The Buffalo Berry (Sheperdia eleagnoides), is a peculiar thorny plant, with a silvery foliage, that is not very abundant. It grows on the Rocky Mountains, whence it was brought by the botanist Nuttall, who named it from an English horticulturalist. The plant is diccious, and bears bright red berries. James Winship, of Brighton, near Boston, has the honor of 
having first introduced it to notice as a hedge-plant, for which, its thick growth and spiny spurs may render it suitable; but it is slender, and better adapted to gardens than field-fences.

In the genial climate of the Southern States, the hedger may have recourse to some plants that make excellent protective barriers, perfect fences, although entirely unfitted for our colder latitudes, because of their inability to stand the action of our frosts. Among these are the cactus, of strong-growing varieties, which is much used in Mexico and Texas. The Spanish Bayonet, or (Yucca aloifolia), which has long stiff leaves, armed with sharp spines, that render it very formidable as a hedge-plant, in Florida and Louisiana, where it is frequently used in close gardens.

The Cherokee Rose (Rosa lcevigata), is planted to a considerable extent for hedging, as far north as Natchez, Mississippi, and in many of the Southern States, where it is highly spoken of as a hedge-plant. The extreme beauty of its shining, persistent leaves, makes a hedge of this plant a beautiful addition to the Southern Winter landscape; and the purity of its numerous, large, white blossoms renders it a brilliant object in Spring. Like other roses, however, it is always liable to an accumulation of dead wood; and, being a rampant grower, it is difficult to keep the hedge within bounds. Mr. Henry, in The Southern Farmer and Planter, describes the Cherokee rosehedge in the following words:

"A great many shrubs and trees have been used for the formation of hedges, but none is better adapted to this purpose than the Cherokee or Carolina Rose. 
This plant is of a hardy nature, rapid growth, easy of cultivation, and makes a beautiful, durable, compact, and perfectly impenetrable hedge; and, so far as has been ascertained, is not subject to any disease, nor to the attacks of any depredators.

"This rose is propagated from roots, seed, layers, or cuttings, and will grow on any land, but flourishes best in a deep, rich, loamy situation. The Fall and Winter months are the proper season for the formation of the hedge. If it is proposed to inclose a plantation with this rose, remove the fence a few feet, in order that the proposed hedge may occupy the space upon which the old fence stood, as it is usually more mellow and fertile than the adjoining soil. Clear the ground of briars, roots, stones, and everything that might tend to retard the speedy and successful growth of the cuttings. Break up the soil deeply, pulverize as finely as possible, and throw up the dirt in the same manner as if preparing a cotton-bed.

"Having procured a sufficient quantity of the rose, cut it into pieces of sixteen or eighteen inches in length. Then insert the cuttings about eight or ten inches deep in the bed, pressing the earth firmly about each one. Having planted your hedge, let it remain till the grass and weeds make their appearance in the Spring and Summer: then scrape between the rows and cuttings, in the same manner as if working cotton. Continue to keep the hedge clear of weeds during the first and second Summer, after it is planted. Be careful, in cleaning out the weeds, that the young cuttings are not injured, or displaced by the hoe, as the least jar will frequently cause them to droop and die. 



\section{PLATEV.}

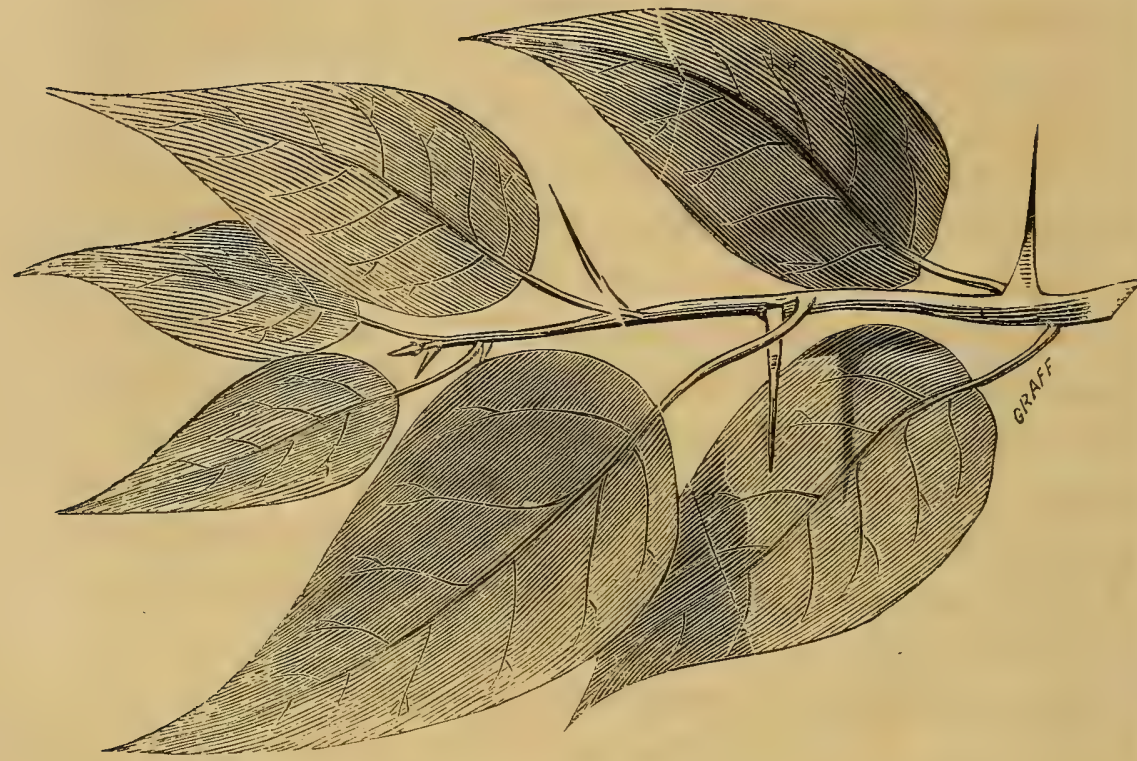

$b$
7
4
0
0
5
0
0
0
0
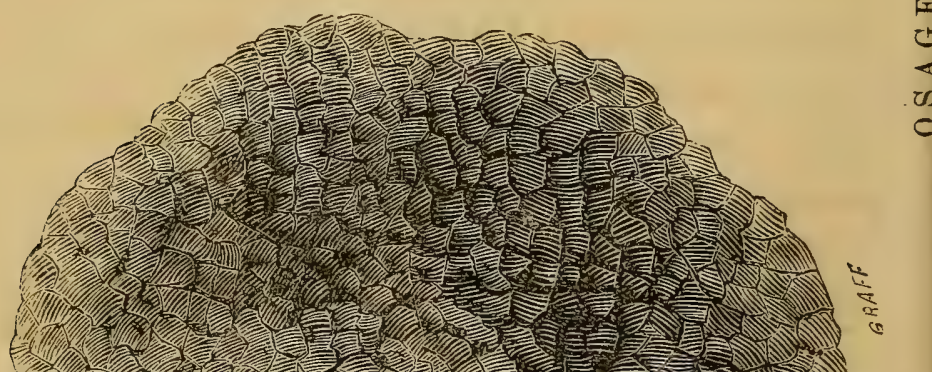
$11,1,0)$

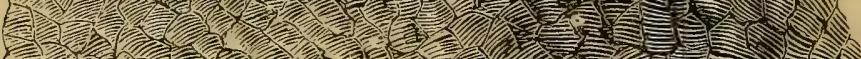

, H.

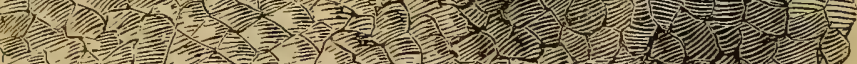

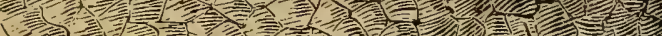

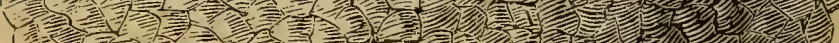
P.


Wi (1. $(1,0), 0$ (III) $\Rightarrow$,

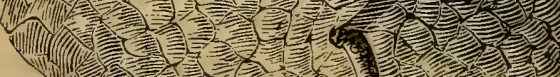
次

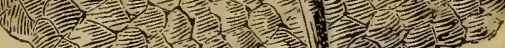
(1) 
"Nothing now remains to be done but to keep the hedge clear of weeds; and as the cuttings advance in length and height, interweave the branches together. This must be done by means of a long-pronged or forked stick, as the briars cannot be handled with ease or safety, on account of the long, strong, and sharp thorns, with which this rose abounds. In three years from the insertion of the cuttings, if the soil has been well prepared, and well worked, a hedge will be formed, which, by its impenetrability, will repel the attacks of any animal, and by its beauty soften, in a degree, the desolate and gloomy appearance of our winters."

That the Osage Orange (Maclura aurantiaca), is The Hedge Plant for the United States, may now be fearlessly asserted. Though some persons may have failed with it in producing the desired effect, still, I am satisfied that a thorough investigation of the facts would show that the work had not been well performed, and that the hedger, rather than the hedgeplant, was to blame.

An Englishman, familiar with the plants and systems pursued at home and in this country, writes: "Objections have been made by some to the Osage Orange, I maintain that it is the only good thing known, and fit for hedges in this country. Any other plants offered as a substitute, I consider worse than useless." Mr. Alexander Smith, of Rural, Ohio, writes, that when he first saw the Maclura at Fort Towson, he became satisfied that it would make a good hedgeplant. From an examination of its natural growth, he does not fear its spreading by suckers, as its roots 
are inclined to run down into the ground, and not upon the surface.

Wm. Neff, of Cincinnati, Ohio, one of the pioneers of hedging in this part of the country, tells me, there is no known plant so peculiarly adapted to the purpose, and so valuable to our agricultural interests, as the Maclura. Some writers are disposed to class it among the humbugs, and many doubt its utility, but among them all, you will not probably find much, if any experience. If rightly managed, it makes the best and cheapest fence in the world, without any special objection whatever.

E. Miller, of Waverley, Ill., says, in the Morgan Journal: "It is no longer a matter of experiment, whether the Osage Orange will make a fence or not. It is a proved fact, that, with proper culture, a hedge can be grown in four years, so compact, that no kind of stock can pass it; and in good soil, this can be effected in three years."

C. R. Overman, of Canton, Ml., who has for many years been engaged in hedging, with various materials, gives the palm, without a particle of reserve, to the Maclura, on the score of its "superior merits over all other plants, being cheaper, of more easy culture, and quicker growth, having terrible spines, being free from the attacks of insects; having great tenacity of life, and great longevity, it will bear crowding and cutting to any extent, and is well adapted to our soil and climate." He further states, that, "whatever credit may be due to the enterprise of hedging, in general, as an acquisition to the State of Illinois, will be claimed by the Maclura, in par- 
ticular, on the score of its superior merits over all other plants competing with it for that purpose. It is assumed in its favor, that, by its agency, not only may the farming of prairies be greatly facilitated and improved, but that the millions of acres, the richest soil on the earth, yet remaining a barren waste in our own State, for want of a material to fence it, may be brought into successful cultivation by growing the fences on the soil ; thus giving homes and sustenance to additional millions of population, immensely increasing the wealth and taxable property of the State, and promoting the happiness of the masses."

Professor J. B. Turner, of Illinois College, Jacksonville, who was one of the most earnest and early advocates of the Maclura as a hedge-plant, writing for The Iowa Farmer, as long ago as June 20, 1848, said: "It is in all respects unrivalled as a hedgeplant in quickness of growth, the stubbornness and density of its branches and thorns, and the extreme beauty of its foliage, flowers, and fruit. They all agree that it will prove perfectly hardy in any climate where the Isabella grape will ripen in the open air. And there are hedges of it standing in every State, from the latitude of Boston to the mouth of the Rio Grande.

"Hundreds of rods of it have been put out in Ohio, even amid their dense forests of timber, and it is doing admirably. There are pieces of it in this State and in Missouri quite to the north of us, which are doing finely. I have had the plants on my ground ten years, and have them now of almost all ages and sizes, from one month to ten years old. 
"I have one piece of hedge three years old next Fall that will turn any stock I have; from the smallest chicken or rabbit to the horse and ox. I have received letters on the subject from all parts of the Union, and have not received one unfavorable account from any one who has made a proper trial, with plants raised from the seeds in this climate. In some one or two instances, plants brought from the South, or allowed to freeze the tirst winter, have been injured afterwards, as, of course, might have been expected. I have some two or three miles of hedge put out around my pet farm and orchard, and have, this Spring, inclosed my house-lot of four acres on College Hill. In transplanting thousands this Spring, I have had to replace only three. All who have seen my hedges intend to plant them next Spring; especially the English, who were accustomed to hedges in the Old Country, are quite taken with it. They say, that there is nothing in England that can be compared to it as a hedge-plant."

E. Miller, of Waverly, Ill., alsu commends the Maclura: "Owing to so many unsuccessful efforts of farmers, the character of the plant has suffered without any just cause; for where the hedge is properly managed, it is certain to result in producing a good fence. There is no question but the hedge will soon supersede all other fences through the country.

"Nothing could be better adapted to fence the prairies of the West. Its cheapness, its durability, and its perfection for a fence, demands its almost universal adoption where fence-lines are to be per. manent. The expense of inclosing a farm with a hedge 
is but one-half what it is with any other fence: while they rot in a few years, the hedge, in all probability, will endure very many years, perhaps for generations.

"There is another fact with regard to this plant. It will not spread; this has been sufficiently tested. The oldest hedges in the country, being now some 16 years old, in Ohio, show no signs of spreading. Here and there, a shoot may come from the root, but very seldom, even where the roots are cut. The probability is, that not one root in ten thousand will spront when they are cut with a plow or other instrument."

D. J. Browne, in a report to The New York Agricultural Society, says: "It is perfectly hardy in every State, south of Massachusetts, is free from the attacks of insects, and is unsurpassed for hedges by any other tree."

A. H. Ernst, says: "I have been attentive to the Osage orange. Every step in my practice with it has been to increase my contidence in its capacity to supply the desired object. Though disposed, in rich soils, when cut down, to throw up a rampant and strong growth, it is also (but less than the buckthorn) remarkable for throwing out laterals near the ground, and readily forming a close, compact base, if this rampant growth is judiciously controlled, so as to prevent the sap from being all absorbed by it. It is a most voracious feeder; it cannot, therefore, be expected to flourish on poor fare. It is also a dwarfish-growing tree. These traits, with its numerous strong and sharp thorns, fit it peculiarly for hedging purposes on our rich bottoms and hills: it will be of incalculable value to the country." 
The maclura was brought to St. Louis at a very early period, and planted by Mr. Chouteau in 1800 . The French are also said to have introduced it to some of their posts in Illinois, a long while ago-but it was only as a curiosity. The plant was brought to Cincinnati, in 1832, by D. Gano, and others: there are now many bearing trees, which perfect their seed annually. It was taken to Philadelphia in 1803 , and grown by the elder Landreth, at the old garden in Passyunk, where it remained a long time before its merits as a hedge-plant were discovered. The original tree is 30 feet high, and has a stem 2 feet in diameter. In D. Landreth's catalogue, for 1842, it is set forth, that further experience has tended to confirm the opinion that this plant is likely to supersede the thorn for hedging. There are some hedges near this, only a few years planted, which are more effective than any thorn of twice their age.

D. J. Browne, in his Trees of America, says, that the seeds were sent to England about 1818, by Senor Correa de Serra. Mr. B. does not appear to have been aware of the value of this tree as a hedge-plant, when he published his valuable work in 1846 . 


\section{CHAPTER III.}

Selection of Plants, continued-The Shelter-Hedge-The Screen and ORnamental Hedge.

Shelter from the cold winds is often an object of great importance to the gardener, as has been already remarked in the introductory chapter. Shelter, however, is a consideration well worthy the study of the farmer; whether it be provided for the economy of his entire establishment, as a protection to his fields, or confined to the home and farm steadings, for the benefit of his household and barn-yard. In the latter, the genial influence of shelters of living green would be most beneficial to the poor beasts, who would silently thank the donor for the warmth, and make ample return to the pocket for the small outlay required.

There are several plants well adapted to this purpose; but the cheapest, most rapidly produced, and therefore the most desirable of all, is the common red cedar (Juniperus virginiana), which is readily grown from seeds, and will be large enough for planting out in two years, and will furnish quite a shelter at the end of three or four seasons. This plant also bears clipping remarkably well; though, if entirely neglected, it will make a compact wall of close greenery from the very ground. This evergreen was one of the first with which I experimented; and though so common 
as to be lightly considered in some parts of the country, where its appearance is supposed to be indicative of poverty in the soil, and of bad farming, its balsamic odor, and its genial shelter from the storm-wind, have made it with me a prime favorite: I shall continue to plant it extensively for this purpose.

The American Arbor Vitæ (Thuja occidentalis), is another native, and one of the very best of the terebinthinate trees, for the purpose of hedge shelters; it branches low, and may always be found in the nurseries, well furnished to the ground. It is frequently propagated by layering the lower branches-which root very freely, and may be removed after one season. This plant may be wonderfully improved in its appearance by clipping. Such as were quite open and straggling in the Spring, became thick and bushy in one Summer, after having their limbs judicionsly shortened-in.

The Chinese Arbor Vitæ (Thuja orientatis), is another beautiful evergreen, with an erect habit of growth; but it is not nearly so good for this purpose as the two just named, on account of its tendency to grow shabby, and its liability to spread open in snowstorms, like the common juniper. It is grown from seed.

The Norway Spruce (Abies excelsa), is perhaps one of the very best plants that can be used in this way, on account of its tendency to spread out its lower branches, assuming naturally the pyramidal form; and it is also found that this plant bears clipping very well: nothing can be more beautiful or more effective, as a shelter, than the Norway Spruce. The American 
Red and Black Spruce (Abies rubra,A.nigra), might answer an equally good purpose, in the Northern States, where they thrive; but they do not succeed so well in lower latitudes as the Norway, nor have I seen them planted for this purpose.

The Hemlock Spruce (Abies canadensis), is one of our most beautiful trees in its native haunts, and it succeeds admirably in our lawns and pleasure-grounds, whether as a single pyramid of darkest green feathery foliage, or as a group. Although this plant makes one of the largest timber-trees, it bears the curtailment of its branches by the trimming shears, and soon forms a most beautiful close shelter-hedge, for garden and grounds-such as would contribute greatly to the comfort of all concerned.

Several other plants are well adapted to this purpose; one of the very best and most beautiful is the Holly (Ilex opaca), which will form a beautiful evergreen hedge, and a pretty good barrier against cattle. It is of exquisite green, and, ormamented in the depth of Winter with its scarlet berries, it is very attractive. This plant is of very slow growth, and does not succeed in many of our heary limestone soils; hence it cannot be applied in such localities. The Yew (Taxus baccata), either the English or the Irish variety, would answer admirably for interior subdivisions of the garden, where the influence of a shelter was required - the latter, particularly, from its very close, upright growth. For the same reason, the Swedish Juniper (Juniperus suecica) has strong claims upon the planter; though it is apt to grow too tall for an interior garden shelter; and from its fastigiate mode of growth, 
it is very easily injured by the snow separating its branches.

For these garden uses, there are few plants so desirable as the Tree Box (Buxus sempervirens), which may be trimmed to any desired shape, and being very compact, makes a most efficient shelter. It is also admirably adapted to cemetery hedges; where a simple border only is desired to mark the boundary, instead of the high, selfish fences, so often seen obtruding themselves upon the view. I do not here refer to the Dwarf Box (Buxus sempervirens, var.), which is of much slower growth, and smaller size, therefore admirably adapted to edgings for flowerbeds. Both of these are grown from cuttings.

For Southern gardens there are many beautiful shrubs, that are well adapted to the purposes we are now considering; though in the Middle and Northern States they have not proved themselves quite hardy. Among these are our beautiful Wild Orange (Cerasus caroliniana), that is much planted about Southern residences, for hedges, because of its beautiful dark and shining leaves, and early white blossoms; it grows rapidly, and bears the knife well: I have seen perfect hedges of this material in Louisiana and Alabama.

The evergreen oaks of the Southern States would also make a very pretty effect. The myrtle, also, is there hardy, and succeeds as well as in the south of Europe. So, also, the Laurustinus ( Viburnum tinus), or Christmas Rose, as it is called in England, where it is hardy, and shows its clusters of white fragrant flowers in mid-winter, though not hardy in our Middle States. This shrub is straggling in its habit; but may 
easily be trained as a beautiful screen-hedge, or as an ornamental object to conceal an old wall, or other object. The Laurustinus needs judicious pruning with the knife, in Spring, to avoid destroying the flower-buds, and injuring the leaves with the shears.

Certain deciduous shrubs, which hold their leaves late in the season, may be found to answer a very good purpose for those who cannot procure the expensive evergreens, to which reference has already been made. Of these, the commonest and most easily propagated is the Privet (Iigustrum vulgare), which will grow readily from cuttings-is thickly studded with small, dark-green leaves, that often remain all Winter. It bears pretty, white, fragrant flowers in Summer, and affords a nice shelter. The chief objection to this plant is, that it has been found subject to blight; some beautiful screens made with it were so much disfigured by dead plants, and consequent gaps, that the proprietors were obliged to remove them entirely.

The Barberry, also, (Berberis vulgaris), when in a healthy condition, retains its foliage late in the season, when it assumes rich hues, that render it exceedingly ornamental. At all seasons, it forms a beautiful screen, and is so thick as to make quite a shelter from the wind. Very early, it presents its threads of sensitive yellow blossoms, which are followed by persistent crimson berries, that furnish us with a grateful acid jelly, and attract the birds of Winter.

Screens and Ornamental Hedges. - These are often needed about our country homes, where there are no private back-yards, as in cities, and where the 
best housekeepers cannot avoid certain disagreeables, that should be concealed from the scrutiny of visitors. Then there is the coach-house, or stable, the smokehouse, the ice-house, perhaps the woodpile, or some other such object, that the judicious landscape gardener may wish to hide. To effect so desirable an object, there are many shrubs which may be advantageously planted. The barberry and privet, where the latter does not blight, will very quickly produce the effect. One of the quickest and most effective screens is made by the Althea, so called (Hibiscus syriacus), which strikes readily from cuttings, grows rapidly, and furnishes a succession of variously colored flowers during the mid-summer, when few shrubs are in bloom. It may be objected to this Hibiscus that it is late in the Spring with its foliage.

The most rapid growth for a tall screen will be furnished by the mock-orange (Philadelphus grandiflora), which bears a profusion of showy white flowers. The lilacs also, are universal favorites, and peciliarly appropriate for screens. Any of the strong growing roses will make a good screen in a short time. The common sweet-brier is a great favorite with all to whom its poetical associations or its fragrance are familiar; its scarlet hyps are very ornamental in Winter. Many of the prairie roses would also be admirably adapted to this purpose ; for here we find a rampant growth, with several different tints in the flowers, that appear in the greatest profusion, and have a very extended season of bloom. For the South, the Cherokee or Carolina, the Chinese Multiflora, Laura Davoust, or the yellow and white Banksian are 
admirable. In the North, the more hardy, free-growing and rich hues, and the shining foliage of the Boursalt roses will render them farorites-and the Glory of Rosamenes, with its abundant autumnal bloom of exquisite brilliancy. In forming a screen of almost any of this class of climbing roses, it will be necessary to provide a trellis for their support: these are now furnished of a very superior character by the Lowell Wire-Fence Company, and at reasonable rates; they make a good fence and support the roses, or vines, at the same time.

Some of the prettiest snug screens, and subordinate divisions of the garden or lawn, may be constructed of the beeches, birches, and hornbeams, which are all notable for the exceeding beauty and feathery lightness of their foliage, which is also remarkably neat and trim, and persistent in Winter. These kinds are not so well adapted for a fence as many others; but for a screen, they may be often selected as preferable to almost anything else. The young plants may be set closer, if the intention be to produce a result quickly, and the wattling process may then be applied with advantage; the stems being interwoven together in two opposite directions, like a lattice, will increase their strength also, as in many places they become inarched. This is the more desirable where the screen may be wanted to serve as a slight fence also, for a part of the year-as for instance in pasturing the lawn occasionally with sheep-as has been recently recommended by some amateurs, who do not like the labor of the repeated mowings, so necessary to keep the grass in order. 
The beech and birch will both bear the clipping of the shear's remarkably well, but will require as much care as any other hedge to preserve the foliage on the lower parts of the plants, especially on account of the natural upward tendency of their shoots, and the strong propensity of those who may have charge of the trimming to be led by the natural growth, and give them perpendicular walls instead of slopes, so strongly recommended under the appropriate head, in another chapter. The almost inevitable consequence of this perpendicularity, will be a leaning over, which results from the natural extension of the upper twigs, and this will soon cause a decay and thinness below. The plants of the Fagus sylvatica are imported by the nurserymen; and after being grown a year or two, are in a very fine condition for setting out. Why will not our own beeches and hornbeams answer an equally good purpose? and why can we not have some grown by the nurserymen?

Siberian Crab.-This plant is peculiarly neat and beautiful at all seasons of the year-even in Winter, its regular form and clean limbs and twigs give it a grace ; in Spring, its blossoms are attractive ; in Summer, its shining leaves always look clean, and contrast beautifully with its crimson and yellow waxen fruit, that hang thickly and long. Besides all these recommendations, its bushy habit renders it very suitable for an ornamental hedge. A writer in The Horticulturist, some time since, recommended it highly, from having seen a piece five years old, which, he says, was one of the best hedges he had ever beheld; it was made from seedlings of this rariety. I have 
so much confidence in its making a pretty ornamental. fence, that I have ordered a quantity of grafted trees from a nurseryman, which shall be planted about two feet apart, for that purpose.

The Pyrus japonica (Cydonia) which holds its leaves pretty well in the Autumn, and puts on its bright scarlet flowers in early Spring-is deservedly a favorite with most persons; and, despite its straggling habit, forms a pretty screen; and as it bears clipping very well, it will make a good hedge. These views are confirmed by the learned editor of The Horticulturist, Mr. Barry. "This beautiful plant grows very readily from cuttings, and forms a superb hedge. Mr. Reid exhibits about four hundred feet of it in the highest perfection, a portion of it well grown about four feet high; it forms not only one of the most beautiful flowering hedges (there being very few hedge-plants that flower when cut,) but it is also one of the most valuable and close defences of any plant yet tried. Interspersed with a few running roses, such as the Multiflora or Prairie, it will produce the most ornamental of screens. No one, who has not seen it, can properly estimate its great value." In this latitude, it also frequently blooms in December.

The Pyracantha (Cratcogus pyracanthus) with its small evergreen leaves, and bright orange-red berries, that remain all Winter, would also make a pretty screen, where it can be trained, as against a wall, for its habit is very straggling; then it is not a rapid grower, and is liable to be destroyed by the thornborer. 


\section{CHAPTER IV.}

The Maclura Hedge, and wiry it has failed-Growing the Plants -Seed, Sprouting, Planting-Colture-Taking up the PlantsSorting-Wintering-PUdding-Trenching-in-Packing.

FrRmLy convinced, as I am, that the Maclura is every thing I have claimed for it, as a hedge-plant, it may be asked, by those who are unwilling to take anything for granted, why are there so many failures in the attempts to make hedges of this plant, in all parts of the country? This is a very sensible question; and it is no wonder there are doubters, since the large majority of persons who have been induced to plant the maclura, under the impression that the hedge would come of its own accord, have failed. But there have also been successes, and if one may succeed in this enterprise, all may do the same: competition among hedge-planter's is a fair race, where all may win.

C. R. Overman, in his prize-essay, gives the following causes of failure:

"1st. In many cases farmers have procured their instructions from agents and dealers in plants and seeds, who have not the first definite idea of what constitutes a hedge.

" 2 d. Many who have been furnished with proper directions have disregarded them; while a few persons 
who have essayed to enlighten the public, though qualified themselves to instruct, have given only a few of the leading, general directions, and omitted the minute, yet most essential and important points.

" $3 \mathrm{~d}$. Numerous failures occur from mismanagement in the preparation of the ground, assorting, handling, and setting the plants, and neglecting to replant or fill vacancies at the proper time.

" 4 th. The most general mistake is in the wide distance at which plants have been set in the row. In most cases, the planting has been twice as wide as it should be. So far as turning hogs is an object, the error of wide planting will be productive of more general failure than all others.

" 5 th. The almost universal neglect to cultivate and clip the hedge. The maclura is a free grower, with formidable spines, yet it cannot successfully contend with blue grass sod, nor with weeds that overtop it; but if the clipping be omitted, whether cultivated or not, it will make anything but a hedge.

"6th. Occasionally the hedge-row is planted in the shade of the fence, or under a row of trees, where it is impossible for it to grow to do any good. Other errors and abuses might be noticed, such as pasturing it while young, and treading it down by the stock; but allusion to one more general error may suffice for the present. Competition in hedging and hedgeplants has so lowered the estimated cost of the finished hedge, that many think less of the importance of it, and consequently neglect it, because it is cheap.

"To make a complete hedge is a very particular business, and requires the strict observance of certain con- 
ditions, which, though easy and simple as A B C, are all of them backed by the imperative must, and admit of no evasion. Yet, after all that has been said of a discouraging nature, every point in hedge-culture is so simple and easily understood, that none who undertake it need err on account of ignorance. If everything is done in season and in a proper manner, it is comparatively a light job to make a hedge; and there is, perhaps, no outlay of time, and care, and patience, that will better repay the farmer than in well-directed efforts in hedging. The cost of the maclura hedge may be set down at a lower figure than that of any effective wooden fence on the prairies. Some are apprehensive that it will require much care and labor to keep the hedge clipped and in proper order. To such we would say, that the hedge will need, and must have, its annual clipping; but any man with a particle of taste will be amply repaid by the enhanced beauty and gracefulness of a well-shorn hedge. Indeed, an object more ornamental than a well-clipped, dense, and perfect hedge, cannot well be imagined to 'set off' and beautify a farm."

James McGrew, well-known to the agriculturists of Ohio as a practical farmer, has shown, upon his farm, near Dayton, Ohio, that he is also a good hedger, and that the Maclura is capable of making a perfect live-fence. Before leaving his former residence for a new home in the prairies of the West-where he is now largely engaged in hedging operations-Mr. McGrew wrote a paper upon this subject for the Ohio Agricultural Society, which is published in their Transactions, and from which I make the following 
extract, in which he explains why these hedges fail :

"In most instances, the planting and cultivating of Osage Orange hedges, have been about as follows: The seed was usually bought by men of means and curiosity, who had no knowledge of vegetating such seed; hence, a great portion of it was lost. The plants, however, that were obtained, were set in hedge-rows around gardens, vineyards, lots, and lawns, in and about towns and cities, crowded close to the fence, which precluded the possibility of giving it the proper cultivation. The ground was generally prepared by digging a trench twelve or eighteen inches wide, and a foot deep, throwing the earth back, and planting the hedge.

"The cultivation amounted to nothing more than keeping the grass and weeds down, and even that was neglected after the first year. The hedge was frequently shaded by trees and shrubbery, with perhaps a tough sod on one, if not on both sides, within a foot of the hedge-row. I would here remark, that if the plants were designed to come up and form trees, they would soon take care of themselves, but as they are to be kept down, until they spread at the bottom, they must therefore receive thorough cultivation; and everything else should be kept down around them, to prevent their being smothered or choked. This should be remembered as a very important item in hedge-growing. The trimming, of course, was done according to the then prescribed method, which was more theoretical than otherwise. With this slight attention, it was expected to make a fence that would be a model of perfection. 
"In fact, many of those persons who were engaged in selling seed and plants, represented it as the easiest thing in nature to grow an Osage Orange hedge. But what has been the result? Do not the mock hedges all over the land speak of the folly of such a course? Does a reasonable man expect to make any valuable and permanent improvement by slighting it, or stinting its cost, so as to obtain it at one-fourth, or even one-half the real value of making such improvement. We do not act upon any such principle in other matters, nor can such a course be successful in this. The greatest error that now exists in the public mind, relative to this matter, is the idea, that any and every body can grow an invaluable hedge of the Osage Orange, at comparatively no cost at all. This view is incorrect: it is ruinous in its effects, and has done more to hinder the successful introduction of hedges than any other error that has been propagated. This notion has been disseminated through the public mind by those who have had no interest or concern in this matter, further than the sale of their seed and plants. The evil must now be counteracted, before this great improvement can assume its true character.

"In consequence of the mistaken ideas that have been advanced, many have been wofully disappointed, and are now disposed to pronounce the whole thing a humbug. Why! says one, there is Mr. A.'s hedge, that has been planted two or three years, and his hostler has been attending to it, and now it is barely a respectable row of briers. And there's Mr. B.'s, his tenant has been managing his, but it don't amount to anything. And there's Mr. C.'s, his gardener attended 
his, and I know he attended to it well the first year; but then it's so open at the bottom, that it's of no account.

"In view of these facts, I do not wonder that people have been discouraged about having hedges succeed. It was after having witnessed just such a state of affairs as this, that Col. Medary stated, in his paper, 'That he had reluctantly almost come to the conclusion that hedging was a species of inclosure that was of doubtful economy.' It was the existence of these would-be hedges, such as I have described, that caused so many members of your Board, last year, at the annual meetings, to question the practicability of hedging. All had seen hedges that were two, three, and four years old, which were not only useless, but a nuisance to the farms upon which they were growing. And yet, perhaps, not one of those who condemned the subject of hedging had ever taken the trouble to inquire closely into the true method of growing a hedge, and then compare the practice that had been adopted, in most cases, to see whether they would correspond-thereby settling the matter beyond doubt in their own minds.

Selecting the Seed. - Without further parley or introduction, therefore, let us proceed to a detailed statement of the maclura matter, from the seed to the finished fence. For, though it is not at all advised to commence with the seed, while plants can be purchased at the present rates, some persons will prefer, and in some situations it will be more convenient, to wait another year, and sow the seed. In purchasing: this article, care should be taken that it be fresh, and 
that its vitality be perfect. Good seed is heary and bright, and should give the sensation of coldness to the hand, when immersed into it. When crushed, it should have a plump, white kernel, and should not have a rancid flower.

This plant produces an abundance of large fruit, resembling an orange externally-hence the common name by which it is so generally known; internally, however, there is no resemblance to that delicious fruit, but a tough, bitter, stringy mass, filled with seeds that are closely packed together, all radiating from the centre toward the circumference, like those of the sycamore or buttonwood. The older trees bear fruit in their new Northern homes, when properly situated for impregnation, for the plant is diœcious. There are, hereabouts, many specimens that perfect their seed, but the chief supply of the seed in market comes from the South, where the trees abound. The seed is separated from the pulp by rotting; and if the fermentation be allowed to proceed a little too far, the vitality of the germs may be destroyed before they are sent to market. After washing, they require to be thoroughly dried, otherwise they. will mold and heat, if put up in large bulk. This may be easily detected; the germ will be dark. The weight of clean seed when thoroughly dry, Overman says, is from thirty-two to thirty-five pounds per bushel. Seeds carefully kept will grow at two years old, but require a little more care in germinating them. The seed, when dried and ready for the market, in Texas, weighs thirty-five pounds to the bushel, but it continues to shrink for several months. 
Germinating or Sprouting the Seed.-Having selected your seed, fresh and plump, as the market may afford, not caring to have it remarkably clean from the naturally investing gum of the fruit, the first object, before planting, should be to scald it, by pouring upon it boiling water, which should be drained off, and the seed is to be then kept covered snugly, until it has swollen, and is ready to sprout; this will require about a week, more or less, according to the temperature. While it is in this state, it should be frequently stirred, to prevent the fermentation which would be very apt to commence in a large mass of wet seed.

Henry Shaw, of Tazewell county, in a communication to the State Agricultural Society, recommends that the seed should, if possible, be of the previous season's growth; older seed being much less certain to grow.

About the first of March, wet the seed by putting them in soak, and letting them remain about forty-eight hours, after which they are to be spread, not more than six inches in depth, in some cool place secure from mice, and kept moist by spreading over them wet sacks or moss in sufficient quantity to confine the moisture, but not so much as to cause danger of heating or fermentation. Keep them in this state until they commence sprouting, when they should be sown immediately. Seed received too late for the above process may be sprouted by wetting frequently in warm water, pouring the same off immediately. In a few days, if the weather is warm, they will commence sprouting. The water used may be near the 
boiling-point, but will answer just as well at a temperature of 100 degrees.

C. R. Overman, above quoted, says: "That the most effectual way to prepare the seed for vegetating is, to soak it forty-eight hours in warm water (about the close of Winter), and then expose it to hard freezing. Once or twice is sufficient, but care must be taken to spread it out so that all parts may be frozen alike. After this the seed must be kept moist and cool as possible, to prevent sprouting too early, or before the ground or the weather is in proper condition for planting. If seeds are much sprouted before planting, the roots will be crooked. After being frozen, the surest way to keep the seed right is, to put it into an ice-house, and keep it there till within a week of the time you wish to plant. It may, however, be kept in any cool or shaded place, covered from the mice, and kept moist."

The method of sprouting seed without the freezing process, is as follows:

Put the seed in a vessel, and cover it with water as warm as you can bear to your hand. Keep the vessel near the stove, change the water once a day, and soak the seed about five days, after which turn off the water, and keep the vessel covered with a damp cloth. The seed should not be more than four or five inches deep in the vessel, as in this condition they are liable to heat if kept too much in bulk. Stir occasionally, and in about one week more, if kept in a warm room, they will begin to start, and should be planted before a fourth of them sprout."

Planting the Seed.-In the meantime, ground is to 
be prepared by deep plowing, and thorough harrowing; if the soil be somewhat sandy, so much the better, as it will be less liable to bake, or form a crust above the young plants, as they issue from the germinating seeds, and start on in their upward and aerial career.

The seed having been prepared, and the ground rendered mellow, by thorough tillage, and of all things, the weather being mild and pleasant, say, in this latitude, about the 1st to the 15th of May, we may proceed to planting or sowing the seed, which should be done as follows: With a line stretched across the plot selected, shallow furrows are to be made with the hoe, as for planting peas or beans. These rows may be 18 to 24 inches apart, or more, so as to admit of horsetillage during the summer. In these drills, the seeds are to be thickly and evenly strewn, so as to lie about an inch apart, and immediately covered with a little fine earth, drawn up over them in a decided ridge, that shall bury them about two or three inches deep, according to the condition of the soil, as to dampness, and according to the dryness of the weather; shallow, if there be a prospect of rain, and deeper, if threatened with drought. If you have access to a drillbarrow, that is adapted to seed of this size, use it by all means, as a labor-saving engine of great importance, and enabling you to distribute the seed with much more regularity than can be done by hand.

The object of throwing up a ridge over the seed, is two-fold; first, it shows you the precise position the young plants are to occupy; and, secondly, it enables you to pass along, just before they emerge, and 
remove the crust of earth which is apt to form after rain, and with it to destroy a first crop of young weeds; this is done with a light garden-rake, and it is a very important aid to the starting of the young plants, in their first efforts to make their struggles in the battle of life, especially if the seeds have been intrusted to a clayey soil. Those who attempt to grow the Maclura from seed, in stiff clay soils, will experience great difficulty in getting the young plants above the surface, unless they pay particular attention to these directions; such soils will bake, and form a resisting crust, that will prevent most of the young plants from emerging; and in such a soil, you will also find the weeds very troublesome; whereas, by a light raking down of the little ridge, the crust, and an infinite number of weeds, are easily destroyed, and the young seedlings are not only freed from hinderance, but are really accelerated in their growth by the culture thus applied.

About the middle of May, Mr. Neff advises covering the seeds in the drills, that are a foot apart, with leaf-mold from the woods, to prevent baking. If the seeds are well soaked, they will all make their appearance before the weeds and grass start to interfere with them. So soon as they are well up, he recommends mulching with leaves, cut-straw, saw-dust, or tan-bark, which are named in the order he thinks they answer best. The whole ground is to be covered (but not the plants), thick enough to smother the grass and weeds, thus saving all trouble of hoeing and weeding.

The large cultivators of the Maclura, on the Mlinois 
prairies, who sow by the bushel and by the acre, have greatly the advantage in their soil, and in their exemption from weeds. Mr. Shaw recommends that "The ground on which the seeds are to be sown should be new and clean prairie, broken early the previous Summer, and well plowed and harrowed on the approach of cold weather; the Winter freezing will then leave it in a mellow condition for the reception of the seeds. Previous to planting, a good roller should be passed over the ground, to break clods and smooth the surface, which will make it much easier to deposit the seed at a uniform depth. If the ground has been reduced to a mellow condition, the seed may be sown to the best advantage by the use of a wheat-drillraising every alternate tooth, so that the rows will average about eighteen inches apart. Before planting, the seeds must be dried sufficiently to prevent all clogging. The driver then proceeds in the same manner as when sowing wheat, except that more pains is taken to have the rows straight than in common wheat culture. In this manner, three men, or one man and two boys, will plant ten bushels of seed per day. Where the land is too rough, or in any way unfit for the use of the drill, sow by hand in the following manner: Stretch a line, and mark by the line, two drills, one foot apart, and two inches deep, with a broad-toothed rake, made for the purpose; repeating the operation at the distance of every four feet. Cover, say two inches in depth. At the distance of one rod, each way, all over the seed-beds, sow one or two castor-beans, to keep away moles."

Overman advises that: "Ground for the seed-bed 
should be rich and well-handled. Prairie sod, broken the previous year and well-rotted, is greatly to be preferred, and it should be deeply plowed the previous Fall, and well pulverized before planting. Procure a strong line, long enough to reach across your ground, a garden-rake, and a drill-rake, with two teeth,-a foot apart. The teeth may be made of iron or wood, about three inches in width, a fourth or a half an inch thick, and tapering or rounding to the end. Stretch your line and set it; next rake the border smooth and fine, then by drawing the drill-rake along the line, you make two furrows at once, a foot apart, rather wide and shallow, about two inches deep, in which sow the seeds regularly in the drills, about twenty-five seeds to the foot, or two seeds to the inch. Before the seeds have time to dry, cover them about two inches deep, with fine, mellow soil. A space two feet wide should be left between the double rows, and if the ground is likely to be foul, three feet, to admit the cultivator. If the weather be favorable, and the seeds properly sprouted, the plants will appear in a few days; but if beating rains and hot sun shonld cause the ground to bake before they come up, the crust should be broken to assist them.

Nursery Culture. - The treatment of the young plants, after having watched them safely emerged from the soil, and after having relieved them from the crust that sometimes forms upon the surface, will consist in setting them up if prostrated by storms, the occasional stirring of the soil, and the destruction of weeds. This may be done by horse-cultivators and by hand-hoeing. If too thick, they may be thinned 
at mid-summer, by pulling out the smaller plants. They should always be sown by drill, and cultivated by horse-power, when grown in large quantities.

Taking up the Plants.-The young seedlings will continue to grow until late in the season, and in the Autumn will not have ripened their wood, but will frequently be covered with soft green foliage, when their growth is checked by the frost. Soon after this occurs, they must be cut off near the ground, either with a brush-scythe, or better, with the mowingmachine; after which, a furrow is opened near the outside rows, and the next passage of a sharp plow will throw the plants out with the furrow. Boys then gather up the plants, either by hand, or aided by that useful implement the potato-rake, and tie them snugly in bundles of one hundred-using a willow, or packing-yarn.

Mr. Shaw uses a coulter, similar to the old-fashioned bull-tongued plow, run on both sides of every row, to break or loosen the side roots. A subsoil plow, invented for the purpose by C. R. Overman, and manufactured at Canton, Ill., is then run under each row, cutting the main root, when it only remains to pull out all inferior plants and throw them away, and to pull the good plants, counting them in each bundle, and bury them in dirt in a good cellar, or they may be buried like potatoes, on a dry spot of ground. If not dug in the Fall, they generally stand till Spring without much injury. Still, the Fall is preferable, becanse it is a season of greater leisure, and because it affords an opportunity to prepare the plants for setting, during the Winter. 
Digging the plants in the Autuinn has many advantages, among which are: the dryer condition of the soil, at that season ; less hurry than in the Spring; avoidance of the effects of frost in drawing them out of the ground, and injuring their bark; and the further convenience of having them ready for sale, and shipment, at a moment's notice. If left in the ground all Winter, those that escape the drawing, and consequent injury by frost, are likely to start their buds earlier than those that were dug in the Autumn; and thus they will receive a severe check, from digging, if this operation has been delayed by the hurry of the season, or by wet weather.

C. R. Overman thinks the digging may be best done with a subsoil-cutter, a plow without the mould-board, made for the purpose. It is drawn by a strong team, and may be regulated to any depth. If kept sharp, it cuts the roots off smoothly, and leaves the plants standing, but easy to pull up and assort at the same time. The plants may be tied in bundles of one or two hundred, with bass-bark or willow; he cuts the roots at eight inches depth.

Wintering the Plants-Sorting.-To preserve the young plants during the Winter, they may be simply " heeled in," or placed in some moderately damp earth, in the cellar. In large quantities, they may be stacked up loosely, in the field, with alternate layers of earth, and covered over with dirt, as is customary with potatoes, or turnips-the object being simply to preserve them in a moderately moist state, rather to prevent their exposure and drying than to exclude 
the frost, which is not injurious, except when the roots are exposed to the air and sunshine.

Others advise that they be kept by packing closely in a dry cellar, covering lightly with earth, saw-dust, $\& c$., to exclude the frost and prevent drying. It is important to have them well preserved.

To secure an even plantation in the hedge, the plants should be assorted when dug, or when bundled for setting, or for sale. Each class should be kept separate, though many consider the healthy small plants quite as good as those of larger growth.

Puddling-Trenching in.-C. R. Overman has made an excellent suggestion as to the treatment of the young plants, which is supposed to apply to the Spring season, after they have been brought out of Winter quarters; it is, puddling the roots-a valuable process even with this fleshy root, which is remarkably tenacious of life. He prepares what he calls a grout, or mortar, by mixing equal parts of cow-dung and clay, well beaten together, and made thin enough to admit the roots, into which they are to be dipped, a handful at a time, so that all parts of the roots are coated with it. Next, dig a sloping trench, into which lay the plants straight, with the roots even, the tops above the surface, sift in fine dirt among the roots, and cover two inches deeper than the top of the roots; tread the ground firm, and if the weather be dry, sprinkle twice a week. In this condition let them remain a few weeks, and when vegetation commences, they will be ready to set out into the hedge-row. Plants and trees thus treated will start earlier than if planted out at once; and if properly set, will grow 
more readily and certainly without being checked by the removal, even though planted in full leaf, if damp weather supervene.

In June, I set my Maclura-hedges with plants thus treated, all of which succeed remarkably well; an especial advantage in starting the plants before setting is, that if any are defective, it is easy to detect them. A few of the strongest and best plants should be left in the trench, so that in case any should fail in the row, their places may be filled the same season; and it may be successfully done, even a month after planting, by choosing a moist time, and pinching off the leaves and young shoots. It is extremely difficult to get replants to succeed well in a hedge-row that has grown even one season, and almost impossible afterwards.

Jas. McGrew takes up his plants by cutting the roots 8 inches deep with a subsoil-plow of his own construction, very like Mapes' lifting subsoil, but of steel, and kept sharp. The plants are then drawn, and in the cellar they are sorted, counted, tied in bundles, and the tops cut with a hatchet or axe; when they are packed in boxes, about 3 feet by 18 or 20 inches deep and wide: the cases should not be tight, lest the roots mold-those I have received from him were in very good order.

The further management of the plants will be treated of in the next chapter. 


\section{CHAPTER $\nabla$.}

HeDGe-Making-How to do it-Preparation of the HeDge-RowSetming the Plants-Distance-Culture the First Year-Shall the Hedge be Trimned?

WE now approach the most important part of the subject that has yet been presented for elucidation in this volume. Most persons who will look to these pages for information respecting the art of hedging, will not care to trouble themselves with the seed and seedlings, so long as the market is supplied by the nurserymen, with good plants, at a much lower rate than they can be produced by the amateur, or in the small way.

Preparation of the Hedge-row.-Those who expect good crops, and intend to produce them, are aware of the great importance of a thorough preparation of the soil. So with the hedge; its success will depend, in a great measure, upon the manner in which the ground has been prepared for its reception. Deep plowing, and even subsoiling, has been highly recommended. In the prairies, or other wild, uncultivated lands, the sod should have been broken up some months previously, so as to become mellow, and then deeply stirred in the Spring, and freshly harrowed before planting, which should be done just as the plants are ready to start.

Overman advises that: "In planting hedges upon 
the new prairie soils, the wild sod should be broken up one season, and left to rot. If sufficiently decayed, it should be deeply plowed in the Fall, and left to the action of the frost during the Winter. In the Spring, the land should be plowed by throwing the furrows outward, leaving a deep dead-furrow in the middle, where the hedge is to stand; if the ground be rolling; dams and side ditches should be formed at intervals, so as to prevent washing. Near planting-time, if the ground be cloddy, let it be well harrowed until quite mellow, then gather the furrows, by plowing from both sides into the middle; and thus form a deep bed, in which it will be easy to plant, and where the roots may grow freely. This bed should be allowed to settle a few days before planting, so that the roots may not be left bare by the sinking of the earth.

In some cases it will not be convenient to prepare the ground by the plow, but we are forced to use the spade, or the mattock. We should still remember to stir the soil deeply, nor should we rest satisfied with less than six feet width of the bed in which to set the hedge. Whether plowed or dug, if wild land, cropping with potatoes will be a good preparatory step.

Shaw advises that: "The ground should be in good condition; that is, dry enough and mellow enough to raise a good crop of corn. If it is new ground, which is best, prepare in the same manner as for planting seeds. Have your line surveyed before preparing it; find exactly where you want the hedge to stand, put a tall stake at each end, and perhaps several between, if it is a long line; plow first out from the row on both sides, then finish by back-furrowing, so as to 
leave the row a trifle higher than the surrounding surface, to throw off standing water. Harrow and roll the ground well, and set stakes in a straight line with those at the ends, every five rods. Stretch a line of cotton cord, six inches to one side of these stakes, for a guide in setting the plants. Prepare the plant for setting, by thinning off all side roots, and cutting back the main root to about eight inches in length."

The character of the soil will have a great influence upon the future of the hedge. It were folly to expect this Maclura, which is the native of the deep bottom lands, bordering upon the Southern rivers, to succeed equally well in stiff clays, light sands, wet spongy soils, or dry rocky places. It needs a good dry soil, suitable for corn, but may be made to grow well on almost any dry soil, with proper care and preparation. Spouty lands should be drained; low, wet places may be filled up by ditching, on either or both sides, raising an embankment, which should be fully eight feet wide. This may often be done by the plow alone, or by using the scraper also, where horses can be worked, otherwise the spade must be resorted to.

Setting the Plants. - Various plans have Fig. 1.* been practiced for performing this work: the trowel, the dibble, the spade, and even the plow, have been suggested. My own favorite mode of proceeding is, to stretch a line upon the course of the future hedge, on the mellow and well-prepared soil, a clean spade is pressed deeply into the ground, the blade being in a

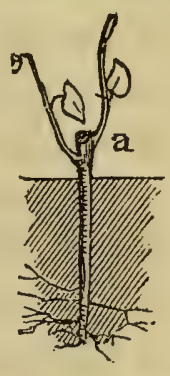

* Fig. 1 represents the maiden hedge-plant trimmed at each end, top and root, and set in the hedge-row with the young shoots starting from it at $\alpha$. 
vertical direction, and close to the line ; pushing the handle from you, a crack is opened to the depth of the instrument; into this the little plant is inserted, with the left hand, and retained in its position, while the spade is withdrawn, and until it is turned, with its face toward the operator, and again inserted, at a distance of three inches from the first cut, in such a direction, that when pressed home, the edge shall reach the point of the first cut, near the place occupied by the root of the plant, when it is to be drawn firmly toward the operator, to fix the plant in its place. This operation is rapid and very simple; in its first introduction, the blade is to be perpendicular or vertical, with its back toward you; in the second, the handle is to be upright, and the cavity of the blade should be held toward the digger; observing this simple rule, the result will be obtained, and the plants will be rapidly and firmly set in the ground: the process is so exceedingly simple, that any person may soon acquire dexterity in its performance; it is preferable to any other method of planting that I have seen. The distance may be regulated by the eye, and a little practice will give sufficient accuracy. I generally advise to leave the width of the spade between the two consecutive openings made by the instrument, for the hedge-plants.

Shaw, and many others, prefer to set the plants with a dibble, made by sharpening the upper half of an old shovel handle, and covering it with tin or iron to prevent the dirt from adhering. Insert this ten inches, and on withdrawing it, you have a space to receive the root; put the plant down two inches 
deeper than it grew; press the dirt well around it with another stroke of the dibble, and the operation is finished.

To C. R. Overman, on account of his great experience, we should defer in this important point of practice. After trying various methods of transplanting, he recommends the use of the trowel, which is made with a blade ten inches long and three inches wide, a quarter of an inch thick in the middle, and thin on the edges, and oval at the point. A curved shank supports a wooden handle at a right-angle with the blade, and on a plane with its edges. To work well, the trowel must be ground, and polished, and kept bright. The line should be light, strong cord, and, for convenience, about ten rods long.

When all is ready for the work, set the stakes at the ends. By these set as many intervening stakes as may be necessary, exactly in range. Do not forget that the beauty of the hedge depends greatly upon the straightness of the row; if planted crooked, it can never be made to appear well. Rake the ridge down level with the surface, taking out the coarse clods, \&c., for about the length of your hedge-line. Tie the ends of the line to stiff stakes, three or four feet long, set these line-stakes to correspond exactly with the range-stakes; stick several small pegs, with hitches cut in them, along the line, to keep it steady. As it is easier to work on your knees, you will provide thick knee-pads for them. On removing the plants from the trench, puddle them again. To proceed with the planting, take the trowel in the right hand, thrust it down its whole length, press the outer edge to the 
right, with a twist, thus forming an opening, into which, with the left hand, insert the plant, two inches deeper than it stood in the nursery. Raise the trowel and put it down an inch or so from the plant, as deep as before, give it a twist towards the plant, and thus compress the dirt around the root. In this manner proceed to the end of the line, when another section may be raked, and the line carried forward. Finish by treading firmly on each side of the row, and your hedge will be planted on scientific principles.

The method of planting with the spade is more simple, and less care is required in preparing the ground A long narrow spade is thrust down by the side of the line, at an angle of about forty-five degrees, as deep as twelve inches or thereabouts. The spade is then raised slightly, and the plant thrust down under it nearly its whole length, and held till the spade is withdrawn, and the ground should be tramped above the plant. In this way, a man with a spade, and a boy to stick in the plants, will easily set a half mile a day. Another advantage is, that the side-roots do not require to be trimmed off. There is no reason why plants set in this way should not grow as well as when planted uprightly; they start a little earlier in this position. The only particular points are, to plant firm enough and deep enough, and to be certain that the roots are not too near the surface. Each plant should be critically examined, and not one that looks in the least doubtful should be used.

It is very desirable, when planting a hedge, to set some of the best plants in a nursery row, as a corps de reserve, from which to fill up any gaps that may 
occur. In adopting the plan of puddling and late planting, recommended at the close of the last chapter, a few plants should be left in the trenches, from which they may be taken to the hedge during the first Summer. It is very desirable to have the row complete; and it is difficult to succeed in replanting, unless great care be taken, and the new plants should be rather better than those in the row already established.

L. H. Ide, in a communication to The Prairie Farmer, says, he intends planting three miles in the Fall, which he would do by covering them entirely in a trench or furrow. It is a new way; but if it succeeds well, it will be a great relief from the pressure of work in the Spring. The inference from this appears to be, that he intended to set them in a furrow, and cover them with the plow, which would greatly simplify the labor; but perhaps he only intends, that after having planted them in the usual way, he would cover them by throwing a furrow against them as a protection from the frost. I have seen quince-cuttings and willows planted by dropping them in a furrow, and covering with a light plow, when, if rolled, or trodden along the row, they grew very well; but were liable to be jostled from the right line, which would not be very well for a hedge, still, the saving of labor might compensate for this.

The suggestion of Fall planting is very attractive, on account of the fine weather and comparative leisure at that time, and the great hurry that prevails in the vernal season. The experiment, however, has not been sufficiently tried; and we know that there need 
be no hurry in planting maclura in the Spring, since they may be in leaf, and bear the removal very well, if they have been properly. prepared by puddling and trenching-in.

Up to this point, the reader will have observed, that all the plans proposed were, for setting a single row in the hedge. Others have preferred a double row in the quincunx or alternate order, and some have even suggested a triple, alternate row. In a communication, sent by Wm. Neff to the Western Horticultural Review, in which are many valuable suggestions, he says, the tops being cut off to about six inches, and the roots trimmed, set the plants in a double row six inches apart, diagonally. Thus:

$\begin{array}{llllllllll}* 1 \text { foot. } & * & * & * & * & * & * & * & * \\ +\infty & * & * & * & * & * & * & * & * & *\end{array}$

a foot apart in each row, making them equal to six inches in a single row. He also advises that, as soon as the plants are set, they should be mulched deeply with leaves, straw, saw-dust, or tan-bark, and they will need no further attention till the next Spring. To avoid the attacks of moles, he recommends that the ground be made dishing, so that the plants should be two or three inches lower than the sides: this, he says, has proved an effectual preventive, and he thinks the plants do all the better for it. Where there is no danger of an accumulation of water about the plants, I have preferred this form of the bed, in which the hedge-row is to be planted, but for a different object; that of having the choice of filling in with the plow 
about the hedge, should there be a defect in the lower branches. Never plant the hedge on the top of a narrow ridge, for the earth will gradually wash away and leave openings - and hogs will be liable to root it away, and make gaps, as well as injure the plants by exposing the roots.

The distance between the plants is another very important matter, to have decided. I consider that most writers and planters have committed the great error of crowding. The different plants used in hedging are so varied in their habits, that no fixed rule can be laid down for all of them, but be sure to avoid setting the plants too closely. Plants like the Honey-locust, for instance, which in our forests often attains a diameter of three feet, or more, and the Bodark, which, in a few years grows to the thickness of one foot, need space, or they will inevitably be smothered. To place them in a single row, four, five, or six inches apart, or in a double row, alternating plants and spaces, as so often recommended, even at nine inches apart in the rows, would surely result, sooner or later, in the death of most of the plants. For the former, I should prefer three feet intervals, in a single row; for the latter, twelve, eighteen, or twenty inches; and this conclusion is supported by experience, and is not a mere theoretical speculation.

For the smaller growing shrubs, a less space should be allowed; but no hedge-plant, unless intended for a mere screen, and to produce a very hasty effect, should ever be planted closer than nine inches. The roses would all do better at three feet or more; the same distance, or greater, would answer for the ever- 
greens: even the Swedish juniper, so remarkably upright in its habit, would soon fill up the space of three feet from stem to stem. Altheas, Barberries, Privet, Beeches, Thorns, Buckthorns-indeed, almost any hedge-plant, unless it be of a very delicate growth, will thrive better, and make a much handsomer and more durable fence or screen, if planted at two or three feet, than if less than one; and even if it be objected, that a year more is required to complete the work, what is that, in the case of a fence which is to last for fifty years or more, in comparison with the prospect of frequent gaps, occasioned by starvation and the suffocation of the plants?

Another serious error is frequently committed by hedge-planters, which should be especially avoided; this is, crowding the line too near a fence-five feet is the least distance that should ever be allowed. I am satisfied, from the character of the Maclura, not only in its native haunts, but even here in the North, that it would be most unreasonable to expect success, health, and longevity, where trees, of naturally free growth, are crowded within narrow limits. I have often observed and pointed out this error, and uniformly advise more space, and direct the stocks to be set in a single line, not closer than a foot apart; nor would I thank any person to furnish me a hedge ready planted, at six inches, in a double row-preferring, infinitely, a single row, at eighteen inches distance.

I cannot, however, approve of another fallacy, which has been urged with some vehemence, that of planting at four or five feet apart, for the sake of economizing plants, by bending down vigorous canes, in 
either direction, in the expectation that a forest of upright shoots will start up from every joint. Such a project must be followed by disappointment; and the reason may be explained upon the plain and simple principles of vegetable physiology. The higher buds are always disposed to break first, and to produce the most vigorous shoots : if a strong cane of Maclura be bent down toward a horizontal position, its elasticity will almost inevitably cause it to assume an arched position, so that some one bud will become the highest, and this will produce a leader or main shoot. Even though this horizontal training may be followed by a tolerably even crop of shoots, some one will very soon make itself the master ; the rest will immediately become subordinates, and most will eventually die out-leaving gaps that will be troublesome.

I am well aware that I stand almost alone in this position as to wide planting; and therefore, though my convictions are very strong, it is but fair and proper, that others, who have had great experience, should also be heard. Overman occupies the opposite extreme from me on this question; he claims, that for an ordinary hedge, it is now generally conceded, that the plants should be set from four to six inches apart; not wider.

Shaw, of Tazewell, Ill., tells us to set the plants at the distance of from four to six inches. The greatest error, heretofore, has been in setting the plants too far apart. E. Miller, of Waverly, Ill., tells us, in the Morgan Journal, that considerable improviement has been made in the cultivation of the hedge, within the last two or three years. The plan of setting the plants 
eight or ten inches apart, and then lopping them under each other, after one year's growth, is evidently bad policy; far better to set them sufficiently close to make a dense hedge without lopping down at all. C. G. Taylor, of Rock-Island, Ml., plants with a dibble, at eight and ten inches apart.

L. H. Ide, above quoted, is very ultra in his communication: "And first, my experience and observation prove to me, that where plants are set from eight to twelve inches apart in the rows, the frequent cuttings necessary to thicken it sufficiently at the bottom, retard the growth of the hedge more than would the crowding of the plants into half that space; and that the fine limbs that at first fill the spaces between the stems, and invariably grow downward and dwindle, will in a few years die and fall off; which will leave holes for snakes, if not for pigs, and possibly for good sized shotes, in some cases. I have been an attentive observer, as well as something of an experimenter in this business for five or six years, and am confident, that scientific hedge-growers will continue to make failures, till they set closer and cut less. I shall never set over four inches apart in the row, for the future; nor cut more than once a year, for a common hedgefence, after the bottom is thick enough, which can generally be secured by the first cutting, with plants four inches apart." To this the Editor of the Prairie Farmer adds, that several good hedge-growers have said the same thing; and that he would set the plants as close as five to six inches, because the stems would then take care of all holes in the hedge.

These opinions are given for what they are worth, 
and some of the writers rank very high as experienced hedgers: yet I cannot coincide with them, while my observation of facts, and my reasoning on deductions therefrom, teach me to anticipate serious evils from crowding, as intimated on a previous page. The only circumstances under which it would be proper to anticipate producing a live-fence, by means of the stems of the hedge-plants, would be, where, from excessive moisture and spoutiness of the land, the Maclura would not succeed, and the gap had been planted with cuttings of the golden or yellow willow-which is well adapted to such ground, and which can be kept within bounds by making it a pollard, trimming off all the twigs every Spring. I have planted this willow in the line of a hedge, setting them very close; and by this annual trimming, the stalks were kept small; but being set closely, the gap, that would otherwise have been caused by the water, was closed effectually: this style of growing plants, however, can never be recommended for a permanent effect. Such treatment will inevitably cause premature decay.

Culture during the First Year-Shall the Hedge be Pruned?-After planting, there is little to do during the first year or two, but to encourage the growth of the hedge, by keeping the ground perfectly mellow, with a frequent use of the Cultivator, so as to prevent entirely the growth of weeds-vigorous shoots will spring up, and often attain the height of several feet, with weaker stalks sprawling about near the ground. Let all grow; their business or function is, to produce good strong roots, that may be able to give us a fine 
crop of shoots the next season. Mulching the ground, instead of culture, has been recommended.

If the ground should become dry after planting, Overman recommends that two shallow furrows should be thrown to the row, on either side. Then when the grass and weeds appear, plow lightly, throwing the furrow outward from the row, and scrape off the surface between the plants with the hoe. These successive plowings to be thrown to and from the hedge, as often as the weeds and grass appear, till mid-summer. Late in the Autumn, throw two rather heary furrows to the row, forming a ridge about it to protect the roots; for if the tops be frozen, it is no matter, as they are to be cut off the following Spring. At the last Summer plowing or cultivating, one or two rows of turnips may be drilled in on each side of the hedge, as they will come off in time for the Fall plowing.

The hedge will rarely require trimming during the first year. A writer in The Prairie Farmer-perhaps one of the Editors, in an article upon Hedging, criticises the plan of allowing the hedge-plants to have free and unrestrained growth the first season; he does not appear to set a sufficient value upon the consideration that the plant requires to be thoroughly established and well-rooted before the severe trimming is commenced. He asks :

"To what purpose is all this waste? None whatever, that we can see. The whole season's growth is sacrificed, with the exception of what is laid up, in the shape of vital power, in the roots. With that exception, we are no better off, or very little so, at the 
end of the first year, than at its beginning. Cannot we save something here, and during every subsequent year, till the hedge is grown. Let us see.

"The object of cutting the hedge is to stop its growth upward, and force it to throw out lateral shoots, till it is thickened at the bottom, so that nothing can pass through it. Why can it not be stopped at once, as soon as its growth is fairly commenced. In the first Summer, the shoots have run up like a parcel of fish-poles, to eight feet in height. They are now to be stopped, by cutting them back to within five or six inches of the earth. Why could not this cutting have been done when the plants had only grown, say eight inches high? Then we should have had to cut away and lose but two inches or so, and when the growth had proceeded, say four inches more, two inches still could be removed. All that is wanted to stop the upward growth of a twig is, to cut off the terminal bud. Being stopped in this direction, it throws out side-shoots, and thus thickens as it is wanted.

"As soon as they have grown to the height of four or five inches, or sufficiently to enable us to strike most of the upward shoots with a cutting instrument, cut them back to within two or three inches of the starting-point; when they have grown again to a height like the first, cut them back again, leaving each time, from one to three inches of the new. wood. The hedge would have to be cut several times in the course of the season.

"It may be thought that this would increase the expense of the hedge, by increasing the number of 
cuttings. It certainly would make more work during the first years of the hedge, but less afterward; and enough would be saved, in the matter of time, to pay for the extra trouble, because the plant would lose nothing of its growth, as by these severe cuttings, it now does. The plants, too, would thicken immediately, and be much less liable to be killed by the Winter, than if suffered to run upward into sappy, illripened shoots."

I would, myself, much prefer to commence with a wild, and utterly neglected hedge, of three or four years, strongly rooted, from which a good fence may almost be made the first Summer after decapitation, than to incur the risk of weakening the plants, by a too early application of the shears; the seven feet fishpoles, cut off at the ground, the second Spring after planting, are not a waste, they have left proportionately strong roots behind them, that will soon supply the place above ground, denuded by the clipping off of the shoots.

E. Miller also advises, if the plants grow thrifty, that they be cut the first year, about the 10th of July. But the danger is incurred of depriving the roots of the young plant, not yet established in its new quarters, of the necessary amount of breathing and evaporating surface of leaves. Great risk will be run of injuring the strength of the plant, by commencing the decapitation too soon. 


\section{CHAPTER VI.}

HEDGe-MARING continued - SeCond Year - Replanting - Culture Trimming-Third Year-Culture-MUlChiNG-FinishiNg UP aNd Seeding-Implements-Shape of the Hedge.

The topic undertaken in the last chapter being one of the greatest importance, embracing practice and involving principles that must be well understood, and efficiently executed, it has been deemed best to divide the subject, which is here continued.

Replanting.-Entering upon the second year, we find that some of the plants have failed, during the previous Summer, or have been thrown out by the frost of the Winter, or they may have been injured by some other cause. The hedge should be carefully examined, so soon as the ground is workable. With a spade, and a basket or sack of plants of good size, and with good roots, the hedger must pass along the line, and replace, by careful planting, all that are dead, or delicate, cutting off the tops of the replants as they are set. The importance of doing this work well, cannot be too strongly impressed; for the new plants will have an unequal struggle with their fellows, already established, and if not successful now, the difficulty will be still greater another year. Indeed, the replanting can always be best done the first Summer, as suggested in the previous chapter.

The culture of the hedge, during this season, should 
be as thoroughly kept up as last year-the object being to encourage the growth of the plants, and to destroy weeds, the ground must be frequently stirred by the plow or cultivator, followed by the hoe when necessary. The July dressing may again be followed by the drill-barrow with the turnip-seed.

Trimming constitutes a most important labor in hedging, and its principles should be well understood by those who contemplate the construction of any live-fence. The importance of allowing the plants to grow freely, and without trimming, the first season, has been already argued in the previous chapter, and in many cases a second year of growth may be allowed.

In the Spring, the whole of the wood is to be removed, by cutting off at the ground, with the scythe or mowing-machine; after this, in the early Spring, the ground on either side of the hedge is to be plowed;

Fig. 2.*


the furrows should be thrown from the row of stubble, and the space between the plants is to be cleared out perfectly, so as not to leave a spire of grass, or other intruder. Proper culture must also be continued, so as to allow nothing but the hedge to occupy the ground. In the month of June, or so soon as the

* Fig. 2 represents the yearling hedge-plant, which has extended its roots downward; the line at $b$ indicates the point at which it is to be eut off near the ground in the second Spring. 
multitude of shoots that will have made their appearance have become sufficiently woody to bear the

Fig. 8.*

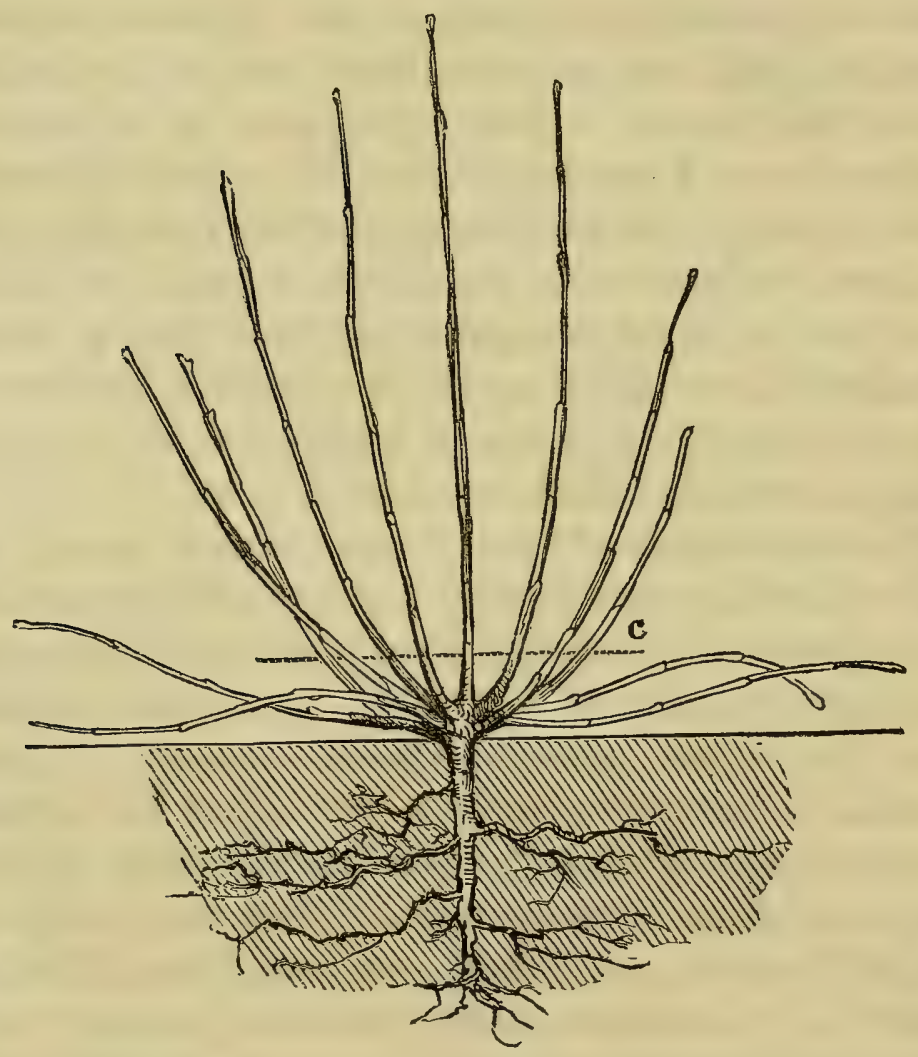

knife, they are to be cut off with unrelenting hand, at four inches from the ground, which will reduce the hedge to a low level, although the horizontal branches may spread over one or two feet, or more, in width. A vigorous, and very thick growth soon follows, which may generally be allowed to grow until Winter,

* Fig. 3 represents different stages in the growth of a hedge the second Summer, as it appears in a transverse section. The line $c$ indicates the point where the hedge is to be cut off in June of the second year in the hedge-row. 
unless the shoots be very strong, when they may bear another clipping, or shearing, in August or September: no rise should be made this year, however, of more than two inches at a time; so that the next Winter pruning shall not be more than four or six inches above the ground. This may appear to be a slow progress toward making a fence, to protect our crops from intrusion, but we should recollect that the labor we have undertaken is one that is to stand for a lifetime, and it is all important to have laid a broad foundation, even if it require two years to produce a young fence of six inches in height, but at the same time, its breadth will be two feet or more.

No disturbance of the lateral shoots should be allowed, unless occasionally a straggler may require to be shortened; these branches must be left to sustain the plant, which is thus severely pruned, and besides this, the lateral growth will be wanted, to give breadth to the future hedge; and unless the bottom is provided at the first, it can never afterward be supplied. If these directions have been well followed, you will have a good, thick, and broad foundation, at the end of the season, which you can pass only with a long stride, and into which you could hardly be tempted to place your foot. In the Winter, or early Spring, the tender and frost-bitten ends, of late growth, may be removed, near to the late Summer pruning of the previous season.

Shaw's advice is: "That after one season's growth in the row, the plants should be mowed within two or three inches of the ground, with a common scythe. This should be done in February or March. About 
the first of June they should be again clipped within two inches of the last cutting; and again, about the first or middle of July, within six inches of the second clipping. After this, one clipping annually will be sufficient to keep the hedge at a proper height."

A question arises as to the best time to do the first trimming, some advising Winter, say February, others early Spring; Mr. Overman thinks the plants should be cut off at two inches from the ground in the Spring, when the plowed ridge which was thrown up as a protection to the roots is removed. He says, the proper time to do this is when the buds begin to start. He also differs as to some particulars advised respecting the Summer trimming. After directing that the weeds and grass be kept down by the plow and hoe, or by mulching three feet on each side; about the last of June, he mows off the tops, six inches above the Spring trimming. The growth being very tender, care is required to have the cutting even, and of uniform height. For the rest of the season, there is little to do except to clip off the rank shoots or leaders that occasionally start up above the rest.

Miller is a terrible trimmer of the hedge, his directions are as follows: "If your plants grow thrifty, crop them about the 10th of July the first year. The next Spring cut very close, quite early. After the Spring, crop as often as the fresh shoot attains eighteen inches height, tolerably close to the last cutting. Continue to cut the second year as late as the middle of August or first of September, generally three times the second year, besides the Spring cutting. The third year, proceed much the same as the second year, 
cropping from four to six inches higher each time. The line should be kept entirely clear from grass and weeds at least for three years, after which it will defend itself. While the upright shoots require frequent cutting, especially after the first year's growth, the lateral or horizontal shoots should not be cut, until the hedge is at least three years old. They are naturally weaker than the upright shoots. Let them grow until they attain considerable size before they are cut. I have noticed many hedges in the country materially injured, and some almost ruined, by cutting the sideshoots too soon."

The judicious advice of W. Neff corresponds with my own notions as to trimming; he begins in the second Spring, by cutting off every thing within one inch of the ground; in the middle of June he cuts off all the tops again, to within four inches of the former cutting; the next Spring, he cuts within five inches of the last cut, and in June to within six inches, and so on, cutting each Spring and Summer, increasing an inch each time, till the hedge is high enough to please him. By this means he expects to thicken the hedge all the way up, and having divided the strength of the stalks by increasing their number, he finds less labor in future pruning, as there are no large stems. By thus trimming off the tops only, the side branches become stronger; these can afterward be trimmed and thickened to any point desired.

Jas. McGrew, whose experience in this business requires us to take counsel from him, makes the first pruning, in the Spring of the second year, in a peculiar manner. He uses shears with which he cuts 
off the whole plant at or near the collar, cutting to the yellow bark of the root, by which he insures branches very low, and he finds no injury to the plant from this severe treatment, for the decapitated root is immediately covered by a callus, from which vigorous shoots spring up.

Trimming the hedge is a matter of the utmost importance, and more failures have resulted from ignorance and neglect in this than in any or all other parts of the business. The establishment of certain principles of action, and their faithful execution, are necessary to success. It is a fact, which all must have observed, that soon as a shrub or tree begins to spread out its upper branches, the lower limbs cease to grow -this is owing to the combined influence of the tendency of the sap to flow more freely to the highest buds, at the expense of the lower; -and of the shade, and want of air, produced by the expansion of the upper branches. This is all right and proper in the production of trees, but a hedge is very different from a forest, or a row of nursery trees, which are grown for their stems, and for sale-while the hedge is cultivated for its impenetrable branches, and to keep for one's self, even though it be the envy of the whole country. An entirely different system of tactics must be adopted to produce this effect; for its neglect gives us a row of trees closely furnished with branches at the top, but naked at the bottom, where we wish to oppose a resisting medium to the long nose of our neighbor's grunter; in fact, such a product is a hedge upside down-a section of it; instead of giving us a triangle with a broad base upon the ground, equaling 
or exceeding its height, it will represent a tall narrow triangle, resting upon its apex or point. This is almost inevitably the result with all the plans for plashing and wattling that have ever been invented, and will probably ever be so, while the laws of vegetable physiology remain unchanged.

Third Year-Culture-Trimming. - The hedgerow this season will require a very similar treatment

Fig. 4.*

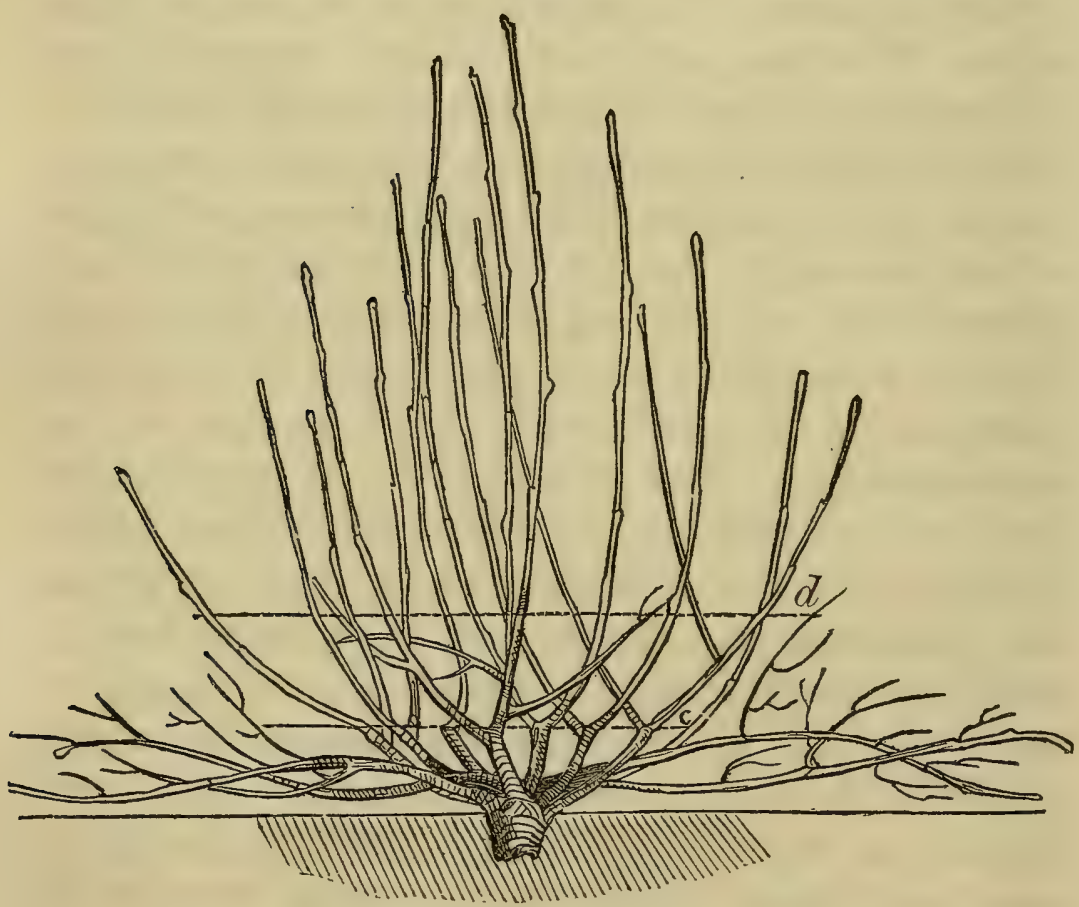

as to culture and trimming, except that the tillage will be much diminished by the width and thickness

* Fig. 4 shows the appearance of a well-grown pjant in the Spring of the third year; and the line $d$ is the place for the cat to be made in the Spring trimming with the scythe. 
of the hedge itself, which should be so thick as to smother all other vegetation; nothing but Maclura should be allowed to remain, however, in the line of the hedge, and the occasional use of the plow or cultivator will suffice to keep down the weeds, and to encourage the growth of the plants.

The Summer pruning should again be performed in June; but now it will not be necessary to clip so closely as during the last season: the shoots may be left four inches, or even six inches above the previous decapitation. Now, also, it is necessary to observe an important rule in hedging - a rule founded in sound philosophy; for there must be philosophy in hedging, or a failure will probably ensue without it: yet so simple is the rule, that every tyro, who has ever held a pruning-knife, or used his eyes among plants, must see and admit its necessity. I refer to the proper shape of the hedge, which is now to be particularly impressed upon it. A hedge should be so trimmed that every leaf and every twig should have the benefit of all the sunshine, air, and rain, or dew, that is possible for it to receive ; this result is easily obtained by directing the cut, at this, and all subsequent prunings in such a manner as to leave a sloping wall on each side of the hedge-row, so that an end view shall present the appearance of a broad low pyramid; never allow the sides to be vertical or perpendicular, much less, flaring outwardly as they ascend, and with a broad flat surface on the top-which is the inevitable result of perpendicular hedge-walls. This is a very common form for a hedge, I admit; but, nevertheless, a very unsuitable one, and not justified by its frequent 
occurrence: on the contrary, the more condemnable is it, because this very error is so disastrous in its consequences as to have deterred many persons from hedging, when they beheld a high wall of bushes, surrounding and shading a field, with a perfect thicket of branches and thorns, from four to six feet above the ground, but beneath this, the naked and meager stems, that appeared thin and ghostly: these are scarcely hidden in midsummer by the scanty foliage upon the starving twigs, which were fast dying out, and leaving open gaps, to be filled with obtrusive and unsightly dead stakes, which the unwise hedger had been obliged to thrust in, to prevent the intrusion of the swine and other invaders. Such a result is, I am sorry to confess, by far too common with many of the hedges that may be seen all over the country, and such a result is inevitable, where the simple axiom I have repeated has not been the guiding principle of the hedger, even where the plants have been lavishly crowded at the planting.

During the third summer, then, the clipping must be continued, with as much severity as heretofore, but the requisite number of shoots having been previously secured from below, the consecutive cuts do not require to be so close together-six inches will do very well-and thus, after the June clipping, we shall have a double slope, or extended pyramidal hedge, with a base of three or four feet, and a height of about one foot, the two sides meeting at the apex, immediately over the line of the original row of plants. In a couple of weeks, when the new growth has again started, you will be delighted with the result; the 


\section{PYRAMIDAL FORM.}

Fig. 5.

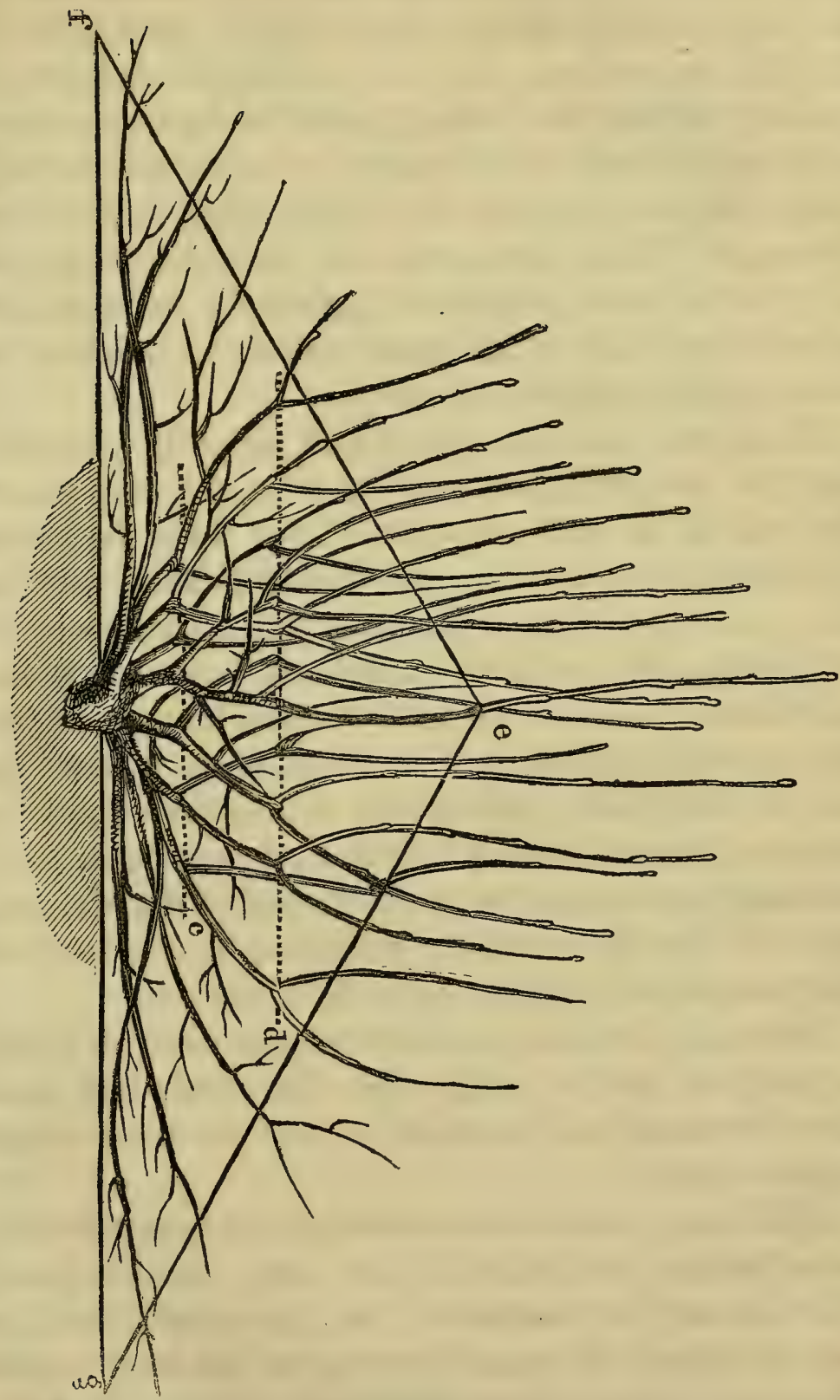

Fig. 5 shows the pyramidal cutting that is to be done in June of the third year as indicated by the lines $e f$ and $e g$, above the lines $c$ and $d$. 
effect will be heightened by the strong central shoots, and the brilliant foliage cannot fail to produce a delightful impression. By the middle of August, or perhaps earlier, the cutting must be again repeated, with another rise of six inches ; sometimes three clippings may be practiced with advantage, in the third Summer. Great care must be bestowed upon the slope of the sides, which will gradually become more precipitous, but which must never be allowed to assume the perpendicular form.

If the soil has been good, and properly prepared, and the hedge kept under the proposed regimen, at the end of the third Summer it will have become a fence against all but the most unruly animals, whether they be rabbits, boys, or bullocks; for, although either of the latter classes of marauders can look over so low an obstacle, a sort of natural instinct induces the de-sire, before undertaking such a feat, to see where they are to land, after performing a desperate leap; in pressing forward for this information, they become too intimately acquainted with the thorns of the Maclura, and will almost invariably withdraw in disgust from the threatened intrusion upon the inclosure.

It is not, however, advised to turn out the hedge so early as this; in some soils the result will have been obtained, but in others it will be best to wait another season.

Mulching, even in this season, is recommended by some hedgers, and when it has been previously applied, it may be continued; but the plow should be used in July of this year, throwing to the hedge about three good furrows from either side, which will aid in 
filling up any openings near the bottom. This should be followed by the harrow, or by the rake or hoe, to dress the surface.

Seeding and Finishing.-After the hedge has been thus laid by-as a corn-grower would call the process of culture, just described-it has been recommended to seed down with grass, the margin of mellow ground sloping from the hedge on either side. White clover has been recommended, on account of its thick, close sward, which will prevent washing, smother, weeds, and curtail the growth of the hedge somewhat, without interfering with its health. Some would prefer blue-grass, but it matters little what be used to produce the effects named, and to give a suitable finish to the hedge.

Implements.--Something should be said of the proper tools to perform all this trimming. I have already alluded to the application of the brush-scythe, and the mowing-machine, to the seedling plants, and to the year-old hedge-row; the same implements may be called into requisition, with great propriety, especially the horse-power one, at the June cutting of the second Summer, and at the August cutting of the same year, if such be found necessary; but, after this period, a horizontal cut is not advisable, and the mowers, as now arranged, cannot be properly adjusted for this work. I have great hopes, however, that hedging will soon require and receive aid from the intelligent machinists who are now creating an important era in the history of agriculture; and that an adjusting hedge-clipper, upon the principle of the harvestingmachines, will be provided by the agricultural manu- 
facturers, so arranged as to give the required slope to the cut; horse-power will then come to the aid of the hedger finely.

In the meantime, the sloping cut is best made with a long sharp knife, that is moderately curved, and set into a light handle, about four feet long, the blade being bent a little to one side from the axis of the handle, and well secured to it. The idea of this implement was taken from what I first had recourse to, after abandoning all the patent shears, and useless bill-hooks, that were furnished in the shops. This was no less than a common old grass scythe, which was bent fifteen degrees from a right line, at about thirty inches from the point; for a handle, the remainder, or heel end of the scythe was wrapped with cloth, and a capital tool was provided, with which a man would soon learn to cut off the shoots with rapidity, and leave a very even surface behind him. As the cutter advances, he should have the hedge at his left hand, and carrying his slashing-knife before him, edge up, and with his left hand advanced, by a succesFig. 6.

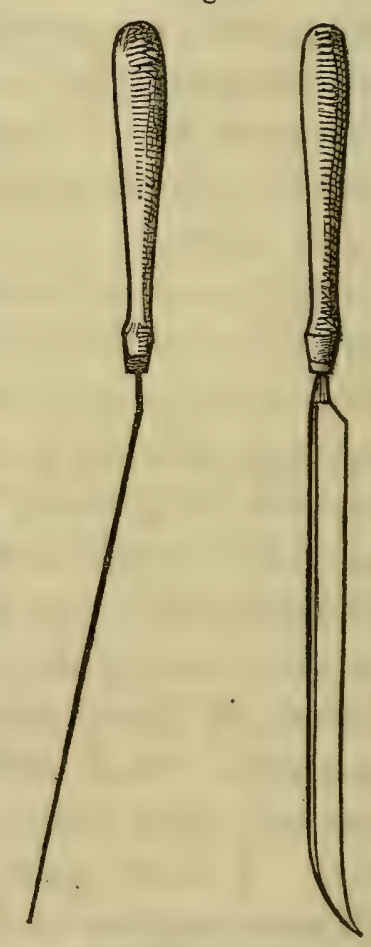

SLASHING-KNIVES. sion of upward strokes, he will remove the shoots with very little effort; the necessary inclination of the blade to the handle, it will now be apparent, must be 
to the right, when the instrument is in use. It should not weigh more than two pounds, and must be kept very sharp. After the second Summer, the trimmer must pass along both sides of the hedge, to complete his work.

Wm. Neff considers the pruning a comparatively small job, using for the purpose a strong knife, about two feet long, or a common grass-hook. He also suggests that some labor may be avoided, by cutting in the Fall, before the wood has hardened, which, however, I consider of doubtful expediency.

My practical friend, Overman, considers the best and simplest implement for hedge-shearing is made by attaching a curved shank to a strong scythe, so as to apply a wooden handle, as above recommended. He does the trimming by an upward running stroke, doing one side at a time. By keeping the tool sharp, the work may be done speedily and easily. He says an expert hand will trim a mile a day on each side, if done at the proper season.

The objection to the machine for trimming by horsepower is, that it provides for an upright and a horizontal cut, which reduces the hedge to a very improper shape. It is elsewhere urged upon all hedgers to observe the pyramidal form, and never to attempt the perpendicular sides with a flat top. A model for a machine, obnoxious to the same objection, was exhibited recently in Cincinnati.

Dibble.-Jas. McGrew uses an instrument of iron, twelve inches long, pointed, and with a socket three and a half inches diameter, into which a wooden handle is inserted; this should have a cross-pin near tr 
socket to receive the pressure of the foot in making the holes. Others use a common garden dibble, of gond size-if sheathed with tin, such an instrument will work better, as it may be kept bright and clean.

Trowel.-This tool, of peculiar construction, described in the previous chapter, is recommended by C. R. Overman: I very much prefer the spade. All implements should be kept bright, clean, and sharp, to do the work well, and with satisfaction to the workman.

Bitl-Hooks and Shears are still used; the former is a clumsy article, too short for the slashing cut, recommended to be made upward, though very suitable for the plashing process, where that is to be performed. The hedge-shears are not of sufficient strength, or require too much labor for most arms, when applied to the strong shoots of Maclura, if they have become woody: the power is applied disadvantageously in this instrument-except for dressing fancy and ornamental hedges, where small spray only is to be cut, I should not advise its use: preferring the strong scythe and the slasher, with a wooden handle, set at an angle with the edge of the blade.

Horse-power Machines, so far as seen or heard from, are not yet according to my notion of what is wanted for this purpose; but such a one as shall trim a slope, and adjustable, will some day be made.

Shape of the Hedge.-Enough has already been said, perhaps, to show that the usual form of an upright wall is entirely unsuited for a hedge. The true form, as already suggested, in the directions for trimming, is that of a pyramid, the two sides of the hedge 
being slopes that meet at the apex, in a line immediately over the row of plants: this is not only the line of beauty for a hedge, but it is also the line of healthfulness for the plants ; since, by this plan, every portion of the hedge, every leaf, and every bud, is placed in the best possible position for receiving the full influence of the air, the sunshine, and the rain. The perpendicular wall may be very much admired, and certainly affords a very fine opportunity for the gardener to exhibit his skill in mechanics, emulating the mason or the carpenter in his faculty of perpendicularity. But, with all his skill, he will soon find it an impossible task to preserve this uprightness: the lower twigs, being cheated of their due share of God's blessed rain and sunshine, will soon suffer from the slow, but sure effects, of natural pruning-that effected by suffocation and starvation: the upper branches, on the contrary, more highly favored, will spread laterally, in spite of the shears, so that the difficulty goes on increasing from year to year.

It may be well here to recapitulate the successive prunings, and the effect they are to have upon the shape of the hedge. The first, practiced upon the well-established plants, the first or second year after setting out, is done early in the season; and, being equivalent to a Winter pruning, will be followed by a crop of vigorous upright shoots, more or less numerous, according to the strength of the roots. Some of these will be thrust out laterally, and will often lie upon the ground; so that, when the June trimming is done, cutting the upright shoots to four inches, the laterals or horizontal limbs will be left untouched, and serve to 
nourish the decapitated plant. This June cutting being a Summer pruning, is not followed by so rampant a growth as that done in the Winter, but several branches start out, more or less inclined from the perpendicular. The next Spring pruning, the third year, consists merely in shortening the second growth of the preceding Summer, and is not necessarily followed by so strong a growth as a common severe Winter cutting; though the upright shoots will again need clipping in June. In the Spring of this year, the laterals will have spread a foot or more on either side, already making a base of two or three feet; if more than this, they may be clipped off. The shape of the hedge at this time will therefore be a very flat pyramid, with a base of two or three feet, and a height of only a few inches.

This pyramidal form changes its proportions with the growth of the upright shoots; and even after the June trimming, the hedge should not be more than a foot high, unless under very favorable circumstances, or where the hedger has failed to cut as low as has been directed. After this, another cutting in August or September makes our pyramidal hedge quite a respectable affair, and all easily produced by making a sloping, instead of a horizontal cut, and by trimming each side of the hedge. The proportions of the pyramid thus change with every clipping, until a sufficient height is obtained.

Amid the great prevalence of error in this matter, I am rejoiced to find Overman giving such directions as these: he acknowledges that he has been forced to the conclusion, that the true form of a hedge is 
that approaching the pyramidal. In support of this theory, the following reasons are adducerd:

"1st. The general direction of vegetation is well known to be upward.

" $2 d$. One of the principal requisites of a hedge is a thick base-a condition which depends entirely upon the number, strength, and vitality of the side branches, near the ground.

" $3 d$. It is plain, that if the hedge is allowed to follow its natural tendency, and force numerous strong shoots at the top, the certain result will be a shaded, starved, and sickly growth at the bottom; consequently, the lower branches will perish and fall off, and the hedge will grow thin: but if, on the other hand, we cut the top more and the bottom less, we shall be more likely to promote an equilibrium of vigor in all the parts.

"The proposition, then, is to trim with a wide base, and bring the top of the hedge to a point.

"On first reducing the hedge to this shape, make the bottom two fect wide, and increase the width and height at each trimming, till it is three feet wide at the base, and four and a half, or five feet high, when, if well thickened, it will be ready to "turn out." "

The pyramidal shape has been urgently insisted on, as the form most readily attainable, and best adapted to the healthy constitution of the hedge-plants of whatever sort. A slight deviation from this, however, is allowable, and very pretty; indeed, it is exceedingly apt to occur without the design of the trimmer, it is what might be called a Gothic arch, and is caused by a fullness on either side of the apex or ridge. 


\section{CHAPTER VII.}

Fourth and Future Years-The Perfect Hedge-The FinalityRoot-Pruning-The Comparative Cost-Chimatic Effiects-CorRECTING DEFECTIVE HEDGES.

WE now come to consider the result of our three years' labor upon the hedge-row. At this time, if successful, we shall begin to have something of an effect. Indeed, the hedge often produces a fence during the third year from planting, though not yet completed. It is not best, however, to expect the fence too soon-better to exercise our patience, thoroughly perform all the various parts of the work, and, of all things, be sure to lay a good broad foundation to the structure you are erecting. Better to lose a year in reaching the result, than to run the risk of a failure, which may render all your efforts abortive, and at last require the whole to be cut down, so as to start again from the ground. A deficient, or open bottom, can never be prevented in any other way. All stakes, and other alterations, may stop the gap, and make a temporary result, but they are a disgrace to the hedger, and act injuriously upon the living fence.

Treatment.-The fourth Summer from planting, the same general rules must be followed, except that culture is not needed, unless the soil is thin, and then manure may be added, to encourage a free and vigor- 
ous growth. The trimming will become less and less onerous, with each succeeding year, if proper regard be had to the simple formulæ that have been laid down-preserve the pyramidal form, and never allow the strong leader shoots to run away from the hedge, or to run away with it-if this caution be neglected, they will assuredly turn the fence upside down; that is, they and their branches, once escaped from their master, into the upper air, will soon spread out on either side, and intercept the invigorating sunshine, the refreshing dews and showers, and the necessary air, to the inevitable destruction of your hedge-it will be turned upside down-the bottom and essential part of it will fail. Fortunately, however, no such catastrophe need be apprehended as the overturning of the proper, pyramidal hedge dynasty, if only the broad foundation has been suitably laid in the beginning, and upstarts be restrained thereafter.

It is well known that the most vigorous growth is made by young trees, and that such a condition will not long continue, if a plant be subjected to crowding, clipping, and a cessation of culture. Generally speaking, the Maclura hedge will cease to make very vigorous shoots by the time it becomes a fence; in this it is as superior to the honey-locust, as in its vigor and rapid growth it is superior to the thorns or Buckthorn, or, indeed, to any plant that I have had an opportunity of observing. Hence, the worst of the pruning labor is over by the fourth Summer, when the hedge will be completed, and will require only a moderate degree of clipping and watchfulness, to preserve the requisite form during the remainder of its existence. 


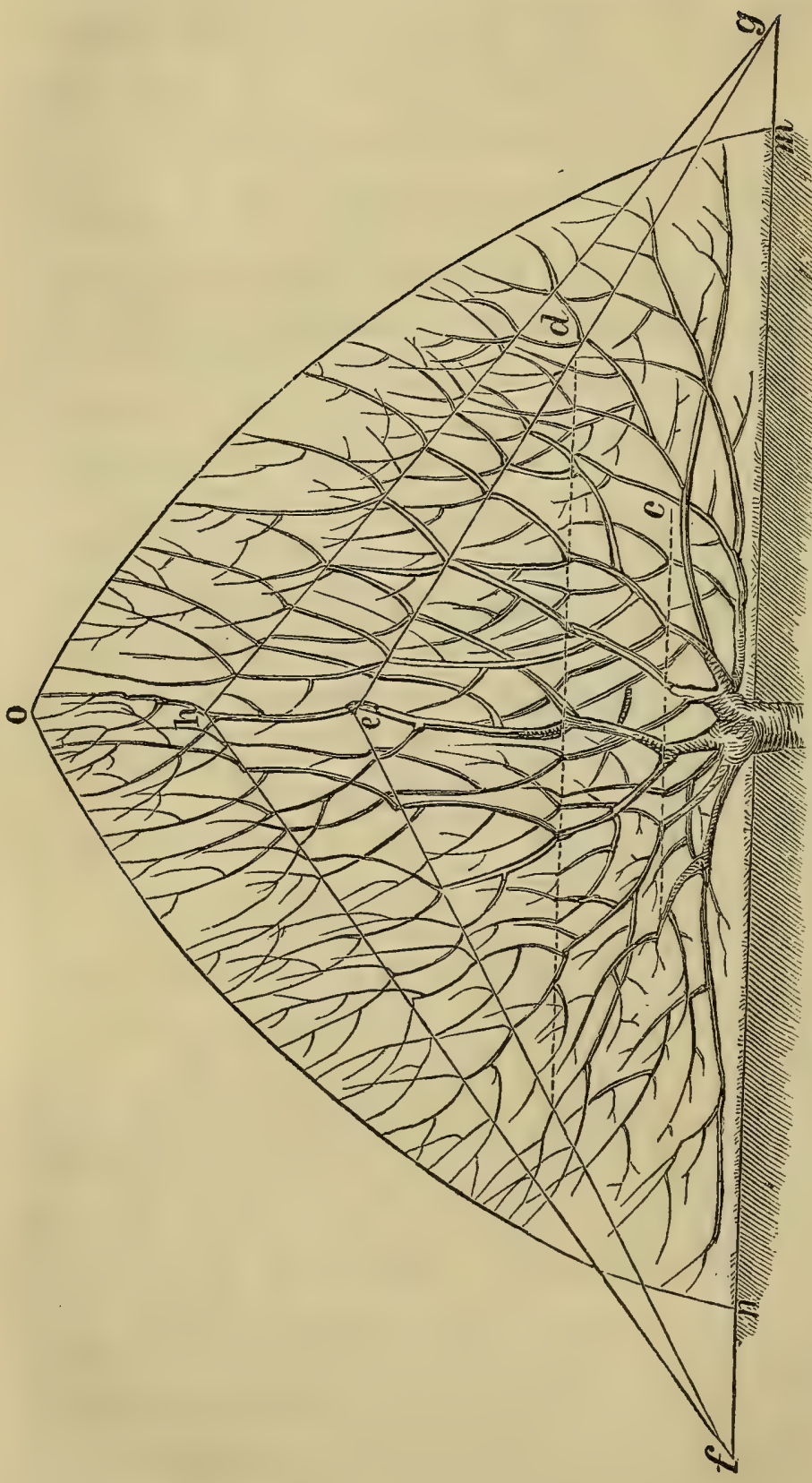

:

沓

त्व

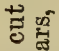

क ळ

원

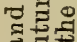

당

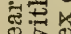

DE

돠요

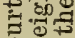

क्ष 0

엄데 항

世

0 孛

․․ㅁํㅁ

켤 छ

월뎨 ह

ฮํ.-

요

$\therefore$ 글

का हี 밍

का क्षै

+ొ

क्ष

象家

ज品

उु०

웒 영

की 0 क

फी

웡

हैं है

월

ब्્व

한

$+8$

때

응

웡용

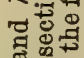

का एक

लिक

\% 8 \%

믐 응

है 
Here, then, we have the Finality. The perfect hedge, made upon the best plan, directed by correct principles. It has been shown that the Maclura is the best plant, and that, if properly treated, so as to dwarf its habit, and to render it compact at the bottom, with a broad base, it may, in the shortest time, and with the least expense, produce a most satisfactory result.

Root-pruning.-It may be found, however, in some rich soils, that the dwarfing has not been thoroughly effected, but that some shoots or leaders will break from the top-line of the fence. These must be watched, and pinched off in the Summer, as fast as they appear, for physiological reasons already given; but we have another resource at our command, to which allusion has not yet been made. Though the Maclura is prone to send down its tap-roots deeply, rather than to ramble near the surface, still, as it is a gross feeder, the roots will occupy a portion of the ground on either side of the hedge-row, but we may check its tendency to a too rapid growth, when this is observed. This may be easily effected, by using a strong, sharp coulter, attached to a plow-beam, and drawn as near to the sides of the hedge as can be approached by the team. This operation should be performed in August, and may be repeated, if necessary, every two or three years.

Many writers show that they have never conceived any correct notions respecting the true principles involved in making the American live-fence, with the Maclura. The old notions of ditches, banks, plashing, wattling, looping, et id omne genus, however beneficial and necessary they may be elsewhere, and with other 
plants, are wholly inappropriate in their application to the Maclura. It was very natural for beginners to follow the printed directions for making thorn hedges; and equally so for Europeans to repeat here the lessons and processes to which they had been accustomed at home. How refreshing, therefore, to find the genius of some of our own men seizing important principles, from which they educe sound practice, and the crowning, happy results. Of such, among the cultivators of the Maclura, are Shaw, Turner, McGrew, Kennicott, and Overman, the latter of whom thus expresses his conceptions of a perfect result:

"A completed hedge should present the appearance of a green wall, when in leaf, from the ground to the peak, which may be five feet high. As its principal use is to turn all domestic animals, it should be strong . enough for that purpose, independent of its armature of thorns; and it should be so dense and thick as to render it difficult to see through it, when the leaves are on. It subserves another important purpose, in breaking the force of the bleak prairie winds in Winter, while it effectually prevents the blowing of seeds and grasses from one field to another, at all seasons. A perfect hedge, well kept, will so blend the beautiful with the useful, that it will improve the taste of the farmer, and promote the love of order, neatness, and method, in all its operations, and, as a consequence, it will strengthen his love of home; hence the importance of properly caring for it, and keeping it at all times in good condition."

Dr. John A. Kennicott, the well-known and acceptable writer on the prairie hedges, speaking on this subject, says : 
"The production of hedging-plants is, in the hands of professional horticulturists, where the process of planting and rearing the hedges, for the first three years, should be also, until our farmers shall have been taught the principles of this particular branch of rural art and science. $* * * * * * * *$

"We have experimented with the Maclura as an ornamental tree and shrub, nearly ever since we commenced the nursery business; but we do not deal in hedge-plants at all, and have no expectation of doing so hereafter. Our opinion is therefore unbiassed by interest, except in the general principle; and our experiments have been made while doubting the hardiness of the plant, and our deductions drawn from much and varied personal observations and extensive personal correspondence.

"We believe in the Osage Orange. We believe that hedges of it may be made to stand our Winter, as far north as Chicago most certainly, and perhaps a degree or two further, under favorable circumstances. But to proceed. We have not enough rail timber left for the present generation, and we must have fences. What shall we substitute? Ditches and embankments have been extensively tried and generally abandoned. We must raise timber for post-and-bar fence or depend upon the pines and cedars of distant regions. We can grow the locust, and, perhaps, other trees, fit for our purpose, in twenty years. Along our navigable waters, and on the lines of railroads, we can afford to build board fences, should the material rise in value no faster than the products of our farms.

"A hedge will cost less and last longer than any 
fence, except the stone wall. A perfect hedge is the most efficient and the most beautiful of all, and subserves several other purposes, besides protection against domestic animals. An Osage Orange hedge will protect gardens and orchards against pilfering animals of the genus homo-a great moral and jurisprudential desideratum. When well grown, it will often arrest the unseen malaria of Autumn, and prevent periodical fever's. It will break off the cold blasts of Winter, and interrupt the heavy sweep of Summer winds; and, in effect, serried squares of the Maclura hedge, subdividing every quarter-section of our vast and naturally defenceless prairies, may be expected to modify their climate, and convert their original naked bleakness into clothed and sheltered tracts of genial mildness and rural beauty. This, in fact, has been measurably proved already, and there can be no reasonable doubt why hedges, orchards, and timber plantations should not meliorate our prairie climate, as surely as they alter the cold, bare features which Nature stamped upon our prairie land.

"The experience of the Old World gave the New early lessons in hedging; and it was natural for us to try the plants here which succeeded there. We have done so, and all are failures. Our climate is too dry and our Summers too hot to suit the best foreign plants. Of our native shrubs and trees, so far as we have experimented at the North, but three seem to answer. These are: the Buckthorn, Washington thorn, and Osage Orange. The two former of these will make good hedges in our region; but it is believed the latter will make a better, if not the best, we can 
ever expect. This has been questioned. Let us inquire into the matter a little further.

"The Osage Orange is indigenous to a region very similar in soil and climate to this for which we write, never quite as cold in Winter, but much the same in Spring, Summer, and Autumn; and, what we deem of most importance, the transitions are as rapid and nearly as broad in Missouri, Arkansas, and Texas, where this tree grows, as here in Illinois, where we propose to introduce it.

"The first great principle in hedging is a broad, permanent, and impenetrable base. After this, with the Naclura, the one desideratum is, ripe wood. To effect the first, cut down the plants in the Spring; to secure the last, cut back the new growth in Summer, and entirely arrest it early enough to cause the ripening of all the wood that must stand a Northern Winter. Where the growth is slow, less and later cutting will suffice; where rampant, no one will cut too much. Hundreds of these hedges without bottoms should be cut down to the ground, or near it, at once, else they will never make perfect fences. We have cut down plants five years old, and four or five strong stems are the result of the one or two sacrificed.

"We distrust thick planting, and believe that one strong root, with three or four stout shoots, is better than two weak plants with twice as many feeble stems. We are not prepared, however, to give definite directions as to distance apart. Perhaps eight to twelve inches, according to fertility of soil and boldness and constancy in cutting down for a base, may be near enough to the popular mark; and it may 
yet be proved, that on our deepest and richest soils, especially if moist withal, a still greater distance, with proper cutting, will be most advisable. One fact is certain, thick planting or thin, there will never be a reliable fence withont severe cutting."

In confirmation of the above, the editor of The Illinois Farmer says: "Our Agricultural Committee have made examinations of Osage Orange hedges in this county; and we found some that had been set only three years, and then turned out-making an efficient fence against horses, cattle, sheep, hogs, pigs, and even chickens. We can now say 'Eureka!' we have found it. The Osage Orange, in our country, has been proved to make a good and effectual hedge fence. I would strongly recommend, however, that it be cut back far more severely than usual, in order to give it a thick bottom; for on that its main excellence depends.

"We find also that the prejudices of our farmers against this species of fence are fast giving way, and the number of those who plant hedges is constantly and rapidly increasing. What a beautiful sight will the rich prairies of Illinois present when covered with farms inclosed by the Osage Orange-and this is soon to be done in Central Mllinois.

"I have often had occasion to say, with you, that by helping to introduce this plant, Prof. Turner has done more good in his day and generation, than if he had expended a long life in pounding Greek and Latin into the brains of that class who prefer ancient lore to living and useful knowledge." 
Cost.-Prof. J. B. Turner, of Jacksonville, Ill., has a little farm of about one hundred and fifty acres, now nearly surrounded and subdivided into twenty-acre lots by this hedge, with gardens and lots of smaller dimensions. He says, he will never allow another rail or board of any sort to be brought upon the place for fencing: I give his estimates.

To make all these inclosures in the best and most convenient manner will require about four miles of hedge or other fence. It would be impossible for him to obtain the cheapest sort of rail, or wood-fence, for less than $\$ 300$ per mile. This would, of course, make a bill in the outset of $\$ 1200$.

"On the other hand, the hedge well set in the ground, at the present price of plants, would not cost more than $\$ 25$ per mile. Here then is a clear difference of $\$ 275$ per mile, or say $\$ 1000$ in the cost of four miles when first put upon the ground. The annual interest of $\$ 1000$ is $\$ 100$, which will hire a good, smart young man to tend the hedges, for five months in the year. Now if, in all coming time, a man be hired to take care of the hedges, and do nothing else for five months in the year, it is evident that the rails and the hedges would, on that score, just balance in actual cost.

"But on the other hand, it should be considered that it will take from three to four years before the hedges will be sufficient to turn stock. We will say the extreme-four years. Here there is a loss of $\$ 400$ interest for which the hedge makes no return, but the rails do.

"To offset this, it should be considered that about 
$\$ 400$ worth of the wear of your rails will be gone in that time; for the whole fence will be virtually gone in twelve years, or even in less time than that; while your hedge, at twelve years old, thus taken care of, will be fifty per cent better than it was at four years old.

"But, instead of its requiring a hand five months in the year, it does not require one month, even in the most laborious and difficult part of the process, to take care of the hedge in the best manner-and after the third or fourth year, it does not require the half of that, for any man who can swing a slasher can trim a half mile of hedge, well enough for any farming purpose, in a day; an expert hand will trim a mile; and whenever suitable horse-power shears are introduced, the cost will be still further diminished."

In balancing his estimates of cost between the hedge and rail fences, he cannot make it come out any other way than that, in the long run, he will be at least as well off, in point of cash cost with the hedges, and a good man hired five months in the year to take care of them, as he would with a wooden fence. In point of security and beauty, there is of course no comparison. But all who know anything about it are aware, that it will not cost even a fifth part of that labor, on an average, to take sufficient care of the hedges, even with the imperfect tools now in common use.

Here, then, is a clear saving of $\$ 80$ per annum, and at the end of ten, or at most fifteen years, there will accrue another saving of at least the whole cost of the rail fence, which will be all decayed and gone, 
while the hedge will be better than ever before. Here, then, is another saving of $\$ 1200$ more, or about $\$ 100$ per annum.

On this place of one hundred and fifty acres, requiring four miles of fence to put it in perfect order, he calculates that he is saving at least $\$ 200$ per annum, in all coming time, by using hedges rather than rails -entirely aside from the additional comfort, security, and beauty of the hedge.

As to security, all his fowls, consisting of some hundreds of hens, turkeys, ducks, guinea fowls, peacocks, \&c., have been inclosed for two seasons past in a half-acre lot, with a seven-foot panel-fence on one side, and a hedge on the other. They sometimes get over the fence, but never have they passed over the hedge.

On this farm there are some seventy-five or more hogs and pigs of all sorts, which run beside a hedge which separates the hog-yard from the orchard and cornfields-and though the young pigs often get through the rail-fence, on the opposite side of the lot, they have not been known to pass through this eighty rods of hedge.

Others, who followed the directions, have as good hedges, and some of them say they are better.

The neglected hedges to be seen all over the country, the Professor observes: "are not all a dead loss; for the roots meantime grow strong and well; and these hedge-rows of three or four years old may be cut down close to the ground in April, and after that, trimmed once in two or three weeks, and thus be brought into a good hedge in a single season, when 
the roots are thrifty and vigorous, and the soil well cultivated. This has been done repeatedly, where "errors in the first management had been committed."

I agree entirely with Professor Turner, and Jas. McGrew, in their condemnation of the advice which has sometimes been given recommending other and erroneous plans for hedging with the Maclura; and concur in the proposition, that this plant needs everywhere a great deal of severe dwarfing, by pruning, before it will make a good and manageable hedge; and probably much more of it on the fertile prairies than anywhere else, or on poorer soils. On some lands it needs at least twice as much pruning as on others; and as a general rule, the richer the land the more frequent and severe must be the use of the slasher. Hence it is utterly futile to think of publishing directions which will apply to all parts of the country alike, without regard to differences of soil and climate.

A writer from Pekin, Ill., comments upon the statements of Professor Turner; he claims that it requires a fence to protect the hedge for four years-an item overlooked in the above calculation; this with its losses and expense of hauling should be charged to the hedge, and amounts to a considerable item; then, he claims, very correctly, that the hedge will require at least an acre to the mile, for itself, to the exclusion of other crops.

He thus makes the hedge cost, for the four miles, $\$ 1397$, while he sets the fence at $\$ 1200$. He admits that it might make a difference if the fence were decayed and gone at the end of twelve years, but claims a greater duration for the rail-fence-this is 
based upon the condition of his own white-oak rails, that have been standing thirty-one years, were never reset, and have never cost an additional rail, nor a dollar of expense! He also has a post-and-rail-fence, that has stood for twenty-seven years, which has never been repaired, nor caused any expense, and which does not contain a broken rail, nor a decayed postthe former are white-oak, and the latter are post-oak -he thinks it will last a good fence, without repair, for ten years more.

This is changing the aspect of the question, and threatens to annihilate the practical claims of the hedge-those of economy-for the beauty part is yielded; but, before deciding, let us inquire whether this is not an extraordinary case of durability of fence-rails.

This is an extraordinary duration for a fence whether of rails or posts and rails, and surpasses the experience of most farmers.

E. Miller, who appears to be a professional hedger, says: That a fence can be grown on good ground at fifty cents per rod, and warranted; which is usually safer and cheaper to the farmer than to dabble with it when they have no experience, and but little time that they can devote to it, thereby often losing both their time and plants.

Henry Shaw thinks, it will not cost more than 25 to 50 cents per rod, to make the best hedge in the whole world for all farming purposes. For one kind it will take 1000 plants, and from that to 2500 for every 80 rods of fence. And had I the time, I would agree to fence the whole Mississippi valley for 25 cents per 
rod of one kind, and 50 cents per rod of the other kind of hedge, all complete, and all cost includedand to perfect the whole in three, or at most four years from the time the plants were set in the hedge. I find by experience that a mile of fence can be set much easier and quicker than I had supposed. My Englishman with a boy to put in the plants, set fifty rods per day after the plants were prepared, which the nurseryman ought always to do before he sells.

Correcting Defects.-So many hundreds of miles of hedges have been planted and then neglected, or badly treated, in consequence of the ignorance of the planters, and often because of the erroneous instructions that have been given by the plant-venders, and also by those who have been looked upon as teachers in this art, that it seems necessary to point out the best means of correcting these very common failures.

Wherever the plants have made a tolerably good stand, and have not absolutely died from their neglect and bad treatment, it will be a very simple matter to construct a good fence upon their roots, in two seasons; and here will be a very pretty opportunity for displaying a thorough application of the plans here proposed, but with some modifications. The same principles of vegetable physiology must be observed in the trimming; but their application must be vigorous and judicious.

Some, unwilling to wait, and preferring to continue some sort of a fence, instead of cutting off entirely, prefer to pursue the old plan of renewal by planting; one of these, already quoted on other points, upon which we more nearly coincide, recommends that 
"old hedge-rows, now apparently worthless through neglect of trimming, may be formed into good fences by the system of plashing recommended for thornhedges, namely, cutting the main stems half off at the surface, and bending them down so as to interlock. with the adjoining plants. This plashing is only recommended when the plants have already suffered from want of trimming, by growing too tall, and leaving the spaces near the ground too large. It is by far the best plan to thicken the hedge by clipping, if commenced in season; and even in some cases where not commenced so early as it should have been, it may be best to cut it down and commence anew."

When referring to this method of renewing a bad hedge, E. Miller says: "If lopping becomes necessary to make the fence close at the ground, it ought always to be done by cutting the upright shoots sufficiently near the surface to let the tops lie horizontal without any withing under each other. This should be done early in the Spring. The wound given the plant in cutting will heal very rapidly, and the lopped branch will not in growing tend to a perpendicular position as when withed down, but will remain horizontal; the branches will lie easy without chafing each other so as to retard their growth, as is the case when they are plaited under. The slashed branch will throw out more and better shoots, and there is no danger of their dying out as in the other mode of lopping. The branches may be cut considerably more than half off without injuring them."

With such ragged and uneven hedges, C. R. Over- 
man advises to "lose no more time, but cut them down, in early Spring, nearly level with the ground, except a sufficient number at one end to fill all the vacancies in the remainder: these may be cut off at three feet high. Remove all the stunted plants. Take up the replants with good roots, and use none but the best and most vigorous. Root out all the grass, and set the replants with great care. Clip, as before directed, but once oftener, say middle of April, June, and July of each year. The replants are not to be clipped for two years; but the growth each side must be checked to give them a chance. A hedge that has been planted too wide, and suffered to run up tall and thin, may be remedied by plashing. This operation consists in cutting the plants two-thirds off, near the ground, laying them down at an angle of thirty degrees, and interweaving them around stakes, set three feet apart in the row for that purpose; or if the stems are thick enough, the largest of them may be left for stakes. Thin places in a cropped hedge may be strengthened by bringing strong shoots into them, and confining them during the growing season. If the ever-intruding prairie rooter could be honored with private apartments, many a ragged specimen, now only a forlorn hope, would still answer the end honestly expected of it."

I consider plashing a barbarous process, and one that should never be practiced, unless under a pressing necessity. It injures the plants more than cutting them off entirely, which may be done with impunity in the Winter season. To expect a healthy growth from the mutilated stocks that are also turned from 
their erect position, and generally twisted and withed between stakes in plashing, is unreasonable. The very presence of the dead wood of the stakes is injurious. That hedgers should complain of failures of plashed hedges is not surprising; but that the fence should bear such treatment at all is the marvel. 


\section{CHAPTER VIII.}

Objectors - Answered - False Methods - European Plans Unfit FOR Us.

Is view of the fact, which is unfortunately too obvious, that there have been more failures than successes in the attempts to produce hedges, it is but natural that there should be many, even of our most enlightened agriculturists, who object to all propositions for hedging, under the impression that any efforts will prove nugatory. Some of these shall have their objections considered in this chapter.

Among those who condemn hedges, we find many who use the argument against all fences for farm purposes, on the score of their great expense. One of these, J. F. Williard, of Wisconsin, has presented the matter so forcibly, that some extracts from his essay in the State Agricultural Report will be here given :

Our present customs and laws concerning fencing against cattle form a most burdensome, unjust, and oppressive system of taxation, to which this or any other country ever peaceably submitted. A similar tax for any other purpose would cause a rebellion; and the only reason which can be assigned for the apathy existing upon the subject is, that people have been born under it, and have grown up with the burden upon them, which has so accustomed them to 
it that it has become a part and parcel of themselves. * * * At a moderate estimate, the annual expense of fencing in the United States is upwards of one hundred and fifty millions of dollars. This sum includes only the estimate at seven per cent per annum on the first cost, with the necessary repairs and use of ground occupied by them. In the single State of New York, more than ten millions of dollars are expended annually to support their fences. * * * The amount expended in Wisconsin is estimated at more than the original amount paid for all the inclosed land in the State; and the fences have cost more than the gross proceeds of all the surplus agricultural products.

The worst feature in the system, and that which should stamp it with unmeasured condemnation, is its injustice, inequality, and oppression. * * * * There are other evils connected with our fencing system, which, of themselves, should be deemed sufficient reasons for abolishing it, were the advantages claimed for it two-fold greater than they are. One-half of our troubles, as farmers, originates in some way in connection with our fences, either directly or indirectly. * * * The cost of land wasted by being occupied by fences is of little consequence, compared with the inconvenience resulting from the play-grounds of noxious weeds and bushes afforded by the fence-corners, besides being a harbor for rabbits and other vermin. They are also reservoirs for snow in Winter, and rain in Summer, and are ever distilling upon the adjacent lands their humid exhalations.

In Massachusetts, there are laws requiring the 
owners of animals to restrain them to their own premises. When the Legislature passed the law, many considered it an experiment of doubtful utility, and it was believed by many that the people would never sustain it. Time has settled the question, and the enactment has been triumphantly sustained by the people, who rejoice in the improvement, and recommend it to others. **** Large tracts of land on the Connecticut River, varying in width from two to eight miles, were subject to annual freshets, which rendered permanent fences impossible. Those lands were too valuable to lie idle, and hence a general law was enacted."

These, howerer, are arguments against fencing in general, startling as they are, and do not apply to hedges alone. Though objectionable on these and other accounts, we have assumed, on a previous page, that fences of some kind were a necessary evil, to which the people have determined to submit.

Among the objectors to hedges in the State of Ohio, we find some very prominent agriculturists-men who have held high positions in the State Agricultural Society, but who plainly show in their writings, as well as in their speeches, as also possibly upon their grounds, that they are not really prepared to condemn hedges, but that themselves, rather than the plants to which they refer, are to blame for the want of success.

There is another class of objectors who are very common in the world, and well known; generally much disliked, and seldom answered; not because their arguments are unanswerable, but because it is 
not worth the powder necessary to produce an explosion of their statements, and because the shaft of ridicule, though it may produce a smarting wound, is really devoid of point, and falls harmless, if not opposed-I refer to the scoffers-numerous as they are. I shall only present a single specimen, and one of the least objectionable, which is selected, because the writer presents a plan of making live fences that are not to be hedges. He writes to the Prairie Farmer :

"About the time of the general introduction of the Osage, I wrote an article for the Ohio Cultivator, doubting its success, and advising farmers not to go into it largely. Many, howevever, were, and they still seem to be, confident of its success, and patriotically and zealously engaged in the seed and plant business, the consequences of which is, in Illinois as in Ohio, long rows of straggling, prickly bushes are very frequently to be seen, intended for hedges. All I have seen are about as sightly, but much less fruitful, than the similar rows of blackberries, thorns, and crabs we often have springing up in Ohio. As a fence they are about equal. Both are much better calculated to tear a man's pants than to turn swine, or even cattle.

"The last efforts I have seen at an Osage hedge are by James Mathews, Esq., Coshocton, and the next by Mr. Bateham, Editor of Cultivator, Columbus, Ohio. These, when I saw them, looked neat and promised to be hedges. But the trouble is, will they stay put? The Osage is a tree. Left to itself, where I have seen it, it does not limb out so low down as the oak. Is it reasonable that the oak may be clipped into a hedge? Could the elephant be compressed into a goat? Dame 
Nature is stubborn. She yields much to wise and gentle solicitations; but to absolute force-work, never. "Still the Osage is not a large tree, seldom exceeding sixty feet in height, or the diameter of our large, full-grown apple-trees. It may make a hedge; and if so, how can it best be done? If the farmer is determined to have an Osage hedge; if he cannot wait a few years until the doctors, and seed and plant sellers have shown him a good hedge, that has turned all stock for at least five years, then how shall he proceed. Of course, all I can do is to give my opinion - for good hedge I have seen none; and I have travelled some, and looked at all I could readily see. To turn hogs, I will give no plan, because I have seen enough to feel sure the general farmer will never make Osage hedges to turn swine. The amateur, at thrice the cost of a post-and-board-fence, may make a hedge that in favorable seasons, for a few years together, may turn swine. This I have not seen, but I guess it may be done. To turn cattle, horses, and perhaps sheep, I will point out what seems to me most likely to answer. Select the plants, set together those of even size. Fill up the second year all vacancies with plants of the same age, and better size than those in the hedge-row. Be sure to do this. Then annually, in June, cut off the strongest plants, so as to keep the growth of all equal-simply to keep all equal, and not to make them bush out. If some plants will grow faster than others, take a sharp spade and root-prune - that is, cut off a few of the roots of each over-thrifty plant, so it shall not rob its neighbor, and cause it to pine from starvation. Of course, in this way the body 
of the trees and not the bush forms the fence; and it becomes important-how far shall they be apart? To hope to turn sheep, eight inches would be far enough; but I believe it would be better not to attempt this, and set the trees one foot. If set one foot apart, TREE as the Osage is, with regular root and top pruning the strongest, all might be kept growing, and a fence made that would defy cattle. This I think probable. But admitting the fact, other plants, shrubs and not trees, would be much more easily kept in order. Of these, the Buckthorn seems to offer many good qualities. The smaller growing native thorns promise about equally well. Nor is it really necessary that the plant have thorns. On this plan the body, not the limbs, make the fence. Of course, a smooth plant could be more easily trimmed and handled, and the body would make an equally good fence."

The Horticulturist objects to the Maclura. "This plant," it says, "has some very good qualities for the purpose, but it requires great attention-more, it has often been found, than the generality of busy farmers can afford to give to it; if neglected, it runs wild, loses its lower branches, which at the best must be interlaced after the first cuttings, or they will admit the smaller animals. Another disadvantage is, that it is a greedy feeder, extends its roots far and wide, and exhausts the crop of its proper food to some distance in the field; the roots are also of an extraordinary size, frequently as large and thick as the wood above ground. It is, however, hardy, and if it loses the tips of the young shoots in a severe Winter, it soon fills up with proper cutting. This plant is seldom 
liable to the complaint of sending up suckers. Where there is a determination to have it as a hedge, and to give it the proper yearly attention, it may do very well; but it is open to some objections, and it is late in coming forward in the Spring, and early in shedding: its leaves. Our own opinion is, that in a vast proportion of cases the Osage Orange, without great attention, will prove a disappointment: we express this with regret, for it has been extensively introduced. The experience of our friends at the West may be different."

The first objection is equally applicable to all other hedge-plants, but should rather be laid upon the shoulders of the hedger. The interlacings, as a remedy, would, by a good cultivator, be considered of doubtful propriety, to say the least, except in a very limited extent. That it is a greedy feeder, will not be denied; indeed, it is on this very account that it is so admirably adapted to make a quick result, but when the plants have been dwarfed by suitable pruning, that is by the time the hedge is made, this character disappears, and such plants are probably very moderate feeders-we see corn and grain crops thriving close to the hedges. The roots do not extend far and wide in any great degree, but are remarkable for their tendency to go down deeply into the soil. This is proved by the absence of suckers, which is admitted by the objector.

False Methods.-Nothing has contributed more than these wrong teachings and wrong practices to. bring the whole subject of hedging into disrepute with the people. The most honest men, and the most 
zealous, have been impressed with an idea, originally correct, upon which they have built up their theories and founded their plans, which, in the warmth of their young enthusiasm, they press upon the public, without waiting for the correcting proof of time to test the value of their inventions. Others, copying the plans that may be suitable in foreign countries with different climates, and perhaps intended for different objects, apply them here, and without sufficiently proving their value, they use their endeavors to persuade their neighbors and friends to do the same things. The people, being good-natured souls, willingly follow the kind advice, and are thus too often led into difficulty.

Fig. 8.

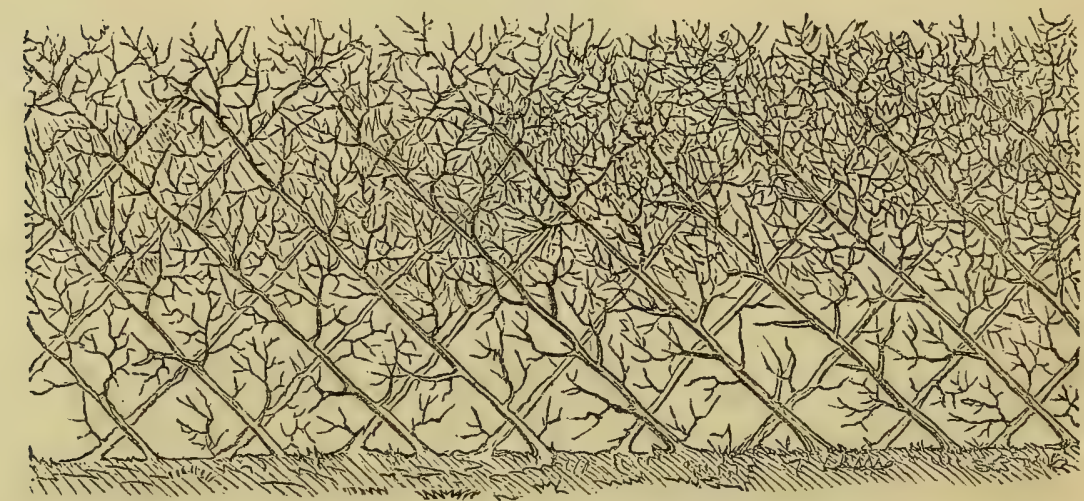

Figure 8 represents the plan of training so as to form an open net-work or trellis, by inclining the plants in opposite directions. The spray-twigs are generally increased above and diminished below, forming the too common shape indicated in figure 10.

One of the most ardent advocates of hedging pursues his early predilections, and recommends the use of white thorns, which succeed well in England and Europe: he plants and waits, and finally he is disap- 
pointed. Another seeks for a substitute among our own native species, more sturdy in their growth, and to the manor born; to these he applies modes of planting and trimming that are wholly unsuited to them, and his efforts are not crowned by the anticipated success. Another, an admirer of formality, sets his plants, of whatever sort, in such a way as to pursue the wicker style, so as to force the plants into a sort of basket-work, that shall make a fence, whether it ever puts on a leaf and grows a twig or not, adopting the plan pursued with the beech and hornbeam screenhedges in Europe, which are intended to be slight structures, and which are frequently in-arched where they cross one another, and thus rendered stronger.

Fig. 9.

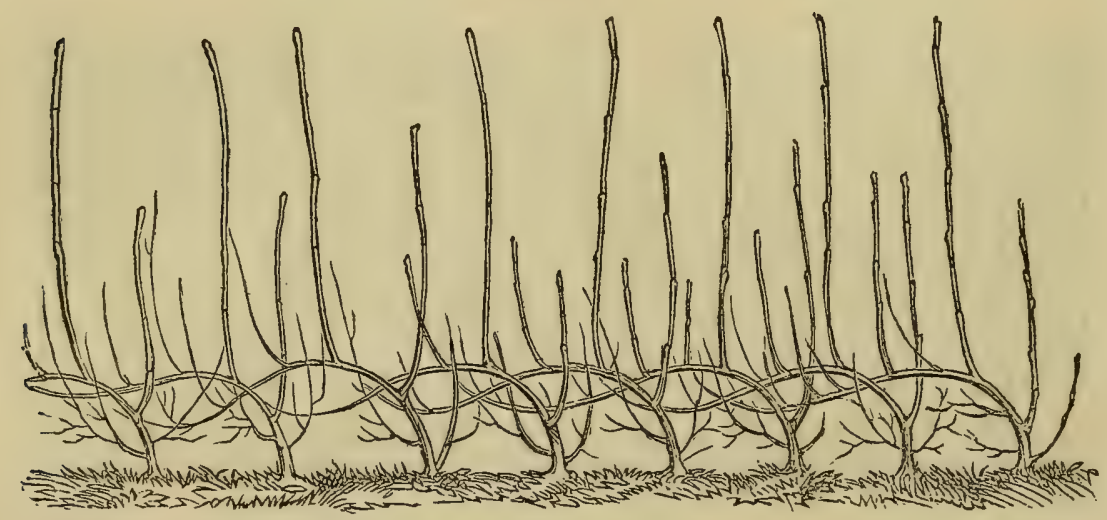

Figure 9. The looping-plan, recommended by some of the early instructors in Maclura-hedging, and extensively practiced with unfortunate results. As shown in the cut, strong shoots come out near the bend, which soon obtain the mastery; while the lower and horizontal branches are smothered and die, and the upside-down form is seen from the end view, as in Figure 10.

Another, after growing his canes one year, loops them together at a foot from the ground, and thus makes a low barrier that is very strong, and from the 
top of which the new crop of shoots comes out the following season, leaving, however, a bare space below the loops which will always remain open, unless, as suggested seriously by one, a large board be fastened beside the stems to close it up. Another thoroughgoing, economical fellow, will tell you to grow your canes two years, and eight or ten feet long-then peg them down to the ground so as to have the shoots rising thickly from almost every bud, and thus save plants. Then, again, we have a very numerous clan

Fig. 10.

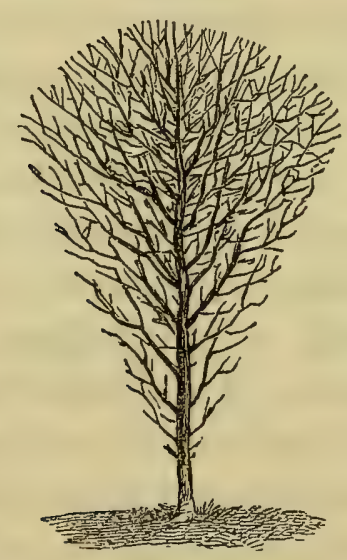

Figure 10. This is an end view of a badly-trinmed hedge, whether of trellis-work or otherwise made; it is the hedge upside down, the pyramid inverted, with abundant interlacing branches above and few below to occupy the spaces between the plants.

in those who have tried the plan of utter neglect after planting, which is indeed quite too common a mode of procedure, and which, necessarily resulting in failure, produces more discredit than any others.

All of these have been shown to be false methods of hedging; and better plans, based upon philosophic argument, and supported by common sense and com- 
mon observations of facts, have been presented in this volume as true and safe guides, well tested by experience, and proved to be worthy.

I must be allowed again to repeat the truismmake the foundation or base of the wall first, and then add the superstructure. You cannot make a hedge as the Chinaman does his cabin, roof first; it won't be built that way-plant-nature is against it; the air, light, rain, and dew, must have access to its parts.

European Plans.-The various plans pursued by hedgers in the Old World, as we find them set forth in their manuals and systematic works on agriculture, though they may be very well adapted to their soil, climate, and circumstances, are wholly unfitted for us in this country. Their introduction here, wherever it has been attempted, has usually been followed by failures, and has thus contributed in no small degree to the disfavor with which hedges are regarded by many of our farmers. The Patent Office Report, for 1855, contained a long article on hedging, compiled almost wholly from foreign sources. To this, however, may be excepted the introduction of some American shrubs in the list of plants presented as suitable for. hedging; and also, a brief essay of about two pages upon the culture of Osage Orange, by that practical and sensible hedger, James McGrew, of Dayton, Ohio. The expensive plans of ditching and hedging conjoined, which are much used in the damp climate of England, and very suitable there, are entirely unadapted to our fine dry climate, where the thorns, at least, are too apt to cast their leaves, even when growing in our prairies and bottoms, and would not 
thrive at all upon a dry bank, as has already been satisfactorily proved upon the sod-bank fences of Illinois, where they have suffered from drought and from frosts.

Those who know Mr. D. Jay Browne, of the Patent Office, and his works, as well as his indefatigable labors for the cause of agriculture in his present position, and the accumulation of cares that devolve upon him there, will know how to make every allowance for these defects. Our excellent townsman, A. H. Ernst, who has received great commendation for his hedges, and who has spent a long and useful life in our country, the fine dry climate of which he fully appreciates, asks, whether in our hot climate it is possible to secure, on a level surface, a close and compact base for any length of time? whether the rarified heat near the ground will not destroy the lower branches? He reminds us that in Europe many of the hedges are grown on raised embankments or ridges, with a ditch on one side or both. This admits, he claims, the free circulation of the air to the lower branches, by which they are kept in a healthy condition. The question may be answered affirmatively - and no better proof can be needed than is furnished by the beautiful specimen trees on his own grounds-perfect pyramids, with their wide bases supported by the soil. This is the very climate and country where we should have low branches: keep the ground shaded by all means. 


\section{CHAPTER IX.}

The Philosophy of Pruning-Summer and Winter TrimaingApplication to the Hedge.

Philosophy of Pruning.-Frequent reference has been made in these pages to the principles which should guide us in trimming the hedge; now, lest in the hurry of announcing and discussing practical points of procedure these important principles may not have been sufficiently elucidated, it is considered best in this place to devote a little time to their examination.

It is premised that every nurseryman and every gardener, as well as every orchardist and every hedger, if not every amateur, should be well acquainted with these principles, and familiar with the facts and natural phenomena from which they are deduced; and yet it is marvellous how great an amount of ignorance of these matters prevails in this country, as will be rendered apparent by the inspection of the orchards, the nursery-stocks, the vineyards, the fruit-gardens, and the hedges everywhere about us. With the latter we have now especially to do ; but the same laws of vitality exist in one case as in the other, simply varied to suit the specific differences of the several plants, and modified in their results by the objects we desire to attain.

It is not necessary to go into the details of the 
theories of the circulation of the sap; neither the teachings of Darwin and his followers, nor those of Schleiden, shall now be called in question; but let us remember the importance of the function of the leaves, whether they be true lungs or mere evaporative and absorptive surfaces-whether the important changes of the sap into the proper juices and tissues of the plant be performed in them wholly, or in various parts of the vegetable system, we need not now inquire: we shall all admit the importance of the functions to be performed by the leaves and buds; in the former, the sustaining and evaporative-in the latter, especially, the generative function also; so that a bud may be considered self-supporting, and is able to become an independent individual.

Of these buds, however, collected as they are in groups or communities in every tree, each being an individual existence, there are always some that have greater powers of reproduction than their fellows-as in other societies, some members attract to themselves an undue share of the good things of this life, robbing their poor neighbors, who are often starved and deprived of their very existence.

Such is the battle of the buds, and such the results! and every leaf performs its function well or ill in proportion to the amount of vitality possessed by its adnate bud. The master-buds in plants of woody fibre are mostly situated at the extremities of the upright limbs-indeed, they are generally the very terminal buds. Hence, we find the first and strongest shoots coming from these buds; and feebler growths, often none at all, from those below, although nearer 
the fountain of supplies of the watery sap. If in pruning and training a vine or tree we desire altitude or longitudinal extension, we carefully preserve such a bud-if, on the contrary, we wish our plant to spread equally on every side, we remove this leader, and divide the responsibility among the subordinate members of the community of buds. Now, here is an application of one of the first and most important principles of vegetable physiology.

If this removal of the terminal bud, instead of being done in the dormant season of the year, be effected in midsummer, while the plant is in full activity, similar results, but more marked and immediate, will ensue ; the sap being no longer powerfully attracted by the law to the strongest, is equally divided among the other foci of vitality, which are thus more fully developed. Upon this fact depends the whole mystery and the whole utility of Summerpruning, which is applied especially to fruit-trees by what is called the shortening-in process of pruning, for the purpose of accelerating the production of those lateral branches and buds which are called the fruitspurs, which would not otherwise so soon receive their sufficient share of nourishment.

Now this principle or fact is equally applicable to the hedge-plant, except that our object here in Summer-pruning or trimming is not to produce fruit-spurs by developing the side-buds, but their parallels, side branches or laterals. Now, then, the utility of Summer trimming will be apparent, and under some circumstances it might be practiced repeatedly during the season of growth, as in the case of renewing an 
old hedge which has been cut off at the ground in the Winter. But it will not do to push this process too far, nor to commence it too soon, as advised by some in the first season after planting; we must remember that a certain extension of the roots is necessary to enable the plant to reach a sufficient supply of moisture from the great reservoir-hence the propriety of leaving the hedge intact of shears the first season, during which its growth should be encouraged by every means in our power; nor is this cutting off of the abundant growth of the previous year any such waste and sacrifice as some writers consider it.

Another fact of great importance, and one that bears upon the great question of Summer and Winter pruning, is, that in the dormant season the plant is better prepared to bear absolute decapitation than when its vitality is excited through every part of the stem and branches in the reproductive efforts of the buds. In Winter, this excitation does not exist, but an unusual amount of vital force is concentrated in the great centre, which has been called the living heart of the plant, the crown of the root, which in many plants is the sole bud, branch, and stem that they possess. If under these circumstances pruning is done, whether partial or general, to the limbs or to the trunk, even at or near the ground, we shall see a very different result. No longer is there a community of buds in the latter case, or but a limited number in the former, toward which on the return of Spring the sap may flow; the whole vitality of the plant, directed into a single channel, forces up a sturdy shoot, emulous of restoring the majesty of its house. 
In a partial decapitation a number of such shoots appear, and soon restore the dismantled tree to its fair proportions.

This result is just 'what we do not want in growing a hedge, at least not after the first year, during which it is desirable to produce strong shoots for the second Summer's pruning to operate upon. It will be recollected that the Summer pruning for the second and third seasons was confined almost exclusively to shortening-in of the upright canes, for the very object and intent of turning the current of vitality into the lateral branches, which were to be left and strengthened as the necessary foundation of the future hedge, and which, if not provided for at this period and in this very way, would never afterward be able to attract the amount of sap necessary to their full support, as will presently be made apparent.

Nature, ever provident of means to effect her ends, furnishes a new leader among the buds when the limb is taken from its upright position and trained horizontally. So well aware of this are our vignerons, that they constantly place the vines in such positions as to have the vitality equally distributed as may be among the buds from which they expect their crop of fruit. In the vineyard, however, this is only approximately effected, for when the bows or loops are tied up to the stakes too early, the bud which occupies the highest position among its fellows often obtains the mastery, to the great annoyance of the vigneron, who is obliged to resort to the practice of Summer pruning vigorously, to direct the current of sap into the lower branches, which he desires to grow 
as strong canes for the future crop. In the grapehouses the vines are under control, and may be kept in a horizontal position until the buds have all burst evenly, and then tied up to the rafter.

Applying this correct principle to the hedge, in the various plans suggested, such as wattling, or looping, or pegging-down, or inter-looping horizontally upon the ground, many writers have fancied that they had correct phitosophy in their support, and so they have; for any deviation from the perpendicular will tend to distribute the vitality among the buds along the whole length of the shoots so inclined. The misfortune is, that they do not sufficiently carry out the principle - they do not produce an equality in the power of the different buds, as the watchful vine-dresser is able to do, by having the more perfect control of his canes. The hedger only makes an approximation to this equalization; for, when he inclines the canes, as in wattling or in looping, the top buds, though no longer perpendicularly above the roots, are still the highest buds; or when he pegs them down to the ground, he does not succeed in making them parallel to the surface; but, as set forth in a previous chapter, there will always be an arching upwards of the canes that are thus bent, and from this point will start up shoots that are stronger than their fellows, and which will sooner or later overpower them and attain the mastery: whereas the great desideratum in hedging is, to have an even growth.

A very ingenious gardener in this neighborhood, some years ago, thought he had discovered a new plan, which he described as follows: "Having 
planted the Maclura four feet apart, they should not be meddled with until the Fall of the second year; by that time they will have made a strong growth of six or seven feet. Then these shoots must be laid down and pegged close to the ground, one after the other, and so on, laid alternately, forming the base two feet wide, which I consider sufficient for the beginning, as, after the first and second clipping, it will have gained three inches more, when they must be kept at that, being wide enough for any hedge of Osage Orange.

"It is well known by every man who has had experience in hedging, or any knowledge of the Osage Orange, that when laid down and pegged close to the ground, it will throw up shoots from nearly all the eyes on each shoot so pegged, and will be so strong as to make a growth of six feet the-same season, if done in the Spring, and a closer and better hedge than if the plants had been set only three inches apart, and allowed to grow upright. The advantages of pegging down are, that you will have three rows of shoots, forming the bottom of the hedge, instead of one, if grown upright; in the second place, you can make five hundred yards with the same number of plants that it takes to plant one hundred yards in the way now practiced in this vicinity and other places; besides, you will, on the lowest calculation, have saved five hundred per cent of money and labor in the operation; and, what is better than all, you obtain a good, close and lasting hedge-so close, even, as not to permit a rat to pass through. The first clipping sught to be done in the first week of the month of 
July following the pegging, at eighteen inches high - the next in September, one foot above the first; thus forming a hedge two and a half feet high, and two feet four inches broad, in one season."

This is carrying out my own anti-crowding notions, in extremis - and from one who had been accustomed to see the quick-sets of Great Britain laid-in but a few inches apart; this is truly extending the area. In theory, the idea of pegging down horizontally is a good one; but the buds will not break so evenly as he anticipates, nor send up so many shoots, nor wil the stiff two-year-old canes of Maclura lie horizontally they will spring up. As an evidence of the superiority of this plan, the writer kindly sent me a portion of a plant that had been laid down one year previously: it was seven and a half feet long, and had more than fifty shoots; the plant from which it was taken had a similar branch in the opposite direction, so that a single plant was furnishing hedge-shoots for fifteen feet in extent, as he expressed it. But what was the true state of the case, as then noted and then published in The Western Horticultural Review? This strong cane of Maclura, which was "laid horizontally and pegged to the ground," was arched upwards, sufficiently to allow a small animal to pass beneath it. In the next place, although it had fifty branches, those nearest the top of the arch or bend were the strongest, and would so remain, while those beyond were irregular, and somewhat feeble, and the disparity would become more and more marked, from year to year. Maclura is a brave plant; but we should not expect from it impossibilities, nor that it will be 
exempt from the laws of Nature-which may not be easily nor safely infringed upon.

The two great objects of pruning are, to remove decaying or redundant wood, and to lead the growth of the young plant in the direction we desire, so that the future tree may acquire the requisite form; this is what orchardists call, forming the head. With the first of these, we need not now occupy ourselves; but the principles that govern us in the latter are just those that most deeply concern us in the formation of the hedge, and therefore need to be considered in this place. When the orchardist approaches a young tree that is badly furnished with branches upon one side, he cuts back, closely, a limb on that side, in the Winter-timeknowing that such a cut, at that season, will generally be followed by a vigorous growth of new shoots, that start up to replace the loss which the community of buds has sustained at that breach. The judicious pruner, however, does not sleep upon his arms after his first exploit : he is not satisfied until he has brought all his knowledge of vegetable physiology to bear upon the case. He returns to the field at the season of growth, and then shortens-in some of the limbs above, and upon other sides of the tree, and perhaps also pinches off the tips of the new shoots from the amputated branch; by which means, in a single season, he may be able to restore the desired symmetry of the tree.

If, on the contrary, the orerhanging branches had been allowed to remain in possession of the air and sunshine, they would have smothered and starved the young shoots below them, and the object of the 
Winter-pruning would have been fruitless. Summerpruning is also of the greatest value when applied to the higher portions of a tree for the purpose of encouraging the development and increased growth of the lower branches, that were otherwise in danger of being overwhelmed by their more aspiring neighbors. Here we have the same facts which we observe in Nature's forest pruning, where, by the crowding of the upper branches to reach the air and sunshine, the lower limbs are smothered, die, and fall off. These facts are all of them just to the point, and are full of instruction for us in the matter of hedges: those who attempt that absurdity in hedging, a perpendicular wall, with a flat top, may succeed in torturing the natural shape of their plants, from the graceful pyramid, or the full swelling rounded tree-top, until they have forced the poor things to assume the most unnatural rectangular and geometric proportionsstiff and staring-how unlike the waving lines of natural beauty! But Nature will prevail over misguided Art-the upper branches will extend more rapidly than the poor starvelings below them, and soon the perpendicularity is lost, and lost, too, in the wrong direction, which causes the more rapid destruction of the lower branches; and the result, as every body knows, is the common hedge, thick and bushy enough, high up in the air, but bare, naked, and open below, near the ground, where we need it as a fence, against marauders of the most troublesome kinds.

These are but a few of the applications and principles that are involved in the philosophy of pruning. 
The beautiful study of phytology is exceedingly attractive, and most practically useful; but, beyond the points to which it is especially applicable to our subject, I shall not now pursue it. 


\section{CHAPTER $\mathbf{X}$.}

Jurisprudence of Fences-The Laws of Maine-Massachusetts -NeW HAMPSHIRE - VERMONT - CONNECTICUT-NeW YORK-NeW Jersey - Pennsyltania - Delathare - Virginia - Maryland North Carolina-South Carolina-Georgia-Alabama-Florida - Mississippi - Lodisiana - Missodri - Tennessee - KentuckyOHIo-Indiana - Ilinois - Iowa-Wisconsin-Michigan-TeXas -California-Rentaris-Advice-Proposition-English Usage.

IN approaching the consideration of this subject, the adage, ne sutor uitra crepidam, stares me in the face. When engaged in the discussion of practice or theory, as illustrated in this or almost any other agricultural topic, the writer might feel comparatively at home, and able to present himself before the reading public; but he is forced to confess his feeling of diffidence when a question arises touching the mysteries of the Law. Therefore, in the preparation of this chapter, the kind assistance of a gentleman of the green bag has been secured.

To the Cincinnati Law Library, with its extensive shelves of valuable authorities, such as could not have been found in private collections, I freely acknowledge my extreme indebtedness. The courtesy of its Directors has enabled me to gather the material for this exposition of the fence-laws of our country.

After this laborious search, I must confess myself somewhat disappointed that I have not found all of the points of issue fully elucidated, and provided for, 
as I had expected they would have been by the laws of some of the States. There are many usages concerning fences and boundaries that I had supposed were of sufficient importance to have led to legislation; and many sources of disagreement exist, that must have caused the establishment of some definite principles in regard to the position of a fence, near or upon a boundary; but these I have not found. Still this subject is replete with interest, and this epitome will serve to put the reader in possession of a knowledge of whatever legislation has been had in the different parts of the country. It is curious to observe how differently the great question, that of the Common Law, with regard to inclosures, is viewed in the different States, according to the character of their agriculture respectively: just as grazing or graingrowing prevails, we find the fences are legally considered inclosures for the cattle, or barriers against them.

It is proposed in this chapter not to give a legal opinion, nor to present all the multifarious legal enactments in relation to fences; but to point out, in the briefest manner, some of those questions which are of the deepest importance to the agriculturist, since upon them, and for want of a proper understanding of them, many causes of unpleasant feeling arise between neighbors-often destroying the peace and harmony that should exist between those pursuing similar pursuits, and in juxta-position with one another, and who should, therefore, live upon the most agreeable terms. Suggestions will also be made, bearing particularly 
upon the construction of partition live-fences, where they are to be of mutual benefit to both parties.

Generally speaking, we shall find that, in the different States, laws have been enacted relating to fences, of whatever structure, the expense of their construction and maintenance, and providing for damages for trespasses arising from their deficiency.

The statute in MAINE respecting fences is in affirm-. ance of the Common Law. Where there is no prescription, agreement, or assignment, whereby the owner of land is bound to fence, the occupant is not to fence against the adjoining close; but, then, each owner is obliged to keep his own cattle on his own land. It is a question, whether leaving wild lands unfenced be not a license for all cattle to run there. To enable an adjoining owner to repair a partition-fence, and charge a portion of the expense upon his neighbor, the Fenceviewers should have adjudged it insufficient, and have served a written notice of the fact to the delinquent, requesting him to repair it within six days.

Where a division-fence is defective, and there has been no division of it, or assignment of distinct portions to each, by the Fence-viewers, by agreement or prescription, trespass will not lie by either owner, against the owner of cattle lawfully on the other side of such fence, when they break through-lawfully meaning, by consent of the owner of the land; nor are parties bound to fence against cattle on the highways.

If, upon the partition-line, there has been a valid division, according to law, for the maintenance of a partition-fence, the owner of each lot is bound to keep his cattle from crossing the line; and it is trespass, if 
the cattle of one cross into the land of the other, even though the latter have wrongfully removed the fence built by the former, they having previously built respective portions; provided there has been time sufficient for the former to replace the fence.

In Massachusetrs, the laws of fences are of a very similar nature. Setting forth what shall be considered a lawful fence, how partition-fences shall be maintained equally by adjoining occupants or owners; that unimproved lands, afterwards inclosed, bounding upon a partition-fence previously made by adjoining party, one-half shall be paid for by the party benefited; that when one party shall lay open his inclosure, which he may do after giving six months' notice, he shall not take away his share of partitionfence, provided the owner or occupant of the next inclosure shall pay what is assessed by the Fenceviewers. That where lands have been held in severalty or common, either of the parties may demand a separate inclosure, and an assignment by the Fenceviewers, after erecting his own portion, if the other party refuse or neglect to make his within the time appointed by the Viewers; the party making the demand may make up the other part, and recover double the expense thereof-this is not the case where the division has been made by private agreement.

In this State they have what are called "General Fields," or pieces of land held in common, when the proprietors agree to inclose them in that manner: The fencing is then apportioned among the proprietors, according to the number of acres occupied by each, 
so long as he shall cultivate his portion. A party neglecting to repair his portion shall pay double value of repairs done by the others.

There is provision against the running at large of cattle. If animals turned into the highway for the purpose of grazing break into a field, the owner of the cattle cannot plead the insufficiency of the fence in excuse of the trespass.

The laws of New Hampshine are very similar to those of neighboring States: and where the owner of land sees his neighbor erecting a permanent fence between their lands, and makes no objection, it is considered evidence of an agreement on his part that the fence is erected upon the true line. Here, as generally elsewhere, it is the occupant of the ground, rather than the owner, who is bound to keep the fences in repair. The fence or ditch may be half on each side of the line, where the ditch is to be used for a fence also. Railroad corporations are required by statute to maintain fences on the sides of the road.

In Vermont, the Common Law prevails that the owner of a close is not obliged to fence against the cattle of the occupant of an adjoining close. The statute imposing the duty on adjoining proprietors to erect and maintain fences recognizes this principle; for these fences are made, not to keep the cattle of others off the premises, but to keep at home the cattle of the occupant. The same principle applies to land adjoining highways.

Connecticut.-Double the value of repairs or fences is allowed to the party building them when the other has refused or neglected them, it having been made 
his duty to erect or repair them. In this State, the owner of land is obliged to fence it against cattle, and if his land is not fenced, he can neither recover damages, nor impound for trespass. In Massachusetts and in England, the owner of cattle must restrain them, or he will be liable for trespasses they may commit.

In New York, there are legal provisions for the division-fences between owners of adjoining lands, unless either choose to let his land lie open; but if he afterward inclose it, he shall refund the amount, or build anew his proportion of the fence, as shall be decided by the officers. Damages from neglect to make or repair such fences, to be appraised by Fenceviewers, and may be recovered by the injured party, who may make or repair such fence at the expense of the party so neglecting, and recover, if the neglect or refusal shall have been continued one month after written notice has been served. Division-fences may be removed by either party wishing to throw his lands open, between November and April, if ten days' notice have been given to the adjoining occupant, that he intends to apply to the Fence-viewers for permission to remove. If such a fence is removed without such notice and permission, the party removing it shall pay to the party injured all damages which may be sustained thereby. When a division-fence is destroyed by any accident, each party shall make and repair his own portion within ten days, after he shall have been so required in writing, signed by any person interested. If any refuse or neglect to do so, the injured party may make or repair, and recover the expense. 
If the town have prescribed what shall be a sufficient fence, those who do not comply with this rule shall not be entitled to recover for damages done by beasts going at large; but a fence shall always be deemed a sufficient one until the contrary be established.

In NEw Jersey, the law begins by defining what shall be considered a lawful fence : those of posts and rails, timber, boards, brick or stone, shall be four feet two inches high; all others shall be four feet six inches, close, strong, and sufficient to prevent horses and cattle from going through or under them. All partition-fences shall be close, strong, and sufficient to prevent sheep from going through or under them. Ditches and drains, in salt-marshes, shall be five feet wide and three feet deep; in other meadows, if they be nine feet wide at the surface, four and a half at the bottom, and three feet deep, on a mud or miry bottom, they shall be esteemed lawful fences : and all brooks, rivers, creeks, ponds, and hedges, may be adjudged lawful by those called to view them.

Where lands join, each party is to maintain his proportion of the division-fence, unless one party choose to let his lands lie open and vacant. Neglect of fence is provided for as in New York. The place of the fence is to be fixed by appropriate officers, in cases of disagreement. The fence shall be equally divided, regard being had to the convenience; each party to take an equal share to make and keep in repair. No such partition-fence is to be removed by either party without giving twelve months' notice in writing to the other party; if removed otherwise, the 
party removing the fence shall be liable for all damages that may accrue. Parties so situated may enter into any written agreement between themselves. Other regulations are very similar to those of $\mathrm{New}$ York. But the owner of land adjoining a highway is not bound to erect a fence along such highway.

Pennsrluania. - In this State, the Township Auditors are required to act as Fence-viewers. Fences that are used as partitions between adjoining owners shall be built and maintained at joint expense. The Fenceviewers shall decide whether the fence be sufficient, and what part of the expense of repairing, if necessary, shall be borne by each party. The time for viewing fences is limited to the period between the first day of April and the first of November. All fields or inclosures shall be inclosed with fences at least five feet high, of sufficient rails or logs, and close at the bottom; those not having such sufficient fence shall be liable for all damage and injury done in driving out animals that trespass, except swine-for which an Act has been passed, restraining them from running at large (unless they be yoked or ringed), within fourteen miles of the Delaware River; all such hogs may be killed by the owner of such lands as they may be found trespassing upon; or he may take thern up, and acquaint a Justice of the Peace of the fact, who shall appoint appraisers to value the animal, and make return-one half of the value to be paid to the owner of the swine, if he apply within one year; otherwise to be paid to the Overseers of the Poor. The party injured by trespass, even if his fences were not lawful, may still proceed at Common Law. An occupant is 
not bound to join a division-fence; he may set his fence within the boundary, and his neighbor trespasses in joining thereto. If the fence be set on the line, the neighbor may join; for when the charge assessed by the Fence-viewers is answered, it becomes common property, nor can the mutual privileges be taken away by the statute of limitations, nor nonuser, for twenty years or more. A party who, on the destruction of a partition-fence, erects a new one on his own land, abandoning the space thus left to the public, is not bound to maintain the former fence. Fences not lawful, but what are called neighborly, and sufficient to prevent cattle, not breachy, it seems trespass will lie for an injury by the cattle of either.

In Dela ware, very early, the attention of the Legislature was directed to the subject of inclosures. Fenceviewers were established, and their duties defined, while yet the country was in a colonial condition. The fences were directed to be four and a half feet high, if of posts and rails; and worm-fences, not ridered, were to be five feet high. Penalties were provided against persons owning unruly cattle, for their neglect to restrain them. Division-fences were to be made and maintained equally by both parties. In 1770 it was found necessary to pass a supplement to this law, so as to cover other means of inclosure, such as ditches, hedges, and walls; from which we may infer that, in this region at least, the subject of hedging very early attracted the attention of agriculturists. This law declared that any fence or hedge that measured five feet perpendicular height from the bottom of the ditch, and within two feet of its bank, should be deemed lawful. 
A curious provision was enacted in case a stone-wall became a partition-fence: the party adjoining, when he inclosed his land so as to make the wall a partitionfence, was required to pay to the party who erected the wall one half of the estimated expense of a postand-rail-fence of the same length; and annually, the estimated sum necessary to maintain such a post-andrail-fence, unless he have preferred to pay one half of the cost of the wall. Division-fences and ditches, in marshes, shall be made and sustained by both parties. The lawful height for fences in VIRGINIA is five feet, which shall include the bank and to the bottom of the ditch when so situated. Certain rivers are considered a sufficient fence. The low grounds on the James river, in the counties of Buckingham, Albemarle, and Goochland, need not have division-fences on the boundary-lines: such lines shall be considered a lawful fence, except where roads cross the river, or run parallel with its bank.

In Maryland, by an old statute, all fences must be five feet high; and from the first of May until the tenth of November, all horses shall be kept within good and sufficient inclosures, under penalty, after due notice has been given, of having them shot, if upon the land of the person shooting them. Or, estrays being found within an inclosure, may be taken up and worked by the owner of the land, if he show the beast to the next magistrate- - the beast to be relinquished to the owner when he may prove his property. A person, having no land of his own, nor renting a plantation, shall not be allowed to keep a brood-mare at large. 
In North Carolina, all persons are subject to indictment for not keeping up good fences. Custom, declared by the courts to be a good custom, entitles him who erects a division-fence to collect half the expense from the adjoining occupant, if he improve the adjacent land. The removal of fences is forbidden, if it appear that the ground beyond the fence was in preparation for a crop, or used in the course of husbandry, though no crop was actually planted or growing upon it at the time of such removal.

In South Carolina, the early settlers, in the days of Provincial Government, appear to have ignored the Common-Law principle; and, in 1694, avowed that it was necessary and proper to fence cattle out, rather than to keep them inclosed-so, to protect the cattle from damage, the law requires that all planters who plant corn and other provisions, or anything they would have secured from damage, shall make, have, and keep, a good, strong, sufficient fence, six feet high. No canes or stakes shall be set to the injury of cattle that might trespass, under penalty; but damages were allowed when cattle break through a sufficient fence, and double damages for a second trespass. This Act was to be in force for two years only.

In 1827, an Act was passed, declaring lawful all fences closely and strongly built of rails, boards, posts, and rails, or of an embankment, capped with rails or timber, or live-hedges, five feet in height from the level surface of the earth. Every planter is bound to keep such fence around his cultivated grounds, except where a water-course is declared to be a lawful fence. If cattle break through such fence, the proprietor may 
seize them, notify the owner within twenty-four hours, and demand fifty cents for every horse or mule, and twenty-five cents for every head of cattle, hogs, sheep, or goats. On a second trespass, the owner of the stock shall be liable for all damages, in addition to the per capita fine. If the fence be not lawful, the landowner shall be liable for all injuries inflicted upon the animals.

In Georgia, all fences must be six feet high, when staked and ridered, and the rails not more than four inches apart for three feet high; if of paling, the spaces between the pales shall not be more than two inches, and the fence five feet high; but if on a ditch four feet wide, the measure shall be six feet from the bottom of the ditch. If the fence be not lawful, the owners of cattle shall not be liable for the damage

- they commit, but shall be liable for injury done to the cattle.

In Alabama, all inclosures must be at least five feet high, if of rails, well-staked, and ridered, or otherwise sufficiently locked; for three feet from the ground, the rails shall not be more than four inches apart; if of palings, they shall not be more than three inches apart; if with a ditch, four feet wide at the top; the fence must be five feet high from the bottom thereof, and three feet from the top of the bank, and so close as to prevent the passage of stock. If the fence be not lawful, no trespass or damage is allowed, nor injury to animals permitted; but five times the amount of injury may be collected by the owner of the cattle injured.

A person using stakes, pits, or poison, where the 
fence is not lawful, thereby injuring cattle, shall be punished by a fine of tifty dollars. The owner of stock must pay for damages done by them, if the fence be lawful; and for after-trespasses, double damage, to be assessed by three disinterested householders. Partition-fences, between improved lands, must be erected and maintained at the joint expense of the occupants. If the parties cannot agree, three disinterested freeholders may be appointed by the Justice, who shall examine and report. Partition-fences here mean: those built on the lines between different persons.

The Florida lawful fence must be five feet high, and well staked and ridered, or locked and braced in the corners; for three feet from the ground, the rails must not be more than four inches asunder; if of pales, the same height is required, and the pales only twoinches apart; or with a ditch, five feet from its bottom, and three feet from the top of the bank. If the fence be not lawful, the entry of cattle will not be considered trespass, and then injury to the cattle shall be finable, ten dollars for every offence.

The Mississippi law makes a lawful fence, such a one as is strong and sound, five feet high, well staked and ridered, or sufficiently locked, and close enough to prevent animals creeping through. The owners of cattle trespassing shall make reparation for the amount of damage done; and for subsequent trespasses, double damage. The fence shall be examined by three honest and respectable freeholders, not related to the party injured, nor interested in the trespass. If the fence be insufficient, the person injuring any cattle within his inclosures shall pay double 
damages. In either case, the party liable for damages may pay what is deemed reasonable and just by three respectable neighbors chosen to assess the same, and this shall bar a suit. In the case of partition-fences, each party shall bear an equal share of the expense. Walls, palisades, dykes, hedges, and ditches, are also allowed. All walls and palisades to be five feet high. All dykes to be three feet from the bottom of the ditch, and planted with thorn or quickset.

Boundary-fences, in Louisiana, are made at the experise of the adjacent estates, if they be inclosed; otherwise, the open estate is not bound to fence. All fences which separate rural estates are considered as boundary inclosures, unless one be open, or there be some proof to the contrary. Every ditch between two estates shall be supposed to be held in common, unless there be proof to the contrary.

In Missouri, it is declared that all fields and inclosures shall be inclosed with a fence, sufficiently close, composed of posts and rails, posts and palings, posts and plank (Yankee bourds), or palisades, rails alonelaid up as a worm-fence-or of turf, with ditches on each side. All such fences shall be at least four feet and a half high; those of turf shall be at least four feet high, and trenches on either side, at least three feet wide at top, and three feet deep. A worm-fence shall be five feet high to the top of the rider; or, if not ridered, it shall be five feet to the top rail, and the corners well locked with strong rails, poles, or stakes. The sufficiency of the worm shall be decided by persons summoned to view the fence. For any trespass through or over such a fence, the owner of 
the stock shall pay the true value of the damages sustained, for the first offence ; for every trespass thereafter, double damages; and for a third offence, from any of the animals so breaking in, the party injured may kill the beasts without being answerable. Complaint being made to a Justice, he shall appoint three disinterested householders to view the fence. If the fence be insufficient, cattle injured shall be paid for to double the amount of damage.

In Tennesseie, every planter must make a sufficient fence about his cleared land in cultivation, at least five feet high in all its parts; he shall also make the fence close enough to prevent hogs passing through, for at least three feet from the ground. In cases of trespass, complaint is to be made to a Justice, who shall summon two discreet and impartial freeholders, who with the Justice shall view the sufficiency of the fence-the owner of the cattle to make restitution. If the fence be insufficient, then no damages shall be assessed. If the fence be insufficient, and the landholder shall maim or kill the cattle trespassing upon his grounds, he shall make satisfaction to the owner of the cattle for the injury done.

A lawful fence in Kentuckr, where the statutes of Virginia were adopted, is declared to be every strong and sound fence of rails, brick, stone, or plank, five feet high, or a ditch three feet deep and three feet broad, with a hedge two feet high, or a rail, plank, stone or brick wall, two and a half feet high on the margin thereof-the hedge or fence being so close that cattle cannot creep through them. If cattle enter grounds inclosed by such lawful fence, the owner of 
the cattle shall be liable to the owner or occupant of the ground for the damage sustained; for subsequent breach, double damage. If the fence be not lawful and the cattle be hurt, their owner may recover damages in double amount. Non-residents shall not bring cattle to run at large. Neither party shall remove an established division-fence, without consent of the other, between the first of March and the first of December. Two months' notice of change is required.

Examining the laws of Oнто, we find that livefences have been recognized by the Legislature, and that that body have passed an act for their protection and encouragement. In this it appears, that when a farmer desires to plant a hedge next to a road, unless it be a street or alley, he may set his plants on the precise line of the road; and for the preservation of the hedge, the protective fence may be placed six feet upon the road. This protection may be continued for seven years; and if the hedge have not been completed by this time, the Township Trustees may grant permission, in writing, for the continuance of this protection for any term they may deem necessary.

We next find an Act to regulate inclosures, and to provide against trespassing animals, passed January 17, 1840, which provides that the expense of making a fence that is built upon the partition-line shall be borne, in equal proportions, by both parties, so far as the fence is a partition betwen improved lands of both. The repairs shall be kept up by the respective parties, whether owners or lessees, in equal shares, so long as both parties use the lands so divided. In case of a controversy, if the parties cannot agree, either 
may apply to the township trustees to act as arbiters. When damage by the trespassing animals arises from the neglect of either party to preserve the fence, the party in fault shall pay damages as assessed by three judicious and disinterested men, who may be appointed by any Justice of the Peace of the township. If either party shall think proper to vacate his part of such inclosure, or make a lane or passage between such inclosures, he shall be at liberty to remove his part of the fence after giving six months' notice, in writing, to the party owning or occupying the adjoining inclosure, or to his agent.

If any animal shall break into any inclosure, and the owner or occupant shall consider himself aggrieved thereby, he may apply to the Township Trustees after giving one day's notice, in writing, to the owner or keeper of the trespassing animals of the fact, and of the time of the Trustees' visit. The Trustees shall repair to the place and examine the fence where the trespass occurred. If they find the fence of sufficient height and strength, they shall assess damages. If the Viewers shall find the fence insufficient, the person calling upon them shall pay all costs. * * Each railroad company shall be required to fence its roads with a good substantial wooden fence, under such regulations as the County Commissioners may prescribe. If any person shall open an inclosure, and leave the fence, bars, or gate open, he shall be fined, on conviction, not more than one hundred dollars, or be imprisoned not exceeding thirty days: the prosecution shall be commenced within one year. The fines accruing shall be for the benefit of schools. 
The lawful fence in Indiana is declared to be: any structure, or hedge or ditch, in the nature of a fence, used for the purpose of inclosure, which is such as good husbandmen generally keep, and such as shall, on the testimony of skillful men, appear to be sufficient. The injured party may recover damage done by cattle, if the fence be lawful; but a person who chases a horse out of his field with a large fierce dog commits an unlawful act, and is liable for any injury to the horse. Animals breaking into inclosures may be taken up as estrays, the owner to be notified within twenty-four hours. If the fence be not lawful, the animal shall be released.

Partition-fences dividing lands occupied by both parties shall be kept up throughout the year, unless otherwise agreed. No person inclosing land that has heretofore lain open shall join his fence to that of another, except by consent. If no consent be given, each shall give one-half the width of a lane, or a reasonable distance for the erection of another fence. In case of consent, the owner of the new inclosure shall pay for half the value of the fence that has been made a partition. If one party cease to use his land, he shall not take away the fence, if the other party will pay its reasonable value-not to be removed until the crop shall have been gathered.

Illinors having been, in its natural condition, a grazing country, where flocks have been herded in the open prairies, we find that the Common Law requiring the owner of cattle and hogs to keep them on his own land has neven been enforced. To this there is an exception in certain parts of the State, where grain- 
growing is the leading feature of the agriculture, as mentioned in the first chapter. To maintain an action for trespass, the owner of the close must have it surrounded by a good and sufficient fence. There is no general law in this State prohibiting cattle from running at large in the highway. This, however, is one of the few States where the subject of hedging has been deemed of sufficient importance to warrant the passage of a law protective of live-fences ; it is precisely like that of Ohio, enacted for the protection of live-fences, except that the protective fence allowed upon the road may be continued by order of the County Court, instead of by the Township Trustees.

In Iowa, a fence built upon the public land, even by mistake, passes with the freehold to the purchaser from the Government; and if such fence is detached from the realty by a wrong-doer, the purchaser's right to it is not divested. (Green's Reps., Vol. II., p. 542.)

[I have not been able to find the statutes of this State, and therefore the report is defective.]

The law of W Isconsin declares all fences legal that are four and a half feet high, in good repair, made of rails, timber, boards, stone, or any combination thereof ; also, brooks, rivers, ponds, creeks, ditches, and hedges, or other things which shall be considered equivalent thereto, in the judgment of the Fence-viewers. The respective occupants of lands inclosed with fences shall keep up partition-fences, in equal shares, so long as both parties improve the same. Neglect to repair or rebuild any such partition-fence, when signified by the Fence-viewers as the 
duty of defendant, may be supplied by the aggriered party, and when adjudged sufficient by the Fenceviewers, the complainant may recover double the amount of the repairs. Fence-viewers to assign the portions to each occupant when they cannot agree; this must be done in writing, and the time during which the repairs shall be made may be stated by them. This assignment, recorded in the Town-clerk's office, shall be binding upon them and their successors. If one party neglect, and the other build the fence, the latter may collect double value. All divisions of fences to be recorded in the Town-clerk's office. If one party erects more than his share, the other party shall pay for so much as is assigned to him. Partition-fences to be kept in good repair throughout the year, unless by mutual agreement otherwise. When water occupies the true boundary, and is not a sufficient fence, the Viewers shall decide which side the fence shall be made. Lands that have been held in severalty may have the fences assigned by Viewers on the request of one party. When either desires to open his close, the other shall have the privilege of purchasing the fence at the Viewers' valuation, otherwise he may remove the fence after six months' notice.

Where fences encroach upon highways, the owner shall remove them; but shall not be required to do so, except between the first day of November and the first of April. Hedges may be cultivated on the border of a highway, except in a street or alley-just as in the State of Ohio.

If any person shall cut through, dig up, or injure 
any hedge, or throw down any fence inclosing grain or other vegetables, or shall leave open any gate or bars, such person may be fined not more than one hundred dollars, or imprisoned not more than thirty days, or both, at discretion of the court.

In Mrchigan, all fences four and a half feet high, and in good repair, consisting of rails, timber, boards, stone walls - or any combination of these - brooks, rivers, ponds, creeks, ditches, and hedges, or other things which shall be equivalent, in the judgment of the Fence-viewers, shall be deemed legal and sufficient. The respective occupants shall maintain partitionfences in equal shares, so long as both parties continue to improve. In case of neglect of either, the other applies to the Fence-viewers, who shall examine and direct the repair, if necessary ; but if it be neglected, the complainant may rebuild and demand double the amount adjudged by the Fence-viewers. Fence-viewers may assign shares to each party, the assignment to be recorded by the Township Clerk. Where one has erected a fence that becomes a partition-fence by the other's improvement, it shall be assigned, and the second shall pay the value assessed. All partitionfences to be kept up throughout the year, unless otherwise agreed between the parties. No person shall recover for damages done upon lands by beasts, unless in cases where, by the by-laws of the township, such beasts are prohibited from running at large, except where such lands are inclosed by a fence. This does not change the Common Law, nor oblige persons to fence their lands; it only precludes damages.

In Texas, every gardener, farmer, or planter, shall 
make a sufficient fence about his cleared land in cultivation, at least five feet high, and sufficiently close to prevent hogs from passing through. There shall be no space more than six inches wide, for at least three feet high from the ground. In case of trespass, the person may complain to the Justice, who shall appoint two impartial and disinterested freeholders, who, with him, shall view the fence, and estimate the damage. If the fence be sufficient, the owner of the animal shall make full satisfaction to the injured party. Any person having an insufficient fence, who may wound trespassing animals, shall make full satisfaction to the owner thereof. Willful burning of fences, in this, as in several other States, is punishable by fine and imprisonment.

A similar law exists in CALIFORNIA: the lawful height being four and a half feet, if of stone, or five and a half feet, if of rails; or, if on a ditch bank, three feet from the bottom of the ditch; the fence must be two feet high; the fence must be reasonably strong, and so close that animals cannot get their heads through it. A hedge shall be considered lawful, if five feet high and sufficiently close to turn stock. The owner of stock to be liable for their trespasses, if the fence be sufficient; on a second trespass, for double the damage sustained. All injury done to trespassing animals, where the fence is not lawful, shall be paid by the owner or occupier of the grounds.

In view of the want of elucidation of several points, relating to boundary fences, I should suggest to my readers, that when they proceed to inclose a piece of land which has heretofore lain open, the first object 
should be to ascertain the precise line of their domain, and to set their fences within that limit entirely; for, by so doing, they need not relinquish any claim to their full measure of land, as settled by the surveyor's monuments; nor can they be annoyed by suits for trespassing with their fences upon their neighbor's property. On the other hand, if at any time the owner of the adjacent land desire to improve and cultivate it, and, of course, to fence it, they have the advantage, nor can he compel them to unite with him in fencing his land; but they may allow him to join fences, making an equitable arrangement by private contract, to be still enforced by an assignment of the several portions to each party, by the appropriate officers, as this, in some States is necessary, in case further legal questions may arise. An amicable arrangement, and perfect understanding as to the assignment of the different portions, should always be made at once between neighbors, to be confirmed officially, where necessary.

Propositions for those interested in partition-hedges. - My views have already been expressed as to the advantages to be derived by most persons who wish hedges, from the employment of professional hedgers, where the parties have not a sufficient knowledge of the subject; nor appliances for its execution. There are plenty of men now in the country who have devoted themselves to this business, and who are entirely competent to accomplish the object. One proposition, therefore, would be for the neighbors wishing a partition-hedge, to hire such a professional hedger, at their joint expense, who shall plant the hedge exactly 
upon the dividing line between them. When finished, each party should trim his own side of the hedge, and they may enter into an agreement mutually, to preserve the fence according to its need, or they may divide the line equally between them. During the growing of the hedge, each party should keep up the protection-fence upon his own side, if that should be necessary, as in case the land on either side be pastured, though in the open prairies, hundreds of miles of hedge are grown without any protection; or, where two fences are not needed, one of the parties should provide the fence, which may be placed on either side of the hedge, according to the use that is to be made of the fields adjoining, and to prepare the ground by grubbing, hoeing, \&c., while the other is to plant and tend the hedge for three or four years, or until completed; and when the fence is perfect, he shall be entitled to the old rails or other materials of the protective fence.

When two neighbors cannot agree to unite in the rearing of a hedge on the line dividing them, and one of them is desirous of having a live-fence, to aroid all difficulty, let him plant the hedge five feet within the line, cultivate and trim the hedge at his own expense; after which he may remove so much of the original partition-fence dividing them, as had been before assigned to him, and then, if the neighbor desired to join, he should be expected to pay the value of one half the hedge, as in the case of any other partitionfences, as provided by the laws, and a consideration for the five feet of land also.

James Todd, an English land-surveyor and valuator, 
has given me the following statements as to the mode of arranging the hedges and ditches, when they are made on partition-boundaries. The ditch is either on one side of the hedge or the other, according to the character and shape of the land. Since its object is to drain, as well as to fence, it is always placed toward the rising ground, or, in other words, the hedge, though planted on the bank of the ditch, is on the original lower side of it; if, then, a hedge is to be placed on the line between $A$ below and $B$ above him, in point of elevation, the ditch is dug upon A's side of the line, the dirt or bank erected still further on A's land, and the divisionhedge is thus wholly on A, ditch and all. On the other side of his farm or field, however, the slope continuing in the same direction, on the line between $\mathrm{A}$ and $\mathrm{C}$, another neighbor, the ditch and hedge are both upon the land of $\mathrm{C}$, and the ditch is unobstructed in its function of draining the land of $\mathrm{A}$, that inclines toward it. In another part of A's boundary, however, where there is no call for a ditch, as where $A$ and $D$ join boundary, the hedge may be set directly upon the line between the parties, and is kept in repair by both; whereas, when wholly upon the land of either party, the ditch and hedge, though a partition-fence, are maintained by the holder of the soil.

In the absence of the law, this is given as reputed usage, at least in a part of that country. On land liable to be overflowed, or low flat lands, the centre of the ditch is made exactly upon the boundary between the parties, and the maintenance of the fence is at joint expense. 



\section{A P P E N D I X.}

THE following statements might have been introduced into the body of the work, had they been obtained at an earlier period; but their value and interest, and the position of their writers, are such as to entitle them to great consideration, and they are, therefore, here appended.

At one of the annual December meetings of the State Agricultural Society of Ohio, at which the presidents or delegates from all the county societies assemble, and take part in the deliberations of the Board of Agriculture, a very interesting discussion occurred upon the subject of hedging.

The diverse and the adverse views expressed were remarkable, and I regret that I cannot procure the report of the discussion. On the 7th of December, 1854, however, the following resolution, offered by Mr. Corwin, was passed: "Resolved, That we recommend to the farmers of Ohio, the Osage Orange as a most suitable plant for hedging; superior in all respects to every other plant which has yet been introduced into Ohio for economical and enduring fences." At the same meeting, the Committee rendered their award of a premium to James McGrew, of Dayton, for the best specimen hedge in the State; and the fol- 
lowing statements were produced by two of the competitors.

HEDGING, BY JAMES MCGREW, OF DAYTON, OHIO.

To the President and Members of the Ohio State Board of Agriculture:

Gentlemen: Having been directed to prepare an article upon the subject of Live or Hedge Fences, to be embodied in your next Annual Report, I beg leave to express a wish that some one more competent than myself had been selected to present this important subject, in its true bearings, accompanied with directions which are of such a character as to secure the general introduction and successful cultivation of hedge-fences: a subject of such vast moment-one in which millions of dollars are involved, and one which will ultimately change the appearance of our whole country, should receive not only the attention, but the candid investigation of the ablest agriculturists of our land.

If it be true, that four-fifths of the people of these United States are engaged in agricultural pursuits, then it follows, that whatever affects the agriculturists has its consequent influence upon the great mass of our people. It has been thought by many, that no one subject was of such vital interest to the people of this Union as that of railroads, and that that great interest more directly affects the interests of the farmers than any other class of men. Yet we find that railroads, with all their importance, do not, in their practical operations, have so general and direct an effect upon the interest of farmers as this great and 
indispensable appendage to our farms, namely, the fences that inclose and divide them into fields, orchards, and pastures. The importance of this subject is just beginning to develop itself. In this connection, I may mention the fact, that many parts of our State, which, but half a century ago, were regarded as a wilderness, are now almost destitute of timber suitable for making fences. Our forests are rapidly melting away before the accumulating population, who, with unsparing hand, are exhausting this resource of Nature. All the present stock of good timber, such as oak, ash, walnut, poplar, pine, and hickory, will very soon be wanted for building and other purposes, for which no good substitute has been, or perhaps can be found. We cannot, therefore, expect to renew our fences with our own material, or material similar to that composing our present fences; consequently, we must look to some other source for fencing: and we should begin to inquire into the present as well as prospective value of material for that purpose.

Few persons have paused to estimate the value of our common fences. A very moderate estimate is, three miles of fence to each quarter section of land, which is barely sufficient to inclose and put two partition-fences through it, to say nothing about lanes, lots, and a number of fields which every farm must necessarily have, but which cannot be had with less than five miles to the quarter section, and no farm of that size would be considered well fenced without that amount. Yet, taking three miles for the estimate upon each quarter section (160 acres), we would have in Montgomery county, two millions seventy-three 
thousand and six hundred rods of fence-which is worth, upon an average, one dollar per rod; and they could not now be replaced at a less expense than three millions of dollars. Thus, it will be seen, that the farmers of our State have an enormous amount of capital invested in fencing, which must be renewed every fifteen to twenty-five years. By examining minutely into this matter, it will be seen that the tax, or expense to which farmers are subject in keeping up their fences, is far heavier than any other item of expense connected with their pursuit. This subject should, therefore, receive the attention of every farmer. $* * * * *$

We have little waste land in our State-land that is of a character unsuited to cultivation, and must necessarily remain in a state of nature, periodically producing timber and wood. We cannot, therefore, expect a supply from that source, and I have shown that the present supply of valuable timber will soon be needed for other purposes. The substitution of other materials, such as stone and wire, cannot be brought into general use. There appears, then, to be but one alternative. We must grow our fences out of the fertile soil. By so doing, we do not exhaust other resources, for which there is abundant need for the purposes to which they are properly adapted. This is in accordance with the true principles of economy, and should be inculcated as a doctrine that ought to be considered important in every subject appertaining to agriculture.

If my view of this subject be correct, the question arises, which one of the many plants that have been tried for hedge purposes is to be used in this great 
work. It is useless to go into a repetition of the failures of the many hedge-plants that have been tried in this country. It is only necessary for me to state, that they have all failed in most instances, except the Maclura or Osage Orange. Our climate is so different from that of many parts of Europe, where the different varieties of thorn have been successful, that it is necessary for us to look for some plant that will withstand the extreme heat and droughts of our climate, that is of vigorous and rapid growth, suited to our goahead habits, and that is free from the attacks of insects. Such qualities we cannot expect to tind combined in any one plant, except it be a native of our own country. All foreign plants have failed-simply because their growth is unsuited to our soil and climate. In the moist, damp atmosphere of many parts of Europe, the several varieties of thorn succeed to admiration. But in this country, their slow growth, the shallow tendency of their roots, and their thorns not affording sufficient protection, have proved them unsuited to our habits of railroad speed, to the severe droughts of our climate, and to the intrusive character of our people and stock. But in the Osage Orange we find all the qualities that are necessary to insure success. Its rapid and vigorous growth proves it admirably suited to our progressive habits, its deep roots enable it to withstand the severe droughts of our climate, and its thorns are of such a protective character as to answer every required purpose. It has no equal as a hedge-plant, upon American soil.

Although this great enterprise is yet in its infancy, it cannot now be regarded as an experiment. It is 
now one of the fixed facts of the times, that Osage Orange hedges can be grown throughout the land, as certainly as that fruit orchards have become general. And the same protection and care that insures success in the latter case, will as certainly (if properly directed), secure success in the former. The Osage Orange grows wild in the uncultivated lands of Texas, and is found as far North as Red River. As a hedge-plant, it is vigorous, healthy, and long-lived; the natural tendency of its growth is to throw out branches from the ground: it bear's the greatest severity in trimming; it has bright, glossy foliage, which, in Summer, gives it a rich and beautiful appearance. It grows upon. all kinds of productive soils, and flourishes in all our varied climates, from Texas, its native place, to Boston in the northeast, and St. Paul in the northwest. I will give the opinions of a few of the many who bear similar testimony as to the success they have had with the Osage Orange.

James Gowen, of Pennsylvania, who, it is believed, has the oldest Osage Orange hedge in the United States, says, he is well satisfied that it can be maintained as a thorough hedge for generations. Prof. Turner, of Illinois, declares, that if any one will describe a hedge-plant, such as he would have, made to order, he will engage to prove that the Osage Orange is in all points as good, and in some points better, than his imagination could wish. Dr. Warder,. of The Horticultural Review, Cincinnati, asserts, that the Osage Orange has justly been styled the best of all hedge-plants. The lamented Downing said, we are glad that this capital hedge-plant, so easy of culture, 
so rapid in growth, so strong in its protective thorns, and so handsome in its foliage, is rapidly rising in public estimation. M. B. Bateham, of the Ohio Cultivator, says, he is well satisfied that the Osage Orange will prove to the United States what the English Hawthorn is to England. A. H. Ernst, of Spring Garden, Cincinnati, well known throughout the West as a Pomologist, Nurseryman, and Horticulturist, speaks of the Osage Orange in this wise: There is no plant so easy of cultivation, better, or so well adapted for a protective hedge, in our soil and climate, as the Osage Orange. It will grow and flomrish in all strong, rich soils, whether they be alluvial, upland, sandy, clay, wet, or dry. It proves capable of enduring the greatest extremes of moisture, heat, and drought, and the lowest temperature to which our region of the West has been subject. There is nothing to my mind so beautiful, or so secure a barrier and protection for ordinary farm-fencing, as hedging; and no country possesses a better plant for that purpose than we do in the Osage Orange.

Gen. Worthington, your worthy President, a year ago entertained serious doubts as to whether hedging could be successfully introduced into this country; yet he looked upon this subject as one of great importance. His deep interest and anxiety in reference to it, led him to investigate it closely, and his conclusions will show that he has bestowed careful thought upon the subject. He said, he had for years been convinced that we had more to fear in this matter from the severe droughts of our climate than from any other cause; for this reason, that the plants, in 
order to form an impenetrable hedge, must necessarily be set close together; and it is well known that vegetables, plants, and trees, closely crowded, always suffer most severely from the extreme heat and dronghts of our climate. He entertained a doubt as to whether we had any plant that would bear crowding sufficiently close in the hedge-row, and yet remain uninjured by drought. But, after having witnessed the healthy and thrifty appearance of an Osage Orange hedge, closely planted, and full grown, which had withstood the most intense heat and drought that we have ever experienced in this country, he expressed himself highly gratified with the result; and stated. unhesitatingly, that he believed the Osage Orange was the hedge-plant of this country, and that in it we possess the element of a great and valuable improvement. The testimony of the gentlemen named is of the most unquestionable character, and their united testimony for or against any issue of Horticulture or Pomology, would settle it at once.

At the Agricultural Convention, Dr. Warder, althongh himself a successful grower and a firm advocate of the Osage Orange, expressed his surprise that, notwithstanding the strong opposition that was manifested by the aged and honorable members of the Board, I should speak so confidently of the success of the Osage Orange as a hedge-plant. But when he afterward saw my hedge, he said, he understood why I had such confidence. It was founded on a practical demonstration, about which there could be no mistake. It is not to be supposed that an individual without any practical knowledge could successfully culti- 
vate and properly form a hedge. It is really no small matter. It is a work that is to last for generations. Those who attempt to grow a hedge should spare neither care nor expense in having it right. If well done, it is an invaluable improvement upon any farm -if not well done it is an entire waste, of time, room, and money. The business can be learned only as other things are learned, by careful study and practical experience. It is not a matter to be intrusted to novices, tenants, and gardeners. They may respectively understand their business well; because they have learned it by years of practical experience. But they know nothing about this business. Who would think of giving a gardener charge of his vineyard, his broomcorn, or tobacco crop, unless he had experience? Why then trust this thing, which is vastly more important, to the care of such hands. Most farmers would neglect a hedge if they knew all about its culture and management, from this fact: that it requires the most care and attention when farm crops need most work-and at a time when the farmer's physical energies are taxed to the utmost. This being the fact in nine cases out of ten, the hedge would be neglected year after year, and thus prove a failure; whereas, if the hedge was contracted for, to be grown by experienced, practical and responsible men-those who have studied and thoroughly understand the business, and are engaged in growing hedges-it will be properly managed, and its success will be certain.

Many persons have gone into hedging, and failed, because they have been misled. They were told that they could have an everlasting fence, and one that 
would be perfection itself, at from thirty to forty cents per rod. And, further, that they grew them in Illinois for $\$ 100$ per mile. But it is all a mistake; for you cannot find a hedge in Illinois, or any where else, that is grown by men who contract at such prices. If men want good hedges they must expect to pay a valuable consideration for them. I treat this point thus plainly, because I believe it to be the cause of many failures and much disappointment. There are men in various parts of our State who object to contracting for a hedge that will cost from $75 \mathrm{cts}$. to $\$ 1$ per rod, who think nothing of paying from $\$ 1.25$ to $\$ 1.50$ per rod for a good board-fence which, they know, will have to be renewed in from fifteen to twenty-five years, at most. If those who are interested will investigate this subject, and start upon the true principle of doing thoroughly what they do in this matter, or be willing to reward those who do it for them-and see to it that they secure such men as are responsible, and will do their work well-then they may expect success.

Enterprises and improvements of a general character like this always have opposition to contend with from the ignorance and prejudices of honest men. This, like every other valuable improvement, must meet with the common opposition that is prompted by ignorance, prejudice and the fear of being humbugged. But with every investigation it will strengthen and increase, until its success will be triumphant. I now come to the directions for successfully growing an Osage Orange-hedge. Great care should be taken in the selection of good seed. The quality can generally 
be determined by breaking the seed and examining the kernel. Fresh seed is preferable on account of its greater vitality; consequently, it vegetates sooner and with less trouble.

Sprouting and Planting the Seed.-Soak the seed in warm water from thirty to forty hours, changing the water several times, then put it.into shallow boxes four or five inches deep. To every bushel of seed put one half bushel of sand, and mix thoroughly. Keep them in a warm place; wet as often as twice a day, with warm water; stir as often as three times a day, or more frequently. If the seed is obtained in time to have it frozen by putting into boxes, mixed with sand, it is undoubtedly of advantage. The boxes, in all cases, should be such as would allow the water to drain off. Some recommend planting the dry seed in March. But as a general thing, the first described method I think far preferable to any other. In that case, the seed should be put to soak about the fifteenth or twentieth of April. Seed attended to as above described, and kept at a temperature of sixty five or seventy degrees, would sprout sufficiently in two days to put into the ground. It is necessary, however, to have the seed well sprouted before planting, as the ordinary moisture of the ground will not soften the hull sufficiently to enable the germ to force its way out; and when that is the case the seed will be lost.

Much care should be taken in the selection of a good piece of ground for the nursery or place of planting the seed. The ground should be new, fertile, and free from the seeds of weeds and grass. It ought to be mellow, not subject to bake, and rather inclined 
to be wet than otherwise. Good prairie, that has been broken the year previous, is undoubtedly preferable to any other soil. The ground should be deeply plowed, harrowed, and rolled, if necessary. When the ground has thus been prepared and well pulverized, the most expeditious way of making the drills for planting is to use a common wheat-drill, taking out one-half of the planters. Have large points, say five inches in width, and about the shape of the common points, upon the planters that are used in making the drills. The drills made in this way will be sixteen inches apart, and by putting weights on the dragbars, the drills can be made of sufficient size and depth. For planting in a small way, the ground being thoroughly prepared, the drills may be made with a small plow or hoe. The seed must then be strewed along in the drills by hand, putting one quart to four or five square rods, which would amount to from one to one and one-fourth bushels per acre. The covering can be done with light steel rakes. The seed buried to the depth of two or three inches, and covered in such a way as to leave a ridge exactly on the row, for a two-fold purpose: first, to show where the young plants are to come up; secondly, that in passing along with a small steel rake, such as is used in covering the seed, the crust which is apt to form after a rain, upon any soil, can be removed, thereby destroying the first crop of weeds and grass, which would otherwise remain among the plants, and be destroyed only by a great amount of labor, and in many instances this would be done at the sacrifice of a large number of plants. Removing this crust also assists the young 
plants in getting a start. When necessary, the spaces between the rows must be hoed, after which all the weeds and grass in the rows, among the plants, should be removed by hand. This process of hoeing the spaces and weeding the rows should be repeated as often as necessary in order to keep the weeds down, and the ground loose and in good condition. If the soil is good, the season favorable, and the proper cultivation given, they will be sufficiently large for trans planting the following Spring.

The process of taking up the plants is as follows: A subsoil plow is used to cut them off. The share of the plow should be of steel, quite large, and flat as possible. The depth of its running can be regulated by a wheel in front, at the end of the beam. With this plow the plants can be cut off eight or ten inches below the surface of the ground, and most of them will remain standing in their places until gathered by hand, assorted, tied in bunches of one hundred each, and then boxed up, or they may be boxed without tying in bundles. Great care should be taken to prevent their getting dry and withered. I should have mentioned that the most even and best method of cutting the tops off is to use a mowing-machine or briar-scythe, about three or four inches above the ground. This should be done in the Fall as soon as the leaves are off, so that the lower buds, which are always small, may be developed by the action of the sap through the Winter. In boxing them much care should be taken to have good boxes, and although they should not be air-tight, yet they should be such as would prevent the plants from getting dry and 
wilted. Moderate-sized boxes are best, say, sixteen to twenty inches wide, the same depth, and three to three and one-half feet long.

Setting the Hedge.-For this purpose the ground should be broken up to the depth of from twelve to eighteen inches, according to the quality of the soil, and at least ten feet wide. If there be any thin soil in the row it should be well manured. It should not only be plowed, but subsoiled, harrowed, and thoroughly prepared. The hedge is then to be set in the centre, which would leave five feet to be cultivated on each side. The law of Ohio allows the moving out fences, along the public roads, a sufficient distance to give an opportunity for growing a hedge at the proper place. When a hedge is to be set along an old fencerow, it is much better to have the fence moved the year previous, and the ground brokên up and cultivated. It would then be in a better condition to receive the hedge. After the ground has been fully prepared it is necessary to stake off the row and draw a line to work by. The holes for inserting the plants, to be made with a steel dibble, twelve inches in length and two and a half or three inches in diameter at the top, with a socket into which to insert a handle, with a pin in the handle, at the top of the dibble, to bear the foot upon in pressing it into the ground; the holes should be six or eight inches apart; the plants are to be put into the ground about an inch deeper than they were in the nursery, the earth is then well pressed about the entire length of the root. Putting the plants in well, when transplanting, is one of the most important matters in having the hedge well 
started. Too much care can not be taken in this particular. Then comes the cultivating, hoeing, plowing, \&c. The soil on both sides of the hedge needs thorough cultivation, and the hedge-row should be kept clean during the whole of the Summer season. No stock should be allowed in the inclosure where the hedge is set until after harvest. In justice to the hedge, no stock should be admitted until Fall, unless the hedge has made a vigorous growth in the early part of the season. In such cases, a few cattle after harvest will not materially injure it. But if no stock is allowed where it is until Fall, the Summer's growth will by that time become hard, and it will then protect itself. The protection from cattle should be continued for three years, at least in the early part of the season.

Cutting the Hedge down.-The next Spring, which is one year from the time the hedge was set, it must be cut off at the surface of the ground, below all the buds, just above where the root has a yellow appearance. The root will then swell up and put out a number of strong shoots just at the top of the ground. It then needs to be thoroughly cultivated until about the middle of June, when, if the season has been favorable and the growth vigorous, it should have another cutting within two or three inches of the former one; but if the growth has not been rapid and vigorous, the cutting should be deferred until the next Spring. The cultivation, however, should be continued as late in the season as there is need of it, in order to keep the hedge-row clean. By this process of cultivating thoroughly and cutting down severely, we at once form a strong, close, and firm base, and 
if this process is rigidly carried out, success is certain. It is thought by some that it is necessary to cut down more than twice during the Summer; but this is a great mistake, for every one who has experience in matters of this kind knows, that it is necessary for a tree to form a top to a certain extent, in order to obtain roots and trunk, and that by keeping it trimmed too closely, its growth will be greatly retarded. This fact I have had fully demonstrated by my own experience, and the view I have advanced is so well corroborated by the best authors who have written upon the subject, that it needs no controversy. The following Spring, cut within three or four inches of the former cutting, and again, in June, four or five inches above that, continuing the cultivation until it is four years old, and even after it has attained the size necessary to answer the purpose of a good fence, the ground alongside should be kept in good condition. Like every thing else upon the farm, the hedge, barns, orchards, and our ordinary fences, need much care and expense to keep them in proper trim; and, as a matter of course our hedges will have to be cared for, if we wish them to be as they will be, the most valuable improvement upon the farm.

The fourth Spring, it may be cut six or eight inches above the former cutting. The following June, eight inches higher ; after which, the latter part of the Summer's growth will be sufficient to answer the purpose of a good fence. After this, trimming once a year will be sufficient, which should be done in the latter part of the Summer or Fall, before the wood hardens; or if trimming twice a year is preferred, trim in June 
and September. It will be found that much less trimming will be required after the hedge is fully grown. The reason is very obvious: the manner of trimming that I have described will cause each part to spread, and throw out a great number of branches; so that, by the time the hedge is four or five feet high, the great number of branches to be supplied with sap from each root, will cause the former vigorous growth to be checked, and it will then grow more slowly. The first cutting, which will be one year from the time the hedge was set, can be done best with a pair of shears, with long handles-they can be had at most of our agricultural stores. I recommend the shears, because it is difficult to cut the plants off sufficiently low with any thing else. The second and all succeeding cuttings can be done with a short, heavy briar-scythe, hung upon a strong, stiff snath. The second, third, fourth, and in some cases the fifth cutting, may be simply square off, letting the side or lateral branches grow. After the fourth or fifth cutting, however, it should be cut of an oval shape. The best way to do this is to walk along with the hedge upon the left hand, and with the scythe making an upward stroke, cutting to the centre of the hedge. When you get to the end of the row, turn round to the left, and come back upon the other side, cutting it in a similar manner; then by going along with the hedge upon the right hand, and making a downward cut with the same scythe, the sides can be nicely trimmed-at all times letting the lower branches extend out beyond the rest, that they may become strong, and the base wide. 
The base should be at least fire feet wide at four years old. If the side or lateral shoots are trimmed as frequently, and with as much severity, as the upright ones, they will soon lose their vigor and strength, as the natural tendency of the growth is upwardhence the necessity of skill and judgment in properly forming a hedge. Great care should be taken to secure a close, strong, and firm base. I have endeavored to be particular in describing the proper method of forming a good base, as a large portion of the hedges that have been set have failed on that account. In fact, I may say that four-fifths, if not nine-tenths, of all the hedges set have failed on account of not having the base properly formed, consequently they have become a nuisance, thereby bringing hedging into disrepute. All succeeding trimmings can be done in the manner heretofore described-at all times keeping the hedge in the shape described.

I have given you, not theory, but a plain statement of my practical operations in growing the hedge (for which your Committee awarded me the premium), and the knowledge I have gained in growing it and other hedges.

DAYTON, Ohio, January 3, 1855.

\section{STATEMENT BY A. H. ERNST.}

To the Ohio State Board of Agriculture:

IN compliance with the request of the Committee on Hedging, I proceed to give you a brief description of the Spring Grove Cemetery hedge, with the manner 
in which it is formed, and the cultivation of the plants, with a few remarks on hedging in general, as applicable to our State.

By a vote of the Directors of Spring Grove Cemetery, I was charged with the duty of hedging the grounds, consisting of something over two hundred acres. I had the ground for the seed prepared by deep trenching, in a black, sandy loam. Sowed the seed in November, in drills, one foot apart, covering it not over an inch, and protecting it with a covering of leaves from the frosts, during Winter. In the Spring, the plants came up very freely; the leaves left on the ground as a mulching caused the plants to grow finely. During the Summer, I had the ground for the hedge prepared. This I had deeply trenched with the spade, four feet wide, raising the border in the middle in a rounding form. Being thus prepared, I had the plants taken from the seed-bed early in November, and commenced transferring them to their permanent location. After taking up the plants, I had the tap-root reduced to nine or ten inches, and cut the top down within two inches of the neck or crown of the roots. Thus prepared, we proceeded by stretching two lines, eight inches apart, in the middle of the border. Then, with a dibble, we made holes eight inches apart, in each line, making them directly opposite the spaces in the other line; the plants were inserted at once, and pressed tight by the foot of the operator. This work can be performed with great rapidity by any man of common intelligence and activity. When this was completed, the border was covered with leaves, to protect the plants against the 
freezing of Winter, and the droughts and heat of Summer.

This year each plant threw up several strong shoots, which were cut down the next Spring within three inches of the ground; from the eyes of these several strong shoots, as well as laterals, were thrown out, thus thickening the growth near the ground. These were again, for the third time; cut back; some near the ground, to force out laterals; others, something longer, to fill out a little higher; and one on each plant was reserved to form a net-work four feet high.

To form this net-work, it is necessary to drive down stakes at eight to ten feet in the line of the hedge.

Fig. 11.

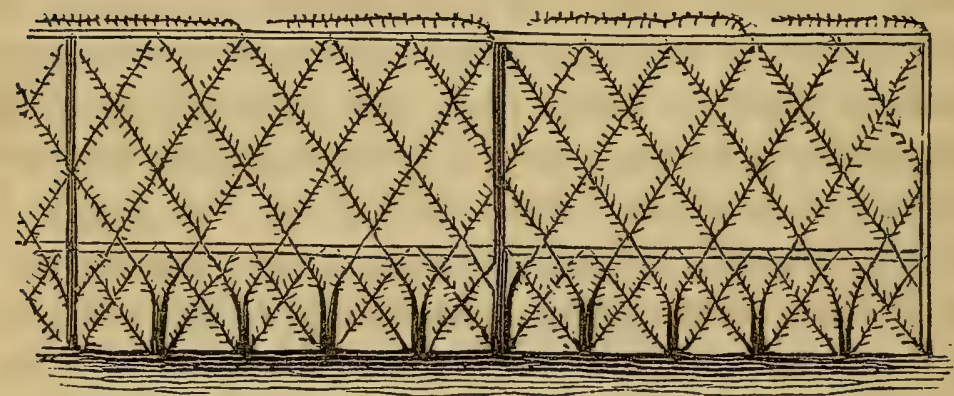

On these two slats are fastened, one at the top, the other one foot from the ground, to form the net-work on. I think the lower slat can be dispensed with. The shoots forming the net-work are bent so as to impede the rapid flow of the sap to the extremity, thereby causing its distribution in the lower buds and growth-a point so apt to be overlooked, but absolutely necessary to the forming a hedge worth the 
name: an angle of nearly forty-five degrees is the proper one. This forces the dormant buds near the ground into growth, and thus forms laterals there, to make a tight and compact base. To make this network complete, the shoots are plaited like a sieve, from the bottom up, and are tied at each crossing with yellow willow. An expert workman can do about two rods per day. This work was performed from Fall to Spring, when not too cold. When the hedge had been thus formed, it was carefully trimmed several times during the Summer, especially to check its upward growth, and encourage the lower growth. This hedge is trimmed in the hog-back form-that is, a straight line from the ground to its intersection at the top with the other side, leaving a base three and a half feet to five feet high. This it is designed to increase in height and thickness of base gradually at each trimming, until it has attained its desired capacity. With proper care this makes an impervious fence to any thing, though it is more costly than is necessary for an ordinary protection. The maxim, however, will hold good: What is worth doing, is worth doing well.

Spring Grove hedge is now six years old. Three sides of it have been exposed, without other protection, since midsummer, to all sorts of stock; especially on the east line, bounding a public road of near a mile long, not an instance has occurred of a breach through it. Rabbits show, by their tracks in the snow, that they have met with a barrier they can not pass-at all events, not until they have by their teeth cleared a passage in some less guarded place, 
where, perhaps, a plant in the first instance had died out and was not replaced.

Owing to a want of sufficient practical experience during its progress, this hedge has cost more than a similar one could now be produced for on the same ground; and yet its cost bears no comparison to any other fence affording suitable protection to the Cemetery; and as for beauty, nothing can compare with it. Of its durability, of course nothing can be said; but all the presumptions are, that it will live to a great age.

The trimming operation is performed with a common Dutch grass sickle, in the hand of a man who passes along one side, giving it a quick motion upwards, by which the tender shoots are shortened to a proper uniform surface. This is done as often as the straggling growth appears, and especially to check the growth at the top. If this were neglected, the hedge would be worthless in a short time. The lower branches always die out, if the upper ones are permitted to absorb all the fluids; and this they are sure to do, if not checked by frequent trimming.

Having said this much on the Spring Grove hedge, I may be permitted to make a few remarks on hedging in general. For more than fifty years, the attention of the agricultural community, in various parts of the Union, has been directed to the increasing scarcity and cost of wood for fencing purposes, and the necessity of some substitute. Hedging is the substitute to which the mind naturally turns. Much has been planted during this time. Large amounts of money, labor, and time, have been employed; and yet we 
have to regret that all this, with very little exception, is wasted; that, except here and there around some small inclosure, we have no hedging in the country deserving the name of a fence. This is mainly owing to two causes, viz.: the use of plants not at all adapted to our soil and climate, and to improper cultivation. In these two causes lie the whole secret of failure. On the first point it is unnecessary to dwell, as we now have a plant which experience has proved to be the plant for our climate and soil. It is not saying too much to call it the best for this purpose. I of course refer to the Osage Orange. Superior as this plant is for the purposes of the hedge, it is a waste of time and money to attempt its use, unless a right principle is observed in its culture, and this carried out with diligence and patient perseverance. The chief difficulties in the way of this are: the want of knowledgea fact many people in these times of progress are not willing to admit; the other is a supposed want of time when attention is most important-other farm duties requiring all this until it is too late: so no. good reason is seen for so much time wasted, when in one season the plants will grow to the required height. Mr. McMahon, near fifty years ago, in pressing the attention of farmers to this subject, says: "I would advise such to hold fast by the post and rail, and not to lose time in doing more harm than good." The next point is, Where shall the inquirer look for reliable information to guide him among the teachings of the day? In most practices, we turn to those who have had the longest and best experience on the points respecting which we seek information and knowledge. 
It is clear that our practice has proved almost an utter failure. Then we shall be not much mistaken in looking to those countries for information where hedging has been successfully practiced for hundreds of years. The plan which I have detailed, on which Spring Grove Cemetery hedge is formed, was simply following a German practice extensively in use there.

The other and more common practice there, as in England, is that of Plashing. This answers all the purposes of the other, at a much less cost, but is not so neat. Plashing is a simple process, consisting of cutting off half or more of the plants near the ground, leaving some at regular distances, cut off at a suitable height as stakes; then the remainder partly cut in, near the ground, and laid, or bent over horizontally, all one way along the hedge, and there fastened down to the stakes, causing a thick intermixed growth at the base. This is sometimes followed up with a second plashing; the next year, and this makes a fence impenetrable to any animal. Among the most fruitful sources of failure is wide planting, and the attempt to form a barrier by an upright growth. This will do for an inside division, where hogs are not permitted to range, but not for a reliable fence on a public highway. When a rabbit once makes a passage, a small pig will soon follow, then one larger, until a breach is made for a cow. Plaiting or Plashing are the only safe modes of protection, and never should be dispensed with for an outside protection. Five or six inches for the single row is the proper distance; for a double row, six to eight inches. When the plants are set wider apart than this, it is next to impossible 
to bring the laterals near the ground, so close in contact as to prevent the passage of rabbits and pigs, and in the event of the death of a plant, leaving a gap for a cow to pass.

Old and defective hedges, if the gaps are not too large, can be improved and made quite good, by cutting the plants down to near the ground, and with care thus to form a tight base, or it may be plashed, as above explained. A reform must be made in our mode of hedging, or an abandonment of its use will be the consequence.

[For my own notions, as to the sentiments contained in the last paragraphs, the reader is referred to the appropriate chapter.] J. A. W.

D. LANDRETH, the well-known Horticulturist of Philadelphia, has kindly sent me the following article from the Germantown Telegraph, to which he made the communication, being satisfied that the Maclura is destined to be an all-important plant in this country, and anxious that his father should have the credit which attaches to his application of it to hedging purposes about 1828.

To the Editor of the Germantown Telegraph:-In the report of the meeting of our Agricultural Society, it is stated, I expressed the opinion that the Maclura or Osage Orange, pruned with the severity recommended by Dr. Warder, of Cincinnati, in his address on that occasion, would not be long-lived. My opinion, founded on the experience of many years, is precisely the reverse; I believe it to be in a remarkable degree adapted 
to hedging purposes-perhaps more so than any other plant. The doubt I did express, imperfectly heard by the reporter, was whether the honey-locust was of a similar value, and I do very much doubt its adaptation to hedges, to which it has been applied; while, on the contrary, the Maclura has every good quality to recommend it-hardiness, vigorous growth, endurance of the shears without disease or morbid growth being induced, acrid juice which protects it against the attack of insects, pungent spines, and disposition to branch when 'cut in:' these and other qualities indicate it as a plant which, it might almost be said, Nature had designed for protecting the labors of the husbandman.

While on this subject, will you indulge me with space for a few incidental remarks, on the original application of the Maclura to hedging purposes? During the administration of Mr. Jefferson, the Western Exploring Expedition, known historically as Lewis and Clark's, was made, and resulted, among other things then considered of vastly more importance, in the discovery of this tree, in the Osage country, which, from its use by them, the Indians, named bow-wood. A few seeds reached Philadelphia, and from one of those was produced the noble specimen still standing in the rear of my father's old homestead, on Federal street, Philadelphia. Its pendant branches and deep green, glossy foliage, which no insect would approach, was for many years the admiration of all who visited the nurseries. For some considerable time the only mode of its increase was by cuttings of the root, placed in pots under glass, and in that way some thousands 
were produced, which from their great rarity were deemed of sufficient importance to be exported to Europe in charge of a special agent, sent out by the late D. and C. Landreth, who disposed of them in London; and, they now doubtless, decorate the pleasure-grounds of our aristocratic cousins.

The parent tree in course of time flowered and produced abundance of fruit, which, from the circumstance of the specimen being pistiliferous, was imperfect. At a later period, another tree of similar origin, planted at our seed-grounds on Fifth street, produced staminiferous flowers, which, as an experiment, were cut off with branches attached, carefully wrapped in sheets, and conveyed to the female tree, a distance of two miles, when, greatly to the delight of all made acquainted with the fact, many bushels of 'oranges,' each with perfect seed, was the result! About the same time, trees at McMahon's nursery also produced seed, and the supply of plants rapidly increased faster than the demand for ornamental purposes, to which they had hitherto been solely devoted.

My father, perceiving the promise of the Maclura as a hedge-plant, used some hundreds to fill open spaces in hedges of English hawthorn, which he had set out, in accordance with his early tastes, many years previously. As he had anticipated, they formed an impenetrable mass, and established it in his opinion, as the best of all plants for hedges. Many thousands were produced with a view to their sale for that purpose, and attention was called to them in various ways: among others, I (then a youth) wrote several articles on the subject, which were widely republished, espe- 
cially in the West, where the means of inclosing prairie lands were of primary interest.

Since then the Maclura has been slowly gaining in popular favor, and the seeds and plants have become articles of considerable trade. The former are now annually collected in Arkansas and Texas, to the extent, it is said, of thousands of bushels; and from reliable statements, it is supposed two hundred thousand dollars are yearly expended in this country, principally in the West, for the seed alone. The plants are also raised in large quantities, and set out and trained at a stipulated sum per rod, by parties who travel from farm to farm. The attention of Europeans is also directed to it, and it is presumed for the same purpose, as within a few weeks I have filled an order from the "Continent," for a considerable quantity of seed.

Thus, Mr. Editor, from an accidental circumstance have important results ensued, and we may, in reference to it, apply one of the early lessons.

"Tall oaks from little acorns grow."

David Landreth.

BlOOMSDALE, March 24.

LETIER FROM PROFESSOR J. B. TURNER.

THe following letter from one of the first and most zealous advocates of the Maclura hedge, and who has done so much to forward the interests of Agriculture, especially in this branch of rural affairs, as to have acquired the soubriquet of Father of the Maclura Hedge, 
will be read with interest, and beautifully exhibits the retiring modesty of the truly great man. Quite a discussion has arisen among the agricultural papers, as to the honor of the first application of this plant to hedging: in this my earnest friend has taken no part.

Bronson Murray, the late Secretary of the Illinois Agricultural Society, however, is not willing to let Professor Turner's honors pass so lightly from him. In The Prairie Farmer of September 1855, he says:

I think I am warranted in asserting that, so far as the public knows, neither Mr. Downing nor Mr. Neff ever did anything to introduce the Osage as a hedge upon the prairies. Neither of them ever, so far as the public know, had put one rod of plants into the prairie soil ; while Professor Turner had as complete a hedge some rods in length as any now in existence, before Mr. Downing or Mr. Neff ever said one word in its favor. This can be substantiated. In fact, it was Professor Turner who corresponded with $\mathrm{Mr}$. Downing on the subject, and enlisted his favor and influence for it. Both Mr. Downing and Mr. Neff cieserve to be remembered among its most earnest and ablest advocates; but neither of them ever pretended to demonstrate, by actual experiment, the above two propositions; and especially not the last, which Professor Turner did do, and gave to the public the results of years of labor and experimenting. This no other man did. It was for this reason the farmers of Mlinois have spontaneously - and justly-and always spoken of him as the Father of the Hedge, and will ever continue to do so.

That many persons had thought of this plant for 
a hedge, and that some had actually tried it around house lots and other ornamental places during those early days, is not questioned-it is apparent from the literature of the time; but the plants were advertised then for sale at from 50 cents to $\$ 1$ each, as ornamental shrubs in the nurseries; and no person thought of making it the exclusive and cheap hedge-plant of the prairies. Professor Turner is not only the first man in Illinois, but the first in the civilized world, so far as I have any knowledge, who boldly advocated, in the public journals and in private correspondence, as well as circulars (the printing and postage of the latter alone costing him $\$ 100$ per annum for several years), the exclusive claims of this plant as the only practical hedge-plant for the farmers of the West. It was not done on the basis of theory, either; but on actual personal practical experience with this and many other shrubs, the remnants of which can now be seen. They are still standing on his place at Jacksonville. In what manner this exclusive claim was met by the public, and especially by the various writers in The Prairie Farmer, even those who have very short memories have not forgotten. I myself was a participant in their ideas, and have a vivid recollection of the cautions which were promulgated at that day even to such extent as to form the topic for an annual address by one of our very best men before the Buel Institute, in which that society had paraded before them the long array of agricultural humbugs.

Editorially, The Prairie Farmer noticed its existence as early as 1841 * * * Its efforts in a practical way were confined, it says, to planting some seeds in 
1845. * * * Its advocacy, as I remember it, was, for years after Turner's positive demonstration of the above propositions, always on the cautious, prudent side, looking moreover to the various thorns indigenous to this latitude, rather than to the Maclura. Did other journals do more? Whatever their action, one thing is certain; their course had no influence on Prof. Turner. He was the man of the field as well as of the pen. * * * * * * * * * * On his first settlement in Illinois, he tried every shrub that he conceived likely to supply the want. From Dr. Nelson he heard of the Osage, and was at work with it before the public journals advocated its claims; before they talked about it he was at work with it; before they recorded their confidence in it above any other plant, he had his hedges; before they urged it upon popular attention with vigor, he was issuing, gratuitously, printed circulars at the rate of one thousand per annum, among the most intelligent farmers of this State.

Whether some other man actually "introduced this plant to the West"-as the editor of The Ohio Cultivator says, and as Turner quotes in his circular of 1849 , concerning Mr. Neff-is not material. It is not the question. It was probably other than either of the men-probably the French or Indians-since scattered trees were found in several parts of this State, of great age; one "older than the oldest inhabitant could remember," and this, too, at a date when Turner believed he had the only ones in the State. I repeat again, it is not the man who "introduced" this plant that is the Father of our Hedge system. 
Dr. WARDER-Dear Sir :-Whether I am, as you are pleased to express it, ' the Father', Godfather, or Stepfather of the Maclura Hedge, seems as yet to be, among the knowing ones, a matter of dispute; and is of so little consequence to the world, that I have never undertaken to decide the question for myself, nor even to read all that others have said about it. I have done what God gave me power to do, and others have done the same; and, among us all, I hope good has been done to the world, especially the farmers of the West.

I am heartily glad that you have undertaken to write upon this subject. I had long purposed to do so myself, before I was prevented by the failing of my eyes, and the multiplied accumulation of other cares and interests; but whether I ever shall or not, is now uncertain, especially as I hope and trust your work will preclude all necessity for another. If you find anything in any of my writings that can be of any service to you, I beg you to use it with entire freedom.

I am not aware that my own opinions have undergone any especial change, so far as principles are concerned. Plants are now so cheap that we set them thicker (six inches in the row) than we used to do, where we wish to stop pigs and fowls without the use of the top-brush, thrown down or woven in at the bottom. I trim or clip also much less than formerly, the first three years, or till a sirong root is made, then cut to the ground, and trim often. You will see 
an adverse article in the March number of The Valley Farmer, St. Louis, originating from Mr. McGinnis, of Clay county, Mo., which the editors and several of our friends have requested me to answer in the next number of that paper, and which I purpose, if able to do: not because it is in fact of any consequence (for the nature and causes of Mr. McGinnis's failure are apparent to every reader of his statement, who understands the true theory and art of hedging), but because, if not noticed in some way, it will be quoted and used to the injury of this great interest of the farmers of the West.

Wishing you still the best success in all your great and good enterprises for the farmers of the West, I am, dear sir, truly yours,

J. B. TURNER.

JNo. A. WARDER: In the year 1832, at my former residence, near the Brighton House, North of Cincinnati, I planted a hedge made of the Osage Orange. From observation and experience, I entertain a high opinion of it, being hardy, well-protected with strong, sharp spines, having a beautiful deep-green leaf, and not subject to injury from stock. It is highly recommended in an article addressed to John B. Dillon, Esq., from Mr. A. H. Ernst, who is so distinguished as a successful agriculturist and horticulturist-he gives particular directions for the management of the Osage Orange, and recommends close planting. Having but few plants, I put them wide apart; the thrifty shoots were cut near the ground, so as to bend and 
plait them horizontally-these threw up numerous perpendicular shoots, making the hedge as thick as was needed. Mr. Wm. Neff has been successful in its cultivation for many years.

This valuable tree is diœcious, and until I discovered this, I had no fruit. The flowers of the male and female are quite different. I have raised plants from seed ripened in my garden. The English hawthorn will not succeed here, being subject to an insect that covers it like a down or mold. When seasoned, the wood of the Osage Orange is nearly as hard as lignum vitæ, and would be valuable to make many tools and implements. From the great resemblance its exudation bears to that from the gum-elastic tree, may not the caoutchouc be obtained from the Osage Orange? One season I confined four lots of silk-worms on four varieties of food, viz., Native Mulberry, Morus multicautis, Chinese Seedling, and Osage Orange. The worms preferred the Morus multicaulis; but when confined to the Osage Orange, were healthy, fed freely, and did well-the cocoons were smaller, but the silk was proportionally finer, and I think the better. Specimens of the cocoons from the Osage Orange feeding, I inclose herewith. Late in the season, the leaf becomes too hard to be freely eaten for a late crop.

Most respectfully yours,

Dan's Gano. 
A. H. ERNST'S PLAN FOR MAKING HEDGES.

More than fifty years ago, the public attention was directed to the importance of hedging, where stone does not abound on the surface. During this period, large amounts of money and time have been expended in the effort to substitute them for the wooden structures for farm inclosures. More recently, a new impetus has been given to this subject, by the settlers of our Western Prairies, where the entire absence of all fencing materials has forced on them the necessity of its adoption. The practice and experiments in the older parts of our country have proved almost an entire failure, amounting to an abandonment for all practical farming purposes. And the success in the West has not been very flattering, nor likely to meet the wants of the farmer.

Much has been written and said of the various modes of forming hedges, during this time. Every periodical having any pretensions to a connection with agriculture or horticulture teems with instructions on the subject, as diverse as the writers are numerous. It may, therefore, seem presumptrous for me to thrust myself among the list of instructors in a field already so fully occupied-a field in which the fancy and poetical genius has been so fully brought to bear. Still, as I shall confine my remarks to my own practice and observations, and as our soil and climate differ, so we may be permitted to differ on results; and as no good fruits have yet been produced from the general practice in use, there can be no objection to going back to first principles, and making 
a right start from that point. Let me not be understood as speaking disparagingly of much that has been said: that is not my feeling.

I will here simply refer to some of the prominent mistakes causing failure; leaving them to be discussed as I progress. It is as much my object, however, to point out a bad or wrong practice, as that of a correct one. Among these are: the use of improper plants; improper cultivation; too much haste and impatience to make a fence in height, without proper regard to base or bottom; wide planting; neglect to replant where gaps have occurred by the death of plants; with general inattention to trimming and keeping the border clear of weeds and other rubbish; and obstructing the free circulation of air and light on the side of the hedge, by the near growth of other plants or trees.

It is presumed sufficient, by most persons, to put the plants in the rows, cut them down once or twice, and then let them take their course. All looks well to them when the foliage is on; when, howerer, deprived of this covering, its deformity and worthlessness is exposed; it is found full of gaps and irregular growth, with abundant openings at the bottom to accommodate rabbits and pigs with free passage, and very soon animals of larger growth. The wider the plants are set apart in the row, the more defective will it be found in this respect. This I shall show before I get through: there is no practice more mischievous in its effect than this.

There is nothing more beautiful and ornamental in the landscape of a well-ordered farm than a wellformed hedge ; but hardly anything more out of place 
than one that has been neglected: it fails to meet the object for which it was intended, occupies room, and is an unsightly nuisance rather than an ornament.

We are accustomed to look to Europe, but more especially to England, for examples in our agricultural pursuits ; so with hedging, and with great propriety we may; but it is to be regretted that there, as with us, it is not all as it should be. According to the testimony of reliable writers and others, many of their hedges are exceedingly slovenly-mere skeletons "for the protection of the game," "covers for partridges and foxes." Here we want something different, and for a better purpose. In a country like ours, where stock of every description is permitted to run at large, more care and greater security is required as a barrier against intrusion. Notwithstanding the length of time that the public attention has been turned to the importance of hedging, few of our farmers have realized its importance, and a less number have had opportunity to inform themselves correctly on the mode of operation from any practical example to which they might resort, but have relied on the fanciful instructions of writers for periodicals, who often write without experience.

The want of knowledge as to plants that are adapted to this purpose in our climate, in the first instances, was a fruitful source of disappointment. The Hawthorn of England-the great hedge-plant there-and even our native thorns, will not endure the clipping and exposure to our hot and dry weather and brilliant sun. The introduction, however, of the Buckthorn, and more recently, of the Osage Orange Maclura- 
which is perhaps the best plant in the world for hedging-has removed the first difficulty. Therefore, we may go to the work of hedging with the confident assurance of success, if we begin right and persevere. The path to this I will endeavor to point out, after a few remarks on the principle of vegetation and growth; from which the reasonableness of the mode for growing hedges that I am about to present will be apparent. In this I present no new discovery, but simply reiterate an old principle; and without its observance, all efforts will prove abortive.

Vegetable growth spends itself upwards, but horizontally, or in an inclination from a perpendicular direction only, as it is forced, either from an exuberance of vegetative force, or the forcible inclination of the plant from an upright position. It does not seek a horizontal direction voluntarily. Hence the feebleness of the laterals, especially the lower ones, compared

- with the shoots near the top of the plant or tree. It is true, that there is in some plants a tendency to grow more dwarfish and bushy than others, as there are some with a pendant habit; but this does not change the general principle. From this it will be seen how important it is to check the upright growth in hedge-plants, in order to secure the expansion and growth at or near the ground-to change its upright character, and force the plant in a different attitude from its natural one. The simple cutting down and forcing out the laterals does not fully accomplish the object. It will answer for an inside division, where hogs are not permitted at large, but will hardly prove sufficiently tight at the base for an outside protection. 
In cutting back, we simply cause a greater number of shoots to proceed from the same point, some of which are forced into the lateral positions, while others seek the upright direction. These last always secure to themselves the chief growth; and though these are again cut back, still the main struggle is to resume their natural upright position, and the expenditure of the sap is exhausted to form growth in that direction, leaving only for the lower laterals what cannot be consumed there.

I am thus particular, that the mind of the reader may be prepared to see the objections to wide planting, and also to an upright growth, however carefully cut back, to form a base and an impervious outside hedge. When speaking of wide planting, I wish to be understood as meaning any distance, in a single row, over six inches; and for a double row in a hedge, any distance over eight inches. All beyond this I heartily repudiate.

The chief principles on which hedging rests are: to force the plant out of its natural habit; to dwarf that which usually grows to a tree; to divert the concentration of strength in a few clants; not to rely on a few absorbents from the soil, requiring long extent of root to supply its top, interfering with and dividing the nourishment of the soil within the inclosure they are designed to protect; to diffuse this strength by dividing it among a number of plants, thus to secure independent, individual absorbents, with diminished roots, confined to a narrow belt in their stretch for food, of less luxuriant growth, less liable to overgrowth, 
to the injury of the next plant, and in the case of the death of one, not to leave an irreparable gap.

It matters not how carefully the cutting back is attended to, and how wide the base is formed, if the plants are not set close in the rows. The first impetus of growth in laterals is more or less in an upright direction, and only becomes horizontal or drooping by their weight or the crowded state of other shoots above. This applies where there is no resistance below to prevent. Of course, this will be at right angles from the line of the hedge; not so between plants. A little observation will show this. The laterals there are rather forced upward than otherwise, as they approach each other from plant to plant, and are supported in that position by each other as they come in contact, forming an archway for the free passage of small animals. This will be found invariably the case with all such hedging, when critically examined with the foliage off. The wider apart the plants are set in the row, the more defective will it be found. Such has been the result of my observations, more recently fully confirmed in the opportunity afforded by the kind invitation of the Committee of the Ohio State Board of Agriculture to accompany them in their examination of hedging. There are defects which never can be cured in wide planting by any process of pruning or trimming, nor can the space between be filled with other plants. It is a wellknown principle in vegetation that the stronger plants always absorb the nourishment from the soil to the exclusion of the younger or weaker ones, until they die from starvation. Of course, none will grow there. 
Having quite fully explained the principle of growth, and the results of a neglect to regard this principle, with the effects of a bad practice in hedgegrowing, I will now briefly point out three modes for forming a hedge, which experience has proved to be such as reliance can be placed on with the hope of success. After having thoroughly prepared the ground for the line of hedge by deep plowing or digging, of four feet wide, always raising the ground in the middle of the border, with a slope each way from the line of the plants, which should be set in the middle, for the purpose of admitting a free circulation of air to the bottom of the hedge. When thus prepared, the plants should be inserted, either with a dibble, or in a trench made with a spade; either mode will do, (but the latter is the best) if the plants are small. Four to five inches for a single row, or six to eight inches for a double row, is as far apart as they should be set. This work may be performed at any time between the fall of the leaves and the expansion of the buds, when the weather is not frosty. When planting is completed, they should be cut back, leaving not over one inch of the top above the ground. Care should be taken to cut back the tap-root to eight or ten inches, and also to assort the plants so that those of the same size may be planted together. They will grow more uniform in this way.

The first Summer, the plants only require to be kept clear from weeds and grass. The next Spring, they must be again cut down within two inches of the ground, and treated in the same way the coming Summer. Care must be observed to replant where 
any have died out; and this should always be with plants as large and old as those in the hedge-rows; for this purpose, there should always be a supply reserved in the nursery.

We have now arrived at the point where a decision must be made as to the fence we want; and in this we shall naturally be governed by the pressure to be brought against it. If for an insiáe division, where hogs are not allowed, the upright form will answer. If, however, for an outside protection, the only safe plan is plaiting or plashing. If the hedge is to be on the upright principle, it is necessary to cut it back the third time, within three inches of the last cutting, leaving all the laterals or horizontal shoots below this point. The plants will now have formed a strong nucleus, from which quite a number of vigorous shoots will put out-some forced into the lateral position, but with the usual tendency to an upright growth. In June, they must be again cut back within five or six inches of the last cutting, again carefully preserving the laterals below this point; and in July or early in August, this process must be repeated, within five or six inches of the last cutting. The next Summer, the same process must be continued until the hedge is the required height; the base should not, in the meantime, be permitted to grow, slovenly and carelessly, but should have such shoots as are disposed to grow irregular or rampant shortened-in, so as to have a uniform, regular, and even surface. It will not do to crowd the forming of the hedge faster than this, or it will not be worth the trouble it has cost.

The best form for a hedge is the hog-back shape. 
What is meant by this form is a straight line on either side of the hedge from the bottom of the base to a point of intersection at the top. This exposes, in the best aspect, the greatest surface to light, air, rain, and the dews of night-very essential points to the health and durability, as also the best form to check a top growth to the neglect of the base. In the growth of the hedge, this form should always be kept in view. Plaiting is the mode adopted with excellent success in the hedge inclosing Spring Grove Cemetery. This course commences in the same practice above pointed out up to the third season. Having secured a good growth for a base, all the upright shoots are cut down to near the ground, except at intervals of four inches. Then stakes are put down in the line of the hedge, eight feet apart and four feet high, on which two slats are fastened horizontally - the first one foot from the ground, the other at the top. When thus prepared, all the shoots not cut down are bent over alternately, in opposite directions, and crossing each other at right angles, so as to form a net-work, and should be woven, which is easily done if commenced at the bottom; one-half, or the alternate shoot, is cut off at the first slat; the remainder are continued to the upper slat, and fastened there. They are fastened by yellowwillow ties to each slat, and at each crossing; this keeps them firm and in place until the growth has become so intermixed that nothing short of cutting it down can remove it. In this form of hedge, the shoots not cut off are all forced into an inclined position, whereby the ascent of the sap is impeded, the dormant buds below and all along the shoots are 
brought into action, and soon form a complete, impervious barrier to man and beast.

Most of this hedging is planted in double rows, eight inches apart, and the plants eight inches apart in the row; and these are set opposite to the open space in the other line, which is equivalent to four inches in the single row. Part of it is, however, set in single rows, plants four inches apart; and is doing quite well. This form of hedge is very beautiful, well adapted to ornamental grounds, but is too costly to be adopted for general farming purposes.

The third and last mode for the forming of a hedge which I shall describe-that which the farmer must adopt as suited to his wants and means, if he hedges at all for an outside protection-is plashing. This is a very simple process; the same practice must be pursued up to the third year. In describing this mode, I do not know that I can do better than to give the substance of a writer on horticulture who possessed much practical knowledge. In plashing, it is best that the upright shoots should be permitted to grow to a good length. This the Osage Orage will do in one Summer in good soil, after it has been cut down three times.

In all cases of cutting the hedge, it is necessary for the operator to provide himself with a good strong pair of leather gloves, pruning-saw, and a hedgehook-that is, a heary instrument with a long and sharp edge, and a sort of a hook on the lower part of the back, by which the operator can draw the shoots.

Thus prepared, he will proceed by selecting some of the main upright stems, at distances of from three 
to four feet, to serve for stakes, which are to be cut off to two, three, or four feet, in proportion to the thickness and strength of the plants to be plashed or laid between them. Where no stems are found strong enough, stakes must be driven down; the distance must be determined by the length of the shoots that are to be plashed." As the object of these stakes is to secure the work when completed, the operator will find no difficulty to determine this point. The hedge is then to be thinned by cutting down to near the ground, leaving only a sufficiency of the best and longest shoots, at regular distances of eight inches. The operator will then proceed to lay down the shoots, first lopping off any stiff, unmanageable or straggling side branches, taking care not to cut them more than is absolutely necessary to lay and weave them between the stakes, almost to a horizontal position, all lying one way. Such shoots as do not yield readily to the desired position should be brought to it by a sloping cut near the ground, taking care that this is not more than is necessary to effect the object. This process, it will be seen, brings the shoots one on the other, each with a shorter lop as the work adrances. When the hedge is thus plashed, finish the top with some of the largest shoots first cut, divesting them of all their side branches, working two together, plying round and over one another between each stake - that is, thrusting the end in below and bringing it across in opposite directions lengthwise between the stakes; then with two others in the same way, taking care to secure the ends of the last in the grip so as to secure them in their places. Thus pro- 
ceed until the whole is completed. This forms a finish somewhat like the rim of a willow basket. "When this is finished, proceed with the hedge-bill to lop off any irregular, straggling shoots or branches on the side; then this part of the work is finished.

Here we have a base that nothing can get through; every plant that has been cut off will throw out a number of shoots, and all the dormant buds along the shoots laid down will burst and grow, making a complete web of an intermixed growth, presenting a strength that may bid defiance to intruders. If this process of plashing is repeated in a year or two, it will be the better; otherwise, it must be cut back on it, and treated as directed in the first case, until the hedge has attained the desired height. I have practiced plashing on the Washington thorn with the desired success, and feel confident that the Osage Orange and Buckthorn will do better.

Old neglected hedges can be made valuable, if the gaps are not too large, by cutting them down, and plashing as above directed.

For trimming a hedge, nothing is better than a common Dutch grass-sickle in the hand of an active man. He will pass over a great length of hedge in a day; all that is necessary is a little practice, when, with a quick stroke upwards, he will make a clear cut from the bottom to the top. This operation must be often repeated, in order to keep the hedge in a neat and tidy condition, and the body in a vigorous and healthy growth. If this is not attended to, the inside will soon become open and ragged, from the exclusion of light and air, by the long irregular shoots on the ontside. 
From the above, it will be seen that a continued vigilance and care is absolutely essential to the forming and after preservation of a hedge. And, as before observed, those who cannot afford time and patience to practice on the principles laid down in the above essay, had better not undertake it. They will only, by their defeat, discourage others of more perseverance from attempting it, and thus do great harm in preventing this addition of ornament and beauty to our rural landscapes.

Spring Garden, Cincinnati, 1855.

\section{HEDGE-FENCES.}

(From The Valley Farmer.)

Mrissrs. Editors :-It has got to be commonly expected that The Valley Farmer will never be entirely silent on this subject. Please publish the following report as the latest and best authority-as it was published with the proceedings of that Society at their late meeting, in May of the present year.

The Special Committee on "Live-Fences," by Mr. Robb, their Chairman, submitted the following interesting and valuable report:

To the Cincinnati Horticultural Society:

Your Committee respectfully report, that on a careful examination of all the different plants that have been presented for our consideration for growing livefences, and after numerous experiments, we arrive at the conclusion that the

Osage Orange (Maclura aurantiaca) - a plant deriv- 
ing its name from Wm. McClure-(the Bois d'Arc of the French, and the English Bow-wood) contains more than any other plant all the requisites for neat and substantial hedging.

Nativity.-The Maclura is found in great abundance and of most luxuriant growth near Red River, in Texas and Arkansas, and abounds in all the country immediately east of the Rocky Mountains, north thirty-four degrees north latitude.

Acclimation.-Numerous and oft-repeated experiments have proved the fact that the Maclura will flourish well in all parts of the United States, from Maine to Florida.

Planting the Seed.-The ground must be thoroughly prepared in the best gardening order; then plant the seed in drills, eighteen or twenty inches apart, with about twelve seeds to the foot in the drills-planting in October or November. For Spring planting, the seed must either be frozen through the Winter or soaked at the time of planting. If the seed is to be frozen, it should be mixed with sand, and placed in boxes that will not hold water, and then exposed to the freezing weather through the Winter, and planted as soon as they begin to sprout in the Spring.

If the seed is to be soaked, as soon as the ground grows warm in April, put the seeds in a tight vessel, and cover them with hot water (not boiling), and soak them in warm water about seven days, changing the water once or twice to prevent fermentation. Then put the seeds in shallow boxes, and mix with sand; keep moist and warm until they show signs of sprouting, which will be in a few days; then plant as be- 
fore recommended; but be careful never to select grounds that crust or bake. Either of the above modes of planting are perfectly reliable.

Setting the Hedge.-As soon as the ground becomes settled in the Spring it should be plowed to the depth of twelve or eighteen inches, and thoroughly pulverized for the reception of the young trees. A line should then be stretched, and the trees carefully removed from the nursery, and planted with strict regard to uniformity of size and distance.

Distance of Planting. - The Maclura is a third-rate forest-tree, and as such, requires either natural or artificial dwarfing. The former is preferable, and can be best accomplished by close planting. For this purpose we recommend planting the trees six inches apart, in a single row. The plant thus naturally loses the nature of the tree, and grows into a shrub, and still retains all its wonted health and vigor, and makes a good protection sooner, and at a less cost, than any other mode of planting. Great care should be taken to fill all vacancies as soon as they occur, that they may have a uniform growth; and thus all gaps and weak places in the fence will be avoided.

Cultivation and Pruning.-After planting, the hedge should be cultivated with care for two years, keeping the ground well pulverized, and clear of grass and weeds. The first Winter after planting, the trees will be liable to heaving up, by the action of the frost. To guard against this, the ground must be well drained by running a furrow with a plow on each side of the hedge, throwing the earth towards the plant. After the trees have thus grown two years, they have then 
acquired a strong and vigorous root, and you may begin your system of heading down and training. In the Spring of the third year, the trees should be cut down to the surface of the ground. Each root will send up a number of strong, thrifty shoots; and as soon as these have grown to the height of one foot, cut them off within two inches of the ground. The shoots thus cut off will send up an additional number of sprouts from the place of cutting. When these have grown ten or twelve inches, cut them off down within two inches of the last cutting, and thus continue pruning several times during the season, always keeping in view the final shape and appearance of your hedge-preserving proportion and regularity of form from the beginning. First secure a good and sufficient base; then let your fence rise gradually and beautifully, and train it into whatever form your fancy may dictate.

$$
\left.\begin{array}{l}
\text { Charles Robb, } \\
\text { R. Buchanan, } \\
\text { F. G. Carey, }
\end{array}\right\} \text { Committee. }
$$

The President, Dr. Warder, and Mr. Mears, remarked that they desired to be understood as protesting against the views of the report as to the spaces of planting-preferring at least twelve inches space between the plants.

Strange! that this matter of distance of setting plants in hedge-row is still a question unsettled. Yet such is the case. It was disputed upon at the meeting at Jacksonville last Winter. We have some facts to present at a more favorable time, that shall help to settle this question; and we hope that others will be 
called out from different points. Our experience has led us thus far to adopt the plan of setting exactly seven and one-fifth inches apart-that is just five plants to the yard, or twenty-seven plants to the rod, which is exactly eight thousand eight hundred plants per mile. We believe this distance is near enough; but we recommend great care in selecting and classifying plants. "SleEPer \& LindLy."

"July, 1857." 



\title{
EVERGRENS:
}

TIRER USES FOR

\section{SHELTER, ECONOMY, AND ORNAMENT ;}

\author{
DIRECTIONS FOR
}

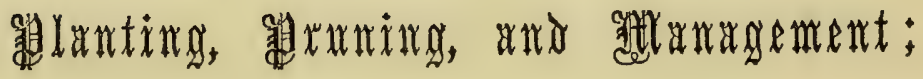

WITH AN HXTENDED

C A t A I 0 G U

BY

JOHN A. WARDER. 



\section{E V E R G R E S}

[Is this Essay upon Evergreens, I shall endeavor simply to indicate some of the objects proposed in planting them, such as their ornamental beauty and their uses for shelter. Under the latter head their economy to the farmer will be urged.

The best modes and seasons for planting them will be discussed, and the manner of pruning, and other treatment, will be considered. Then will follow lists and descriptions of different evergreens, with indications of their different capabilities for the plantation, and for application in the arts of life.]

Ornament.-Miss Cooper says, in her Rural Hours, "I think a fine tree near a house is a much greater" embellishment than the thickest coat of paint that could be put on its walls, or a whole row of wooden columns to adorn its front; nay, a large, shady tree in the door-yard is much more desirable than the most expensive mahogany and velvet sofa in the parlor." Who cannot appreciate the beauty of a fine evergreen, or, better still, groups of fine evergreens about a country residence? He who cannot, should be condemned, for the rest of his life, to be shut up in one of the many dreary, desolate, bare and unpro- 
tected farm-houses, that are so common throughout our country; there he should be confined, with nothing like tree or shrub, to refresh his weary eyes, nothing to relieve the bare and desolate appearance of his vis à vis neighbor, who occupies just such another desolate castle. This by way of punishment; but perhaps the moral treatment of such a case might, after all, be more efficacious than the physical. The most indifferent person could surely be made to appreciate the difference between such a scene of black desolation, and the snug nestling cottage, embowered in bright evergreens, screened from the northern blasts, and protected from the western winds, by belts and groups judiciously arranged. This moral treatment already begins to have its effect upon our people, so far as it has been able to extend its influence: the isolated plantations of evergreens are all nuclei, around which others are clustering under the contagious effects of imitation, until they are isolated no longer; but the people of whole neighborhoods are becoming tree-planters, and the entire aspect of our residences is being changed.

Evergreens are particularly valuable for the purpose of ornamentation, since they are always objects of beauty; Summer and Winter alike, they lend us their shelter. They are coming into requisition more and more; and indeed they should, for by their means a fine picturesque effect may be produced at a very moderate expense.

One of the commonest faults in planting evergreens is their situation in regard to the house; and is so frequent that it should be pointed out in this place. 
I refer to the common practice of planting the little stranger in the dooryard, very close to the building. When first obtained from the forest or the nursery the plant will have cost something either in money or labor; it is often a wee thing, and certainly, if well shaped, it is a very pretty object, hence it is jealously set close to the window. Were it always to remain a sort of parlor-pet, this position might answer very well; but it is to grow, and develop itself into a large tree, and in so doing, it should preserve its fair proportions: for this, space is required; if crowded against the house, its beauty will be marred, and, instead of being of service, and a beautiful object, it will become an eyesore and a nuisance.

The economy of planting evergreens may be computed in dollars and cents; for while these trees mitigate the severity of a boreal Winter, they will enable us to economize in the amount of fuel consumed. J. J. Thomas has stated his conviction, after considerable observation, and actual experience, that, on many bleak situations, at least one half of the fuel consumed might be saved, by planting twenty-five to fifty good evergreen trees across the sweep of the prevailing winds. This effect, I am satisfied, would also be very much increased by planting evergreen hedges as screens and shelters. Only think of saving half the expense of the wood-house; and how many farmers of our country now spend at least fifty dollars a year, in this item, when, too, they have nothing but the cutting and hauling to provide; the saving of half this sum annually would yield a nice little fund in a few 
years, infinitely greater than the interest on the investment made in planting.

A writer in The Albany Cultivator speaks to the point: "We have long held the opinion, that the character and morals of a rural community are necessarily improved by that most interesting of rural embellishments, ornamental planting. But for those who cannot appreciate these advantages, we shall present another view of the subject-the saving in dollars and cents. This the writer has had an opportunity of verifying in his own case.

Nine years ago, tinding a serious inconvenience from the sweep of Winter tempests, to which his residence was much exposed, a large propotion of evergreens was mingled with the trees and shrubbery, then newly set out. About a dozen white pines, as many American arbor vitæ, and a few balsams, white spruce, Norway firs, and hemlocks, were placed, so far as practicable, on those sides of the house most exposed-regard being had, at the same time, to the exclusion of uninteresting points of view.

"Now for the economy of the plantation, which some of the neighbors thought was entirely useless labor: it has saved the present Winter, by the protection it affords against storms and wind, at least ten dollars in firewood; and this amount saved is increasing every year, as the trees advance in growth. The cost of procuring and setting out the evergreens was about three dollars."

In another mode, evergreens will prove economical to the farmers of many parts of the country, especially in the prairies-I mean, in the shelter they will afford 
to cattle during the Winter-breaking the force of the bleak winds to which the poor creatures are exposed in the open fields, they will sensibly modify the temperature, and thus economize in the food they consume, just as barns and sheds contribute to their comfort, and are economical to the proprietor, in regions where agriculture has reached a more advanced stage. Those who have farmed only where barns and other stock shelters are common, can form little idea of the manner in which the beef and pork of our great markets are produced; nor do they dream, that of the thousands of cattle, sheep, and hogs, which supply the hungry millions, not a tithe have ever been inside of a barn. In the absence of such proper shelters, as the nice farmer would consider absolutely essential, but which are not to be found in the great feeding farms of the country, these shelters of evergreens, and belts of other timber, will prove of the greatest advantage and economy.

This operation cannot be too strenuously urged upon the farmers of the great West, where the expanse of prairie land exposes every object to the fury of the winds, that are scarcely interrupted by the occasional groves of timber, as they sweep over hundreds of miles in their onward course. The first object of the settler upon such lands should be, to plant timber, and among this he should provide a large proportion of evergreens. Even in the hill-country, in the midst of a heavilywooded region, upon the Ohio river, thousands of cedars and other evergreens may be planted with the happiest effect upon a farm of moderate size. I have now growing some two thousand evergreens, of differ- 
ent sorts, for planting, with this view, upon one hundred and fifty acres-and more will be needed.

Transplanting.-Many persons suppose that a tree may be planted like a post; that the object is so to fix the plant in the ground that it will not fall over; and they forget that it has vitality to be preserved, and that this vitality is often a very delicate thing, needing great tenderness and care for its preservation. Such planters, being averse to extra labor, will open but a small hole; and in digging up the tree, they will take little care to preserve the roots, so as to have as large a proportion as possible of these most important organs attached to the young plant. In transplanting evergreens, the preservation of these rootlets is particularly desirable; but besides this, it is important to have them preserved from the action of the atmosphere; they should never be for a moment unnecessarily exposed to the sun, or winds, or frost; for in all the resinous or terebinthinate trees, the proper juices of the roots are of such a character, that when once dried, they cannot be restored to their fresh condition, by the application of water, or moisture, as is the case, to a certain extent, with most deciduous trees; once dried, the roots of evergreens are gone forever; they are no longer useful; but, indeed, become deleterious agents - dead parts, which must slough away from the stock; if, perchance, the whole plant does not follow the same process.

The preservation of the roots, then, and their protection from external agents, becomes a matter of the first necessity in the removal of evergreens. This may be accomplished in different ways. The ground where 
they stand, if in a state of nature, may be prepared so as to effect this. A trench may be dug around the tree the Summer before it is to be transplanted, especially if it be large; the extremities of the roots being thus cut, and the trench left open, or filled with rubbish, an increase of the fibres nearer the stem will follow, and this ball of earth will be held more tirmly together, when the tree is removed in the following Winter and Spring. The time for transplanting large trees of this class is often selected with a view to having the earth solidified by frost. In the Fall or Spring, the tree is dug, and laid upon its side; water is poured upon the ball, and allowed to freeze into a a solid mass, when the whole is removed to its future site, a sufficient hole having been previously opened.

The Summer root-pruning is a great desideratum, where practicable, with many kinds of trees that are to be taken from their natural position in open woods, fields, or fence-rows. But a similar process, with even better results, has always been practiced with nurserytrees: in every well-managed establishment, they have been transplanted from time to time, and the soil among them has been frequently stirred in their cultivation; hence their roots are in a very different condition from those of a wilding. There is also a difference in the soils in which they have grown. Sandy, open soils, generally furnish plants well-provided with small roots; while those growing in stiff, tenacious, clayey lands, will be found to have longer, scattered, and bare roots, reaching out beyond the limits usually opened by the spade in digging up the tree: this is an important fact for nurserymen to bear 
in mind, since their reputation will suffer with the unsuccessful plantations from their grounds, that are too apt to follow, when they send out plants that are not well furnished with roots.

When the tree is to be removed, a cloudy and still day is to be preferred rather than a bright, sunny, and windy one. Many persons, also, envelop the whole mass of roots and earth in bagging, to exclude the air and to retain the soil, which, if at all sandy and friable, is very apt to fall off. Boxes are often used in removing smaller specimens, or tubs made by cutting barrels in two. This plan is very desirable if the trees are to be kept some time out of the ground, or if the plants are to be transported to a distance. Large flower-pots are often used with the smaller plants, and they offer a very good means of transportation. Handsome evergreens, put into pots in the Autumn, may be used for ornamenting a door-yard as a winter-garden, and can be transferred to their permanent sites at any time during the following Spring or Summer with perfect safety. I have set out such specimens in the month of June, without losing a plant. This plan is very desirable for those who are commencing a new home; for they may produce an immediate effect about their houses in the first Winter, and thus take off the bleakness and unfinished appearance that always follows the labors of the house-builders. The hurry of Spring planting is also relieved by being enabled to transfer the evergreens to their permanent sites at any convenient time.

The ground should always be rather moist when 
the trees are dug up, as in this condition it will adhere better to the roots; though planting evergreens, and all other trees, should never be done when the soil is in a sticky, pasty condition. Water may be used for puddling the ground, as the holes are being filled up, and if the roots have become bare of soil, they should always be dipped in a creamy paste of clay, or a mixture of earth and cow manure, reduced to a proper consistence by the addition of water.

Before proceeding with the work of transplanting, it is essential to pay some attention to the preparation of the soil for the trees. Where a plantation is to be made, the ground should be well dug to the depth of a foot or more; good plowing and subsoiling will answer very well, and drainage should be practiced, where necessary. Almost any good soil will grow evergreens; but there are some species that require a peculiar kind of earth. If the land be poor or exhausted, it may be manured with great advantage by applying decayed leaves from the woods, rotten sods, or even good surface-soil from the road-sides or commons.

An excellent compost may be made of peat earth, or vegetable mould, mixed with ashes, and allowed to remain some months, if possible, to be decomposedan addition of sand and well-rotted manure, about the time of using, will add to its value; or a barrow of wellrotted manure to a cart-load of coal-ashes, mixed with a quantity of mould or common garden-soil, will be serviceable. Evergreens do not relish fresh animal manures. If the trees look unhealthy, and fail to make satisfactory growth, a top-dressing of either a 
bushel of ashes to each, or one pound nitrate of soda to a square rod, applied after stirring the soil to a depth of six inches, will much improve their color and general condition.

Time for Planting.-Evergreens have been moved successfully at almost every season of the year. Some persons advocate one period, while others insist upon a different time for the work. That which appears to have been most successful, is the early Spring, when the necessary indications may be controlled. The Winter, or late in the Autumn, is recommended by those who remove large trees with a frozen mass of earth; some planters prefer to wait until the new shoots have begun to grow ; but at this time care must be taken, lest the young growth droop. At the completion of these shoots, in midsummer, the plants of some varieties will bear removal. The early Spring, when the plants are dormant, is the season in which I have been most successful, and this is the experience of many others. The season may be prolonged by digging the plants early, and setting them back in the soil till wanted for planting.

With regard to the appropriate arrangement of the trees, it will not be advisable here to enter into a discussion of the subject of landscape gardening; though much of the effect of the plantation, in future years, will depend upon the proper disposal of the trees in regard to their shapes, altitudes, and contrasts of color. The planter should be familiar with the habit, annual growth, and outlines of every tree and shrub he intends to set out; he may thus avoid the blunders we 
constantly see committed in planting, even by those who profess to be landscape gardeners.

Beautiful scenery, with varied character, may be produced by judicious planting on almost any piece of ground. Common sense has well been suggested as the best guide to direct the planter, who has a knowledge of the characters of the trees and shrubs he is setting out. This will be likely to produce infinitely better results than the blind imitation of plans, that may or may not have been well adapted to their original places; but which are too often followed by those who profess great skill in this line, without exercising any real consideration of the adaptation of their designs to the grounds upon which they are to be executed.

The following suggestions from the pen of James Richardson, Jr., of Dedham, Mass., have a value which entitles them to a place in the memory of all who would create forms of natural beauty in "living green:"- "If we would produce an effect, either lovely or picturesque, we must follow beautiful Nature, avoid all stiff, straight lines, all precise regularity and uniformity, and dispose our trees in graceful groups, with here and there a single tree of fine form and habit, resting its rich dense foliage upon the green lawn. Evergreens have a very natural and pleasing effect planted upon a slope or steep bank-especially if there be mossy rocks-different shades of green being mingled by way of contrast; or, if we wish to give the appearance of distance, to place those with lighter hue and finer foliage in the back ground, with those of more sombre colors, such as the Fir and Black 
Spruce, and the Pines with coarser foliage, in front. This, though difficult to manage, has the effect of perspective. Larches may be combined to advantage with the evergreens in the back ground. A collection of beautiful evergreens, tastefully arranged, with an underwood or bordering of Rhododendron, Kalmia, and our rich, green, trailing $\mathrm{Yew}$, is one of the most charming pictures that can meet the eye, in Winter especially. There are certain trees, however, we confess, that lose much of their beauty by being crowded in with others, and only appear to their best advantage when set alone. This is particularly true of the Hemlock, and the Black and Norway Spruces, and the Arbor Vitæ; at least they should form the outside of a group, while the stiff, ungraceful Fir, gives the finest effect by thrusting its tall spires through the masses of softer foliage, by which it should be surrounded. Evergreens, however, when set alone, should be allowed to grow naturally, with their lower branches leaning upon the lawn. Indeed, nothing is in worse taste than an evergreen with its branches lopped off half way up. It is but half a tree. It resembles a wretched man, who has undergone some surgical operation that has taken his arms off to his shoulders; and we should as soon think of shaving off the wary, silken tresses of a fair girl-Chinese fashion-up to the crown of her head, as of mangling in this way a beautiful tree. The Black Spruce, with its thicktufted, and dense foliage, of sombre deep sea-greenthe Norway, with its fringed branches of bright goldbronzy hue-and the graceful, feathery Hemlock-are objects of unwearied delight, when thus treated. If 
the upper branches tend, when young, to overshadow the lower, they may be easily clipped, so that those below may never suffer from the exclusion of sunlight and air."

Evergreens are desirable not only in the Northern section of our Union, but in the sunny South, also, they are of great value in the ornamenting of rural homes, and some of the most beautiful varieties of evergreens are adapted to the Southern climate. The non-resinous are among the most beautiful of these. The new Araucarias, Cryptomerias, Junipers, Deodars, and even the Norfolk Island Pine, of surpassing beauty, may be successfully planted there-though too tender to succeed in the Northern States, and embrace some of the most beautiful trees and shrubs. The magnificent Live-oaks, the glorious Magnolias, the exquisite Holly, the Wild Olive or Lauri mundi, the Orange, and many others, are admirably adapted for ornamenting Southern homes, and, in many instances, they have been judiciously applied with most excellent effect. The evergreen hedges around some Southern gardens have attracted deserved admiration, and are a source of much pleasure and comfort, as well as security, to their owners. The Holly, Lauri mundi, Cherokee Rose, and Yucca, as well as Cedars, and other evergreens, make beautiful protective fences about the gardens and orangeries, and are infinitely preferable, both for ornament and use, to the wretched-looking picket-fences, too often occupying such situations, even in the towns in many parts of the Southern country.

Pruning.-Evergreens differ in their ability to bear 
pruning; but all may be pruned with safety, if with good judgment, and most of them require trimming, at some period of their growth. Many appear to assume their proper forms of beauty in a natural way, and some of the most beautiful specimens I have ever beheld were of the native growth, upon which neither knife nor bill-hook had ever intruded. The chief rules are, to shorten-in protruding branches, in order to preserve symmetry, and cause thickening, and to cut, or pinch, or twist, all shoots that have an aspiring tendency, likely to interfere with the one main stem or leader, which should reign supreme in all the conical terebinthinate trees. Trimming up this class of trees should never be practiced, unless the lower limbs become shabby, as their beauty is most complete when they are well furnished from the surface of the ground, the lower limbs being always the longest. The pyramidal growing kinds, especially, should have their bases resting upon the ground.

If in the removal of evergreens the roots have been considerably injured, it is generally well to make a corresponding reduction of the top by the process of "shortening-in" the side branches, cutting within an inch of the place on the larger branch, where it forked out, applying to the wound a solution of gum shellac in alcohol, or grafting wax. Some writers, with a show of reason, advocate shortening-in in all cases of removal.

It has been recommended where an evergreen, such as the White Pine, Silver Fir, \&c., has lost its leading shoot, to cut back all the shoots in the uppermost whorl, to within an inch of the main stem, 
covering the cut with shellac solution, and a new upright shoot will probably be formed.

A quaint writer, in The London Cottage Gardener, gives the following excellent directions for pruning evergreens: "When people have leisure in Winter, they know that it is not the right time to put their evergreens into good shapes, or keep them to their proper bounds; and in Summer, when the work should be attended to, they know just as well that they have no time to attend to such things. Young evergreens get up, in the course of a few years, with all sorts of defects; and fifteen or twenty years hence, a practiced eye can see what has been going on among them now, as well, if not better, than if the same eyes were present this very July. Leaders and side-branches grow as they list. Fastigiate and upright growing sorts get round-headed forms-round-headed ones grow to one side, the leading limbs to this or that side of the tree -all this, and much more besides, for the want of the pruning-knife, or of the finger-and-thumb way of stopping, applied regularly at the proper season. It is not too much to say, that in a first-rate garden the pruner is, or should be, as busy in July as at any other period of the year; and, as a criterion as to how far he is advanced in his art, we shall lay it down thus: A stranger looking at an evergreen bush or tree, of any size or age, directly after it has been pruned, should not be able to perceive, at a cursory glance, that the knife has touched it for the last twelve months. If one can see that an evergreen has been recently cut-in, depend upon it, the pruner wants a notch or two. The worst of the matter is, however, that it is 
very difficult to convey, by verbal or written descriptions, a just notion of how this high style of art is effected.

"One of the first fundamental rules in pruning evergreens is, that the lowest branches should be the longest, whatever the shape of the head may be. There is no exception to this rule that I know of. No sooner is a higher branch allowed to grow out further from the main stem of a tree, or from the general mass of branches of a bush, than the lower branches, than a direct error is committed; and if not remedied by cutting-in this longer branch, a sure foundation is laid for the destruction of the lower part of the tree, which will eventually cause it to grow naked below, because the longer branches will shade the others, and throw off the rain from them. You may see examples of this bad management along the road sides, in every parish in England. Hedges, in general, are so unskillfully treated, all over the country, that there is no lack of bare bottoms anywhere, and this from allowing the hedge to be nearly as broad at the top as at the bottom. Let us, therefore, bear in mind, that every branch, yea, every leaf of an evergreen, should stand in the same relation to the others as the slates and tiles on a roof, no matter what the outline of the head be.

"The second rule is, that no leaf should be cut through in pruning an evergreen, clipping evergreen hedges does not come under this rule. The last rule applies to the mode of cutting. No cut ends should be seen on the bush or tree; and that is effected by beginning the cut on the opposite side to where you stand, and 
always cutting with an up stroke; then the cut part will either face downward, or towards the centre of the plant; and if you cut close to a lateral branch, or to the bottom of a leaf-stalk, as all good pruners do in the Summer, and as the worst kind of pruners do in the Winter, I should like to know how I, or anybody else, could find out, at a yard distant, that your plant has been pruned at all.

"There is a very common and most mischievous pruning-cut, which, as far as I am aware, has never yet been mentioned in print, and I hope to put scores, yea thousands, to the blush when I mention it, for of all the cuts in this cutting world, it is the one against which there ought to be an Act of Parliament to put it down; but I am wrong-it is not a cut at all, but a snap-off, and is done in this wise : a knife is held firmly by the four fingers of the right hand, the edge facing the thumb, the thumb itself being free, but bent on mischief; a rose-shoot, or the branch of some other plant, is now grasped between the edge of the knife and the thumb, the shoot is then pressed against the edge of the knife by the thumb, and by a turn or twist of the hand, the shoot is snapped asunder on the edge of the knife, leaving a bruised or jagged cut, just as if a wild goat had gnawed it off. Now a dozen of such bruised or gnawed cuts over the top of a fine rosebush are as bad as anything can be, and will be sure to do it much injury, as the bruised ends will either die back, or let in the wet, or be a harbor for insects or their eggs, beside the slovenliness of the thing." 


\section{EVERGREEN HEDGES.}

Beautiful hedges may be made by planting rows of almost any of the common, thick-growing evergreen trees and shrubs. The Norway Spruce has been applied in this way; the common Cedar is very efficacious, and much used for producing a shelter-hedge, where a quick, permanent, and effective wind-screen is wanted, but is liable to grow thin at the bottom. The American Arbor vitce and the Hemlock are admirable, where a neatly-trimmed garden or lawn evergreen hedge is desired-one which can be kept within bounds. Where a moderate or low hedge is needed, as for a small cemetery lot, or subdivisions of a flowergarden, or boundary of a parterre, nothing can be better than the Tree-box. In the South, the Holly and the Lauri mundi are the favorites; the Euonymus balearicus is also used; and several other evergreens are applicable. The Cherokee Rose is a good farmhedge.

The general rules for planting the hedge, laid down in a previous section of this volume, the Hedge Manual, are equally applicable to the evergreen live-fences. The distance from plant to plant becomes now a matter of great importance. Those who may not think well of my recommendations to plant the Osage Orange at distances of a foot or eighteen inches, will now probably complain, when they learn that my cedars, at two years old, were set three feet apart; but so perfectly are the branches united, it would be difficult to tell where the stems of these plants emerge from the ground, in a hedge of three years' growth. 
I should not desire to plant the Hemlock or the American Arbor vitce any closer than the Cedars. The Tree-box may be planted at one foot, especially where an immediate effect is desired; if set too closely, for the sake of present appearances, it may be thinned in a few years by removal of alternate plants, but it will be more difficult to produce an uniform surface, than if planted wider at first.

Trimming.-The general rules, already laid down, will apply here; except that the evergreens must be treated as a completed hedge from the first. There is here no cutting down to the ground, as with the Osage Orange, to produce lateral branches: they are already provided in abundance in the young plants. We may, after planting, remove the tops of some of the tallest, to bring all to the same level, and many gardeners, using tall plants, cut-in the tops severely. The trimming must be conducted upon the principles previously advocated, so as to preserve the pyramidal shape with the greatest exactness: no perpendicular walls, no flat tops in the evergreen hedge should ever be allowed; the two sides should meet in a middle line.

The cutting or clipping may be done with the garden shears, by which all protruding spray is removed to the proper surface of the hedge, which should be kept even and regular as possible. This process must be performed from time to time, during the season of growth, or at its close, more or less frequently, as the plants are young and vigorous, or older, and have reached their mature state; in the latter case, they will require very little clipping. While pruning the hedge, care must be taken to preserve the upper line, 
regular and even, as this will contribute to the beauty of the whole affair, and any deviations from it will sadly detract from the appearance of finish and completeness which should characterize the evergreen hedge.

James Busby, who travelled extensively in Spain and France, for the sake of investigating the culture of the grape, observes, that one great cause of the low state of agriculture in the former country was, the want of inclosures to protect the growing crops. Vineyards and gardens alone were allowed to be inclosed. He describes the hedges of Andalusia as being made very readily by planting the Prickly Pear-Cactusand the Aloe-Agave. The former makes a fence in two years, which is said to last for forty years; and, if cared for, Cactus hedges might be perennial. He says, it is not possible to imagine a more effectual fence, or one more easily planted and kept in order. The only objection is, that they sometimes occupy too much space, and that the trimmings are so tenacious of life, that they will live even if thrown together on a spot of dry ground. This difficulty could be obviated, and the land benefited by composting these trimmings with lime. The Aloe hedge is also much used in Spain, but inferior to the Cactus, because the plants die when they have flowered. 


\section{CATALOGUE OF EVERGREENS.}

Is this list of Evergreens, little attempt at classification has been attempted, beyond arranging species of each genus together. Many have been introduced that are not usually planted, others that are not easily obtained, and some of no particular interest or beauty, except in the eyes of the curious amateur and collector; but it was considered best to make the list as complete as possible. This has cost much labor, in collecting, condensing, and collating the accounts of the best authors, so as to present, in brief language, the leading characters of each, which will enable the planter to arrange them judiciously upon his grounds, with a view to the best ulterior effects. In this work of condensation, the chief sources of information were: the elegant work of Michaux, the Sylva Americana, and the complete descriptive and systematic Arboretum Britannicum of the indefatigable Loudon, confirmed, in many cases, by extensive personal observation of the plants of our own country.

CONIFERS, ABIETIN $A$-CONIFEROUS EVERGREENS.

Plants of this family, Coniferce, are all woody, and generally characterized by persistent foliage; they are 
also provided with a proper juice, turpentine-hence they are called terebinthinates. In a systematic study of these plants, they may be separated into two sections-A -ALEtina, and Cupressine.

The Abietras constitute a very important class of trees-they are generally lofty and pyramidal, and have needle-like leaves. They are natives of temperate regions, and chiefly of the Northern Hemisphere. One of the physiological peculiarities of these plants is, that the roots do not develop buds; hence they never sucker, althongh they run near the surface, and often rise above it, forming knees. The trunks always grow erect and straight, often attaining a height of one hundred and fifty feet, and sometimes reaching two hundred feet. When clustered, the stems are beautifully clean, and tapering gradually to a great height without limbs. The branches are generally verticillate and horizontal in their direction; and as the trees grow old the spray is apt to be pendant. The natural character of uprightness may be changed by repeatedly pinching out the leading shoot for a few years, by which the force of the tree is so divided among the branches that it never recovers its pyramidal character. The opposite of this has already been pointed out as the advisable practice in the nursery or young plantation, where a single leader only should be allowed to remain; and the others, when they appear, should be removed or twisted down, so as to subordinate them. In case of injury to the leader, a little care may be taken to bend up to the vertical line one of the branches from the highest whorl, and it will become the leader; for 
without such a spire young trees will remain a long time stationary in the nursery. This is particularly the case with the Silver Fir, Picea pectinata, which, when so injured, will frequently stand for years without growing any taller.

Trees of this class have an extensive range, but they are chiefly found in the temperate portions of the Northern Hemisphere. The lowest mean temperature necessary for the existence of the Abies is thirty-seven and a half degrees; that for the Pinus is thirty-six and a half degrees. Humboldt found the Pines at the extreme limits of arborescent vegetation on the mountains of Mexico. Glennie found Pines on Popocatapetl to the height of nearly twelve thousand six hundred and ninety-three feet. Pinetums, or collections of the different species of this class, have been formed in many parts of Great Britain ; in some of which there are one hundred sorts. The nurseries of Messrs. Loddiges, in England, are said to contain the most complete collection. The Pineries of America are native collections of these trees, generally composed of a very limited number of species and varieties.

\section{PINES WITH TWO LEAVES IN A SHEATH.}

The Pinus sylvestris, or Scotch Pine (see PlateVII.), is one of the favorite European species; and as it succeeds remarkably well in this country, it will always be largely planted. There are many varieties of this, some of which are so distinct that they might well be mistaken for different species. In favorable situations, the Scotch Pine will grow eighty or one 
hundred feet high. The leaves are glaucous, and in pairs; in young trees they are from two to three inches long. They do not drop from the tree until the fifth year. Hardy.

Pinus pumitio, Dwarf or Mountain Pine, has its varieties also. All are smaller and less glaucous than the preceding: the leaves are thicker on the branches. This species is highly terebinthinate, hardy, and desirable as a dwarf-tree, only growing about ten feet high.

Pinus Bantsiana, or Labrador Pine, is also a low, scrubby, or straggling tree, rising only five or eight feet. Michaux says this is found further north than any other American pine. This is the Scrub Pine of Maine and Nova Scotia, and the Gray Pine of Canada. Franklin found this as far North as sixtyfour degrees.

Pinus inops, or Jersey Pine, a low tree with crooked branches : the young foliage is glaucous and tinged with violet. It grows from thirty to fifty feet high. The branches are irregular, not in whorls. The Jersey Pine is an American, and found on dry soils from New Jersey to Carolina. This tree preserves its lively green color throughout the Winter, and is on that account of peculiar value in the Winter landscape.

Pinus mitis, or Yellow Pine, is a beautiful tree, fifty to sixty feet high. The leaves are four or five inches long, fine and flexible. It is found in the pine forests from New England to Georgia, growing on the poorest lands. This tree furnishes the yellow-pine lumber much used in civil and in naval architecture. 
Pinus pungens, or Table-mountain Pine, makes a tree forty or fifty feet high, with the habit of Sylvestris : the young leaves are not glaucous, and being of a paler green, the tree is less gloomy in its appearance than the Scotch pine. It is confined, says Michaux, chiefly to the Table Mountain, in North Carolina.

Pinus laricio, Corsican or Larch Pine (see PlateVI.), has many varieties, which have been described. It forms a tall tree in Corsica, growing to the height of one hundred and forty to one hundred and fifty feet. The leaves are long, being from four to eight inches, according to the age of the specimen. This species is a native of Corsica, but is found in other parts of the Mediterranean, and according to some authorities, in other parts of Europe. It is a useful timber-tree, of rapid growth. Hardy as far north as Pennsylvania. A rapid grower.

Pinus laricio Austriaca, Black or Austrian Pine, is much admired for its sturdy habit and yellowishgreen leaves. It grows wild in Austria; it prefers a loose soil. The heart-wood is tough and strong: it is the richest in turpentine of all the pines in Austria. This species succeeds well where planted in America, is quite hardy, and very valuable.

Pinus Zaricio Pallasiana, or Tartary Pine, is a large tree, confined to the Crimea. Professor Pallas says the wood is knotty, resinous, and very durable. Mr. Lambert says it is well adapted to thin chalky soils and maritime situations.

Another variety of the Zaricio is called Pyrenaica, from its locality.

Pinus resinosa, or Red Pine, so called, says 
Michaux, from the color of its bark, forms a tree seventy or eighty feet high, with a trunk two feet in diameter. The leaves are five or six inches long, and dark green, collected in bunches at the ends of the branches. The wood is compact and heary, from the amount of resinous matter. This species is rare south of the Hudson River, but abounds in Nova Scotia. The planks of this timber are sometimes made forty feet long, and almost without a knot. This tree is worthy of extensive cultivation.

Pinus pinaster, the Cluster Pine (see Plate I.), also has many varieties, as is apt to be the case with those trees that have an extensive range. The $P \cdot p$. escarenus and lemonianus are the only varieties particularly deserving of culture. The Pinaster is indigenous to the South of Europe, North Africa, Asia, the Himalayahs, and perhaps also to China. It thrives in deep sandy land, and is said to perish in calcareous soils. Immense tracts of barren drifting sand have been covered with this tree in France, which now yield abundant crops of inferior lumber, fuel, and pitch. Hardy.

Pinus pinea, or Stone Pine, is a lofty tree in the South of Europe. The leaves are of a deep-green, six or seven inches long. The fruit is three years in ripening; the seed is larger than other pines-the kernel is white and sweet. The Stone Pine is a native of Italy, Spain, Greece, Barbary, and perhaps parts of Asia. Hardy.

Pinus halepensis, Aleppo Pine, has several varieties that are not very distinct. These are not large trees, seldom exceeding thirty feet. The young plants 
have spreading heads; the old ones round heads, wider than high. The leaves are deep green, two to three inches long, and never remain longer than two years on the tree, which makes the foliage look open and sparse.

Pinus brutia, or Calabrian, has long, slender, wavy leaves. It is a middle-sized tree, with spreading branches.

\section{PINES WITH THREE LEAVES IN A SHEATH.}

Pinus tosda, the Frankincense or Loblolly, is a lofty American tree, often attaining eighty feet, with a clear trunk of fifty feet and two to three feet in diameter, and a wide-spreading head. It is found on poor sandy lands from Virginia to Florida, and comes up in old clearings. Michaux, ever mindful of the agricultural interests of his country, suggested the introduction of this tree-which delights in the exhausted sands of the New World-to aid the Pinaster in securing the blowing sands of Bordeaux.

Pinus rigida, or Pitch Pine, varies in its height from twelve to eighty feet, according to the soil. The buds are always resinous, and the leaves vary in their length. The bark is thick, furrowed, and blackish; the tree is very branching, the wood knotty, and rich in turpentine. Michaux says, this tree abounds in the United States, except on the maritime border, and in the Mississippi Valley. He found it as far North as Maine and Vermont, where it is a small tree.

Pinus serotina, or Pond Pine, is thirty-five or forty feet high, the leaves five or six inches long. Pursh thinks this only a variety of the rigida. It grows on 
the edges of ponds and swamps from New Jersey to Carolina.

Pinus ponderosa, or Heavy-wooded Pine, has leaves from nine inches to a foot long. Branches are regularly whorled, horizontal, and inclined to droop. This tree has a noble appearance, even when young. It is from the north-west coast of America. Hardy, and grows rapidly.

Pinus Sabiniana, or Prickly-coned Pine, has long leaves, cones, large, persistent. This is another of the great pines of the north-west coast. Douglass found them from one hundred and ten to one hundred and forty feet high, and from three to twelve feet in diameter-not perfectly hardy at the North.

$P$. Coulteri, Coulter's, is from California. It has long leaves, grows one hundred feet high, has large branches and a spreading top. This is supposed to be a variety of Sabiniana.

Pinus longifolia, a Nepaulese species. Leaves of bright green, from nine to eighteen inches long, very slender, and generally pendulous. Its favorite haunts are in the Himalayahs. It is too tender for planting in this country.

Pinus Gerardiana, is another Nepaul species, with short leaves. The seeds are eaten by the inhabitants of India.

Pinus australis, or Southern Pine. The variety called excelsa is found in the Southern States, from Virginia to Florida. Michaux says, it grows from sixty to seventy feet high, and sometimes larger, in favorable situations, in Florida. The leaves are about a foot long, and brilliant green. This tree furnishes 
our resin and tar-turpentine being the fresh juice, and tar is distilled from the dead wood of fallen trees. This is the prominent variety in the pine-barrens of the South.

Pinus canariensis is a tender species from the Canary Islands, where it forms extensive forests at a considerable elevation, thriving upon the volcanic rocks.

Pinus sinensis, or Chinese Pine, with slender, spreading, grass-green leaves, five inches long. It is a large tree.

Pinus insignis has grass-green, twisted leaves. It is as hardy as any of the Californian pines.

Pinus teocote is a rare Mexican species, from Mount Orizaba, near Vera Cruz.

Pinus patula, another Mexican species, from the cold region.

Pinus llaveana is a very rare and handsome pine, from Mexico. It seems quite hardy in England.

Pinus californiana. The Californian Pines-the tuberculata and radiata-are all from the neighborhood of Monterey, California. They form excellent timber, being large trees, a hundred feet high.

Pinus occidentalis, or West Indian, and P. Montezumce, are little known.

Pinus leiophylla, or Smooth-leaved, is from Jalacinga, in the cold region of Mexico.

Pinus cembra, the Siberian Stone Pine, is described by Pallas as a lofty tree, straight, and often one hundred and twenty feet high. When standing singly, it is handsomely furnished with limbs that are disposed in whorls. This is an Alpine species, of very extensive 
range in Europe. The wood is soft; it is used by the Helvetian shepherds to carve the toy animals that afford so much pleasure to the juveniles in all parts of the civilized world. Hardy.

Pinus strobus, or Weymouth Pine is more familiarly known as the White Pine, in various parts of our own country, where it grows from Canada to Virginia. This is a tall tree, rising from one hundred to one hundred and eighty feet. The branches are in regular whorls; and in young trees, and where openly exposed, they form a beautiful pyramid; the foliage is pliant, leaves slender, from three to four inches long, of a light bluish-green. This is one of the most beautiful trees for ornamental planting. It has been sometimes troubled with aphis in calcareous soils. Universally hardy.

Pinus excelsa, or Bhotan Pine, is a tall, handsome, pyramidal tree, with numerous ascending branches, disposed in whorls. Leaves, long, slender, and glaucous green. The wood is soft, and furnishes quantites of liquid resin when wounded. The excelsa resembles the strobus in many respects; but is even superior to it as an ornamental tree. It grows well in the United States, and is perfectly hardy. In its native haunts, it attains a height of one hundred and twenty feet.

Pinus Lambertiana, Lambert's or Gigantic Pine, is found in the north-west coast of North America, where it was discovered by Douglass, who says, it is from one hundred and fifty to two hundred feet high, and sometimes nearly sixty feet in circumference. It is allied to $P$. strobus; the turpentine or resin that 
exudes from trees partially burned is sweet, and is used instead of sugar; the nuts are eatable. A hardy variety. - Pinus monticola, or Short-leaved Weymouth Pine, is a native of high mountains on the Columbia river, and in California.

We now come to study another division of the $A b i$ etinae, that which gives the name to the family.

THE GENUS ABIES.

Abies excelsa, the Norway Spruce Fir (see PlateVIII.), is sne of the loftiest trees of Europe, growing one hunr.red and fifty and one hundred and eighty feet, with a straight trunk. This is one of the most beautiful pyramidal trees, and one that has succeeded admirably in this country. The branches and twigs are often beautifully pendulous when the tree has attained some size. This species is very characteristic, and therefore peculiarly valuable in adorning the landscape; it bears trimming, and therefore makes a good shelter and barrier hedge. Withstands the severest Winters. Abies alba, or American White Spruce (see Plate IX.), resembles the Norway, but is not so fine a tree; this and the $A$. nigra, which has darker foliage and bark, grow in the Northern States, and where the soil is adapted to them, they may be planted advantageously. They do not, however, compare with the excelsa in beauty or usefulness. A. rubra is a variety of nigra, according to Michaux. Entirely hardy.

Abies Smithiana, the Himalayan Spruce Fir (see Plate IX.), is a pyramidal drooping-branched tree, growing fifty feet high. Branches verticillate, spreading. 
This has been called the Rhutrow, and has been sold as the Pindrow pine: it has also been confounded by some with the $A$. orientalis. Somewhat affected by severe Winters in the Northern States.

Abies Douglasii (See Plate X. A.), has flat leaves, more than an inch long; cones, from three and threefourths to four inches long. It was discovered by Menzies, and then by Douglass, on the north-west coast. A variety is called taxifolia, from the size of its leaves.

Immense forests of $A$. Douglasii are found from latitude forty-three to fifty-two degrees. Menzies found it at Nootka Sound. Douglass says, the trunks vary from two feet to ten feet in diameter, and from one hundred to one hundred and eighty feet in height. He found a stump at Fort George, on the Columbia, which was forty-eight feet in circumference, at three feet from the ground. Hardy, with slight protection when young.

Abies Menziesii, somewhat analogous; has leaves set in every direction, short. It is a native of the north-west coast, and of Northern California. Is hardy.

Abies canadensis, Hemlock or Hemlock Spruce Fir, is one of the most beautiful of American evergreens. The tree is tall, pyramidal, when in open grounds, well-furnished with slender limbs that decline gracefully, forming a cone of perennial green, of a bright dark tint, that is very refreshing in the landscape, though it renders the dense forest of Hemlock rather gloomy or dark. This species is found in the coldest parts of the country, about Hudson's Bay, in Canada, and, at elevations, in North Carolina; on limestone 
cliffs beside the streams tributary to the Ohio; but, strange to say, young trees, set in rich loamy clays, have been known to lose their leaves in cold Winters, like tender species; but is, under favorable circumstances, everywhere hardy in this country.

Abies dumosa, the bushy Alpine Spruce Fir, resembles the preceding; it is a native of Nepaul.

Abies cephalonica, the Cephalonian Silver Spruce Fir, growing in Cephalonia, is sixty feet high. The branches extend on every side, to a great distance, when the trees are not crowded. The leaves stand out on every side; they are terminated by a brown prickle. Quite hardy.

\section{THE GENUS PICEA.}

Picea pectinata, the European Silver Fir (see Plate $X I$.$) , like all the tribe, is remarkable for the regu-$ larity and symmetry of its form. The heads of these trees are always pyramidal. The foliage may be distinguished from that of the Abies by being more decidedly in two rows. The Silver Fir sometimes attains a height of one hundred and eighty feet, with a straight stem, with regularly whorled branches, that stand out horizontally. The leaves are very darkgreen above, with silvery lines beneath. The Silver Fir is found upon the mountains of Central Europe, and in the West and North of Asia, approaching the elevation of the Scotch Pine. This tree has not been appreciated by our fast-moving people, as it is very slow in its growth during its early life, and the nurseryman often has to wait for several years before 
the central shoot begins to grow freely, being liable to lose its leader during the Winter; but when it has greater age it is hardy and beautiful.

Picea pectinata pendula is a variety of the above, quite hardy and distinctive.

Picea pichta, the Pitch Silver Fir, is a native of the Altai mountains, where it forms whole forests ; at an elevation of five thousand two hundred and seventytwo feet it becomes rarer. Don considers this only a variety of the pectinata: the leaves are less silvery. Quite hardy.

Picea balsamea, or Balm of Gilead, is the American Silver Fir. (See Plate X., B.) It is a pyramidal tree, resembling the pectinata, but seldom growing more than thirty feet high. When standing alone it forms a regular pyramid, and small trees are very attractive in the nursery; but in temperate latitudes, at least, it does not form a durable ornament to the landscape; and $I$ have observed, even in its native haunts at the North, that the old trees lose their beauty. This tree abounds in resinous matter, which is collected and known as Canada Balsam. The Indians use it for smearing their bark-canoes. Hardy.

Picea Fraseri, the Double Balsam Fir, resembles the preceding. Pursh found it on high mountains in Carolina. It is a smaller tree than the batsamea; its leaves are shorter and more erect. Hardy.

Picea grandis is a noble tree of the same family, found growing one hundred and seventy to two hundred feet high. It is a native of California, where Douglass discovered it in low valleys.

Picea amabilis, of Douglass, is very similar. 
Picea nobitis, Noble Silver Fir, has its falcate leaves mostly on one side of the branches. This majestic tree forms large forests in the northern part of California, and produces timber of excellent quality. Hardy in the latitude of New York.

Picea Webbiana, Webb's Silver Fir, is a large pyramidal tree, with numerous branches that spread horizontally, are much divided, and are densely clothed with leaves; they are disposed in whorls. Captain Webb describes the leaves as an inch long, of a beautiful light-green, with a white stripe in the centre. The wood equals the Bermuda cedar in fineness of grain and in odor. The cones are purple, and yield a pigment by expression; they are covered with globules of transparent resin, which render the tree very ornamental. It has appeared rather tender in England, being native of Nepaul. It is reported by Mr. Sargent, of Fishkill, N. Y., hardy in his latitude.

Piced pinarrow, the Pindrow, grows eighty or one hundred feet high, with verticillate, spreading, and leafy branches. It has strong resemblances to $\bar{W} e b-$ biana, and Loudon thinks it will prove to be only a variety. It is hardy as far North as the Hudson River.

Picea bracteata is a tall pyramidal tree of California. The bracts, of its cones are furnished with leaves projecting from their margins.

Picea religiosa was found by Humboldt on the lower hills of Mexico, at an elevation of four thousand feet; it is remarkable for the slenderness of its twigs, 
and is used by the Mexicans for ornamenting the churches. Supposed to be hardy.

\section{CEDARS.}

Cedrus libani has tufted perennial leaves. It is a native of Syria, on Mount Lebanon, and in Northern Africa on Mount Atlas. This plant is intimately associated with sacred history, and has æsthetical associations of a high order. The tree is widelyspreading, and rises from fifty to eighty feet. The branches being arranged in stages, nearer as the tree ascends, and those below being longer in proportion than those above, the tree has a broad head. The famed Cedars of Lebanon are claimed to be the very identical plants set by Solomon, in the quincunx order. They are visited by all travellers in Syria, and yet we have very different accounts even as to their numbers. This plant has been introduced into England and France long enough to have some very tine specimens, which show that it may be there produced in great beauty. Those in the United States are still of small proportions; but some are large enough to satisfy us of the beauty of the tree, and of its adaptability to our climate, although while young it is somewhat tender.

Cedrus deodara.-The Deodar, or Indian Cedar, is a lofty and graceful tree, in the Hirnalayahs becoming one hundred and fifty feet high, and the trunk thirty feet in circumference. The leaves are paler than those of the Zibani, and of a glaucous hue. It is found in Nepaul and other countries of the Himalayahs at 
elevations of from seven thousand to twelve thousand feet. The feathery lightness of the young trees renders them great favorites; but the severe Winters in many situations in the Northern States have sometimes seriously affected their appearance. When well established, however, they prove quite hardy.

\section{ARAUCARIAS.}

THese magnificent trees are natives of South America, Polynesia, and Australia.

Araucaria imbricata.-In young trees the surface is covered by the leaves, which remain for twelve or fourteen years clasping the stem. The branches are in whorls, horizontal, and covered with imbricating, flat, and pointed leaves. The whole tree abounds in resin. The imbricata is native of the South American Andes. Its range is supposed to be between thirtysix and forty-six degrees south latitude. Its habitat is steep rocky ridges, where there is no water. This beautiful evergreen has proved hardy in England; but it has not been universally satisfactory, on the score of hardiness, in the northern portions of this country.

Araucaria braziliana.-The general appearance of the Brazil Pine is very similar to that of the imbrica$t a$; but the leaves are large, less rigid, and less imbricated. It is also more tender than the preceding species.

Arancaria excelsa, the Norfolk Island Pine, is a most beautiful evergreen of this genus, still more tender than those before named. It is a majestic tree, rising from one hundred and sixty to two hundred and 
twenty-five feet, with a trunk eleven feet in diameter, and free from branches for eighty or one hundred feet. Young trees are remarkably beautiful; their frondlike branches being very regular and graceful. It has been planted in Florida, by Messrs. Parsons, of Flushing Nurseries.

The turpentine is found only between the bark and wood, and is of a milky character.

Araucaria Cunninghamii, is a tall tree, growing on the shores of Moreton Bay, and elsewhere, in New South Wales.

Cunninghamia sinensis, the Chinese Fir, is a middle-sized tree, having the general appearance of the Araucarias. It has proved hardy in England, and I have seen it planted in Baltimore, Md., on the grounds of Mr. Winans; but decidedly yellow, rather than evergreen, during the Winter.

Dammara orientatis, the Dammar or Amboyna Pine, furnishes the Dammar pitch. It has still less the appearance of a pine than the Araucarias. The $D$. occidentalis is a native of New Zealand, where it grows to a great size. Both these are tender.

\section{THE CYPRESS TRIBE.}

Plants of this order differ from those of the preceding group in their leaves. Many are small, and are all evergreens, except our own cypress, the Taxodium distichum. There are three leading genera, THUлА, Cupressus, and Juniperus.

Thuja occidentalis, the American Arbor Vitæ, is a moderately-sized tree, of fifty feet in height, of rather 
slow growth. The leaves are small, opposite, imbricated scales, which have a peculiar essential oil that diffuses an agreeable odor when they are bruised. The trunk tapers gradually from the ground, and the branches are so arranged as to form a pyramidal tree with a broad base, the twigs are drooping, and all the branchlets have a flattened character. The wood is reddish, odorous, soft, and fine-grained, not very resinous, but of great durability. This is justly considered one of the best of American evergreens for general planting, on account of its adaptability to various situations; since its native habitats are peaty swamps, and rocky cliffs, it will thrive in almost any situation; and its conical figure, and rather free growth, make a good effect. One of the characters that recommend this tree is, that it bears clipping, and hence it is well suited for ornamental hedges, and wind-screens, for which purpose it is frequently used. Indeed, this species, the Abies canadensis, the Abies excelsa, and the Juniperus virginiana, are, of the terebinthinate trees, those best adapted to this purpose.

Thuja plicata.-The Plicate Arbor Vitæ is a native of Mexico and the north-west coast of America, at Nootka Sound. It is a branching, spreading, low tree. The branchlets and leaves are closely crowded. There are several grades of difference between this and the preceding, so that this may prove only a variety. Not hardy.

Thrija chilensis is a dark-green spreading tree, with drooping branches, crowded with branehlets at their extremities. It is a native of the Andes. Hardy.

Thuja orientalis, or Chinese Arbor Vitæ, which has 
been classified as the BготA, has its branchlets remarkably two-edged and upright. This is a low, upright, fastigiate tree, native of rocky situations in China and Japan. There are varieties, one of which, the Tartarica, is more compact in its figure. This species is hardy in Scotland; but in many parts of the United States it is inclined to become very shabby after severe Winters, though scarcely to be considered tender. Its fastigiate character renders it peculiarly prone to be parted by heavy snows, which injure its appearance sadly. There are few evergreens that present a more beautiful appearance in a young state in the nursery, where the rapid growth of the trim, snug, little, upright trees of beautiful green renders them very attractive; but the older plants are very liable to become quite unseemly, and the foliage is often dull-colored, particularly in the Spring. The spray is often used as a back support in forming flat bouquets, and is also mingled with the flowers with good effect. If trained to a single stem with spurs, it may be trimmed constantly for this purpose; for a succession of side branchlets will be produced from the laterals during many years. For general planting, either for single shrubs or for hedges, it should not be recommended.

Thrijc, cupressoides, or Cypress-like-a native of the Cape of Good Hope-is not well known.

Thuja pensitis is an elegant, much-branched tree from China, not generally known.

Thuja pendula, or Weeping Arbor Vitæ, has filiform, drooping branchlets. The branches also are 
very long and pendulous. It is a native of Tartary, and is a beautiful shrub. Hardy.

Callitris quadrivalvis is a tree of fifteen to twenty feet in height. It is a native of Mount Atlas and other hills on the Coast of Africa. In Paris it requires protection. Broussouet says that gum sandarach is furnished by this tree. The wood is odorous and balsamic, and is supposed to be the sandal-wood of the Orientals.

Cupressus sempervirens, the Evergreen Cypress, is a tapering, cone-like tree, with upright branches that grow close to the trunk, like those of a Lombardy poplar. The branchlets are dichotomous, and covered closely with imbricated scales or leaves, which are yellowish green, shining, and remaining on the tree five or six years. It is a native of the islands of the Archipelago, and is mentioned in the Bible. The gopher-wood used in the construction of the Ark, is supposed to have been the cypress. It was very highly esteemed by the ancients, on account of its balsamic odor and its durability. The Turks plant it in their cemeteries, and these sometimes extend for miles and resemble forests, from the number of these trees planted at the graves. The Evergreen Cypress is planted considerably in England; but is scarcely hardy in Paris, where it is sometimes killed to the ground. In some of our Southern States it has been found to thrive. It cannot produce a grand effect in masses; but may sometimes be advantageously planted in rows, or singly, to break an outline of round-headed trees.

Cupressus thyoides, or White Cedar, is a tree of 
eighty feet in height; when grown closely, they have long, straight stems, clear of branches. The wood is soft, and fine-grained, and assumes a rosy hue. In its native haunts in this country, the White Cedar grows in wet grounds near the sea-coast, from New Jersey to Virginia; in the latter State, it constitutes the chief timber of the Dismal Swamp, mingled with the Deciduous Cypress. This can not be considered a very ornamental plant, though, from the durable quality of its wood, it is a highly useful one. For cooperage, joinery, and particularly for shingles, it is highly prized; roofs of this cedar will last thirty or forty years; fence-rails made from young trees keep sound for fifty or sixty years.

Cupressus lusitanica, the Portuguese Cedar, is a native of Goa, East Indies; it is a branching tree, growing fifty feet high. This is a very handsome low tree, with pendulous branchlets, covered with a glaucous foliage. It cannot be considered quite hardy.

Cupressus torulosa, the Bhotan or Twisted Cypress, is a native of Nepaul. This is a beautiful pyramidal, much branched evergreen. It has been found on the Himalayahs, at an elevation of eleven thousand five hundred feet. It appears tolerably hardy in England.

Cupressus pendula, or Weeping Cypress, has a large, expanded head, with very pendulous branchlets, closely covered with leaves. It is a native of China. One of the most beautiful of small trees. Hardy.

Taxodium distichum, though not an evergreen, is here named on account of its being one of the noble forest trees of our own country, which is one of the same family; indeed, it is known as the Cypress among 


\section{PLATE VI.}

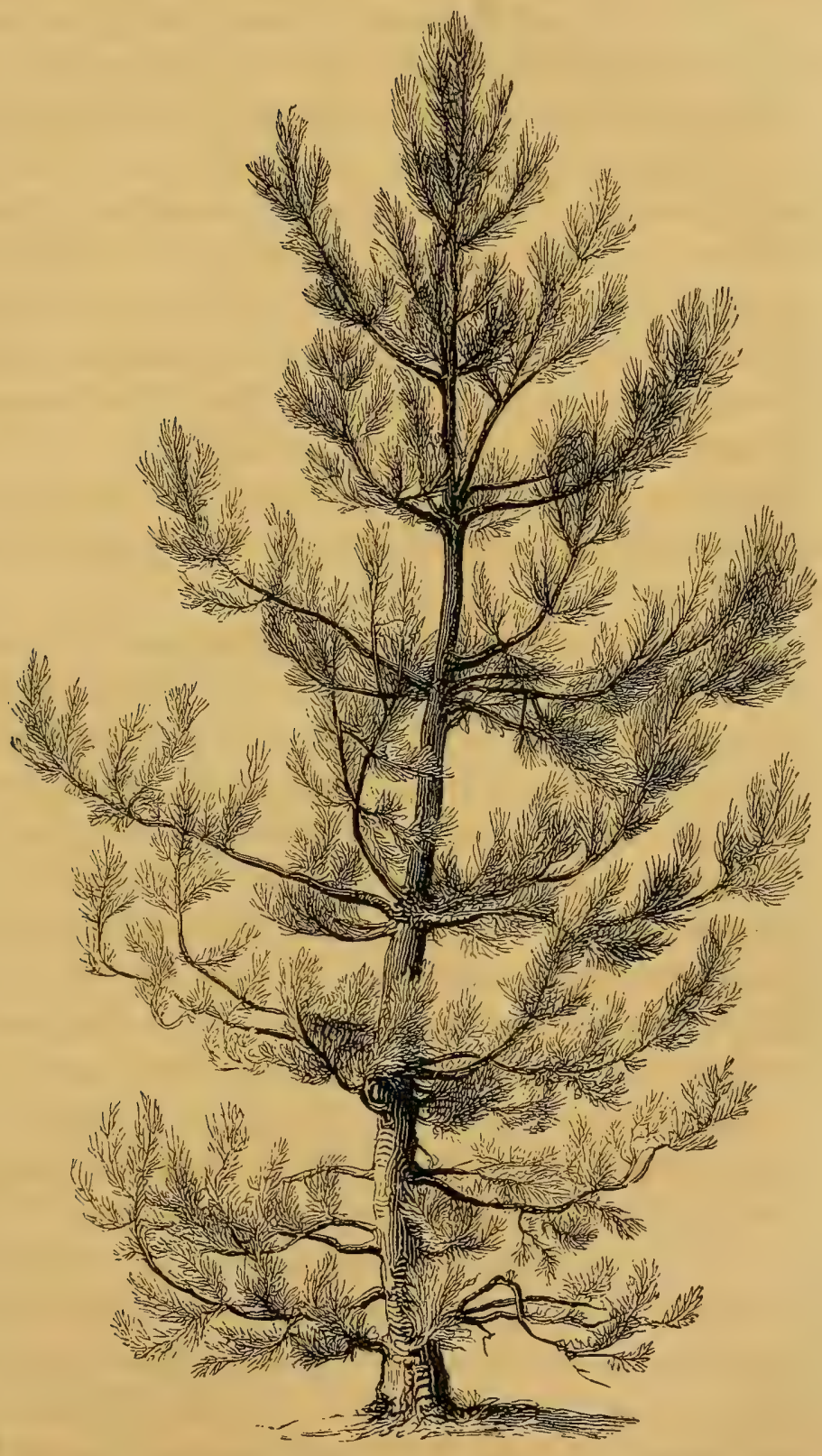

PINUS LARICIO.

The Corsican or Larch Pine.-(SEE PAGE 24i.) 



\section{PLATE VII.}

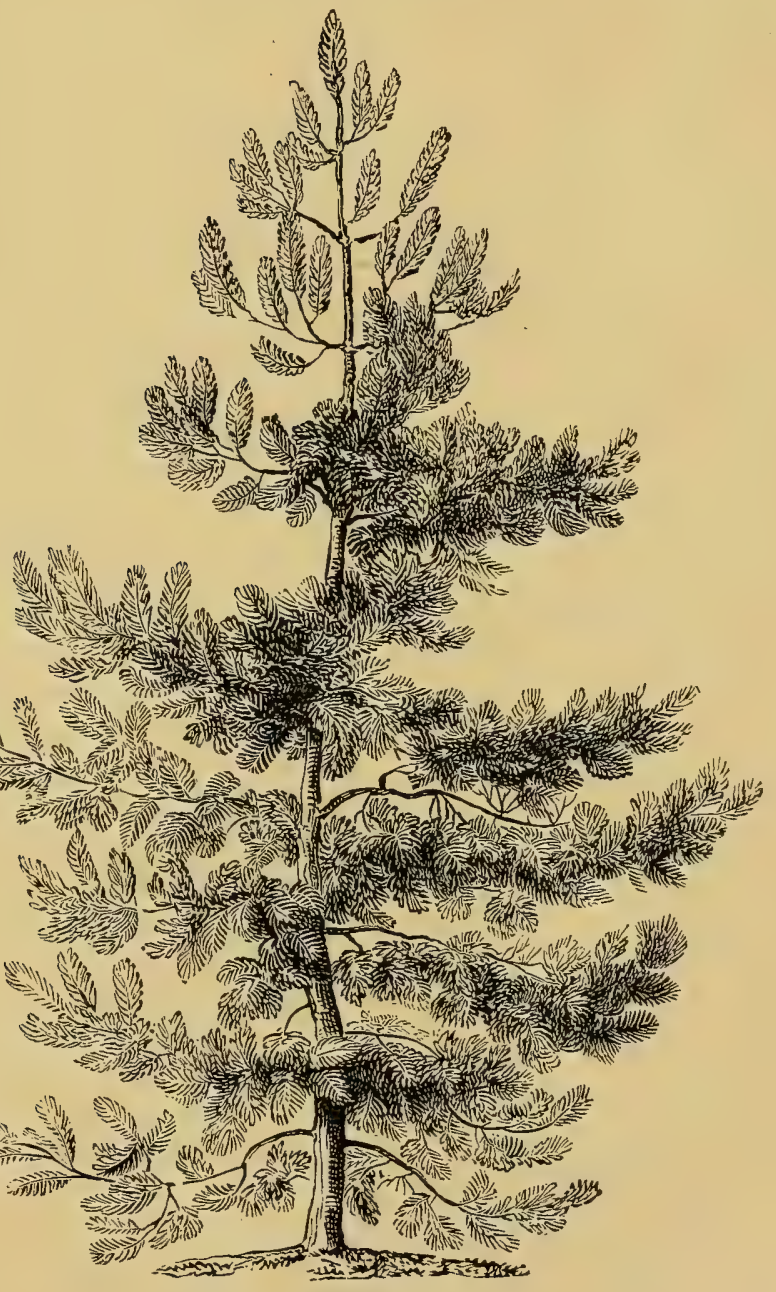

PINUS SYLVESTRIS.

The Scotch Pine.-(Ste PAGR 245.) 

PLATE VIII.

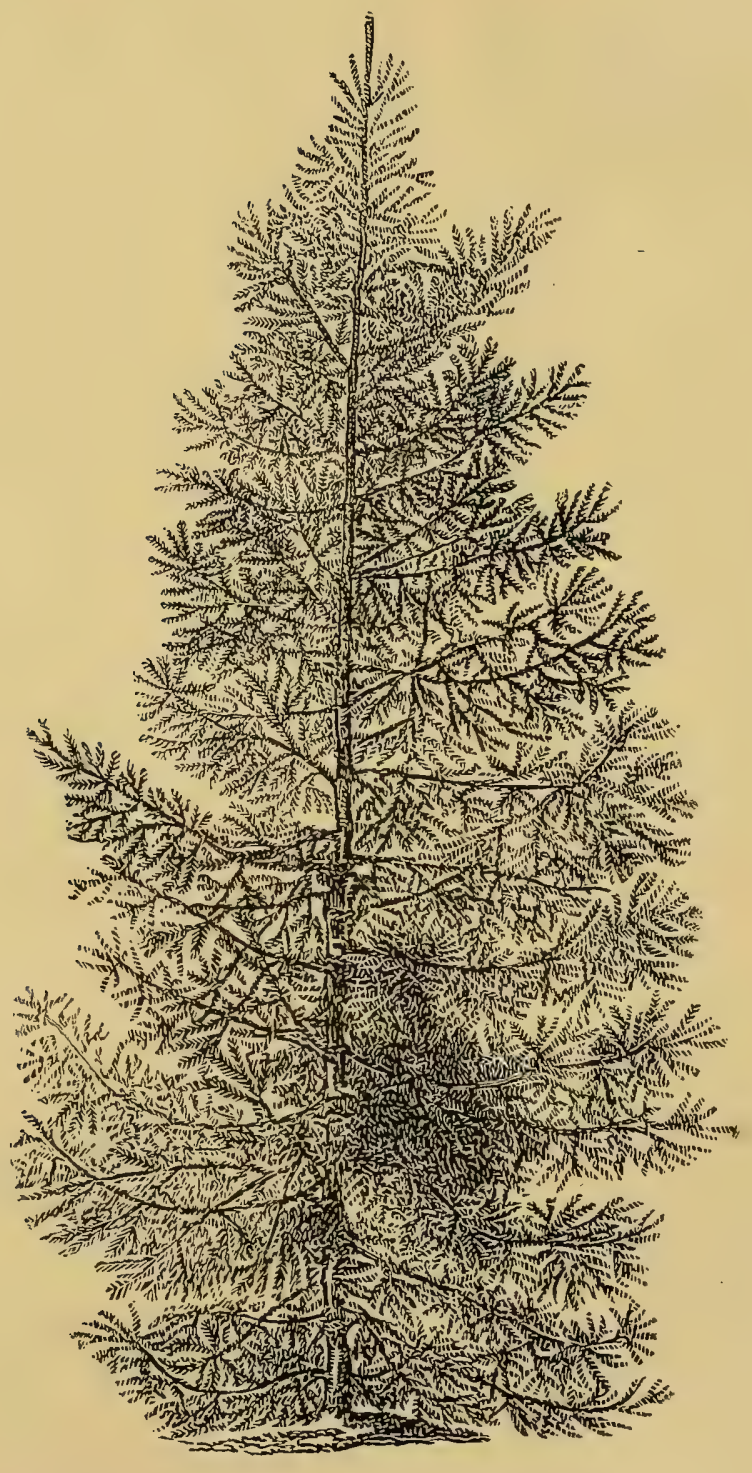

A BIES EXCELSA.

The Spruce Fir.-(SEE PAGE 253.) 




\section{P LATEX.}

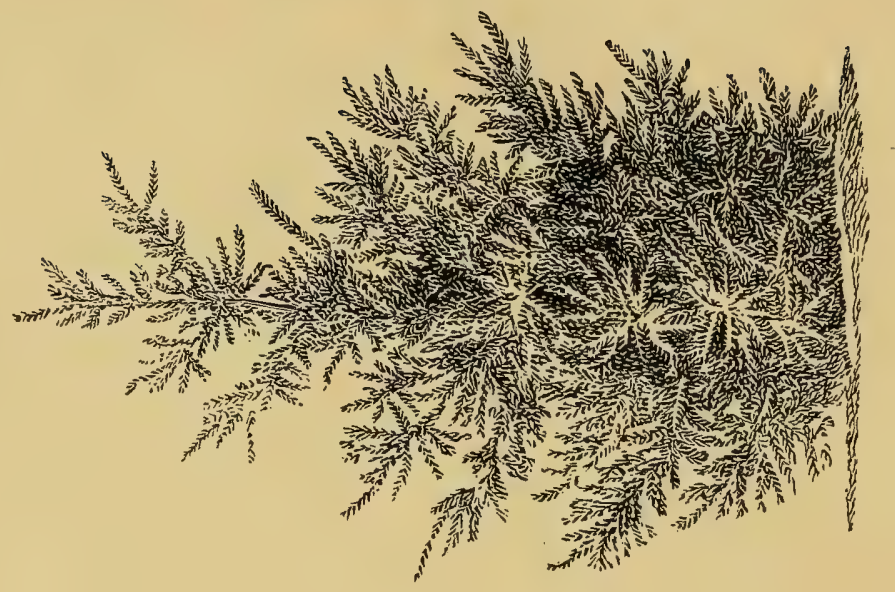

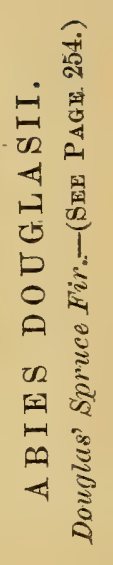

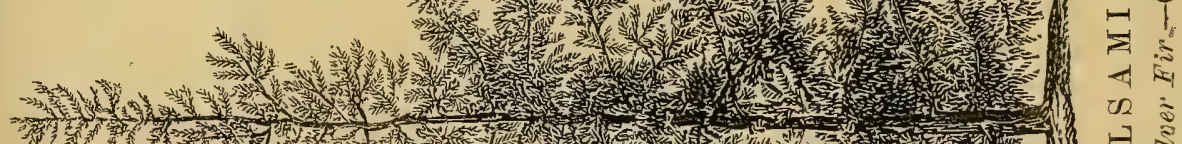

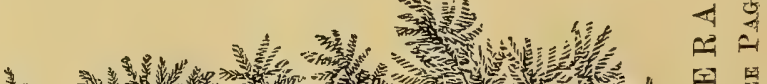
3.

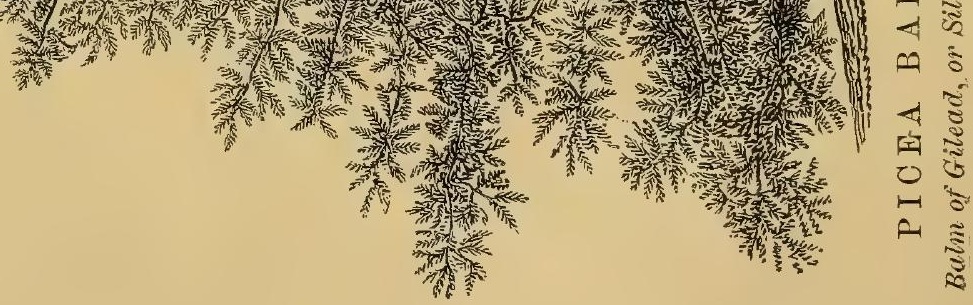





\section{PIATEXI.}

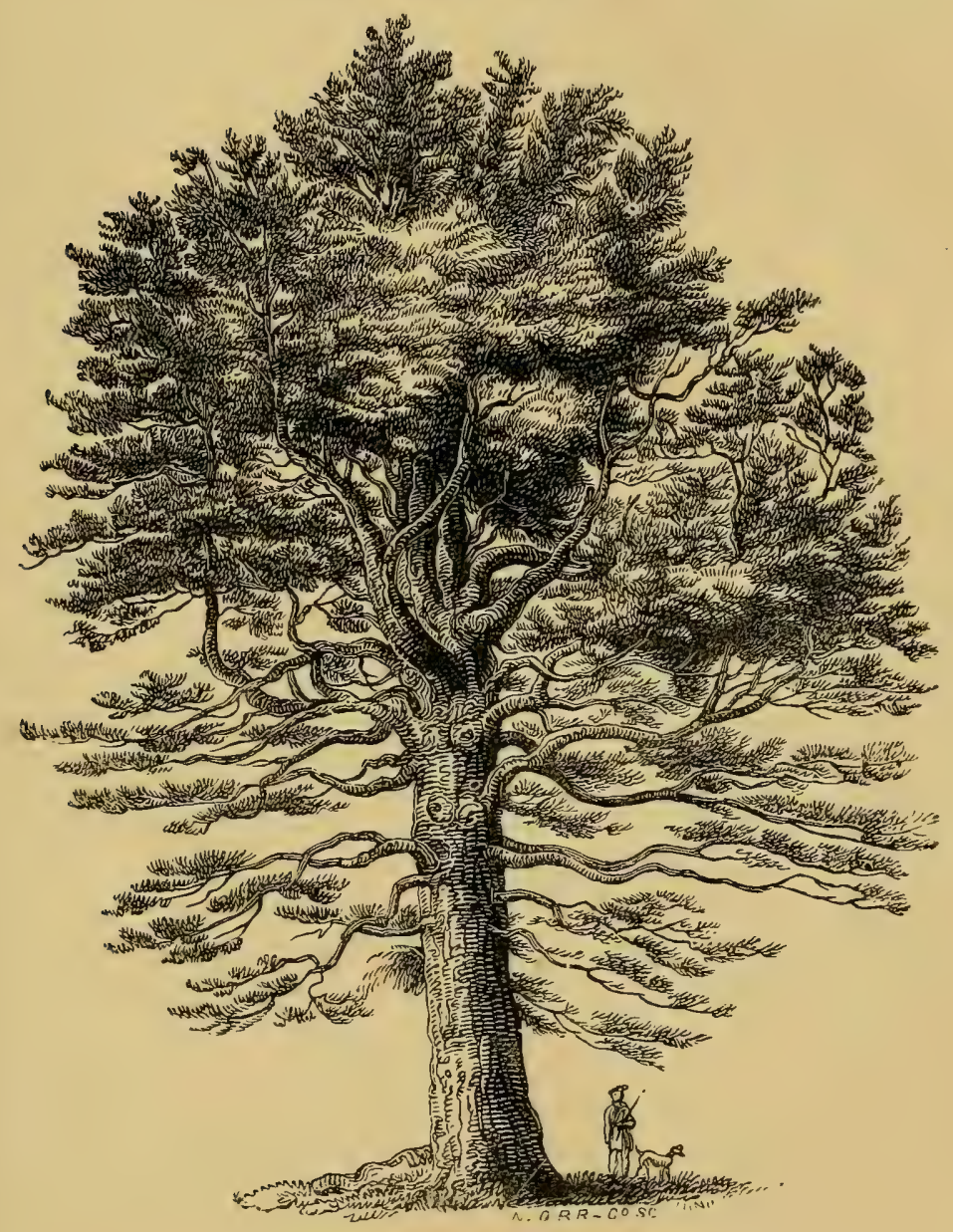

PICEA PECTINATA.

European Silver Fir.-(SEE PAGR 255.) 

us, though deciduous. When young, it is pyramidal; but when old, in the forests, the tree assumes a widespreading flat top. The trunk becomes very thick, often forty feet in circumference. The wood is finegrained and of a reddish color, it is strong and elastic, less resinous than the pines. Branchlets are very slender, elegantly pinnate, the foliage is open, light, and of a fresh tint that is very agreeable, the leaves being small and graceful, becoming red in the Autumn, when they fall. The favorite habitat of the American Cypress is the swamps of the Southern States, where the trees are immersed for months under water. The roots of large trees are furnished with conical protuberances, called knees.

The northern limits of the Cypress are in Delaware, latitude thirty-eight degrees fifty minutes, and on the lower portions of the Ohio river, in latitude thirtyseven degrees thirty minutes. Though naturally a lover of wet places, this tree has a remarkable facility for adapting itself to elevated positions, even those that are dry; but when so situated, it is not likely to fruit. Mr. Loudon has stated that it would not thrive in elevated situations; the contrary is well established. The range of the plant, as already mentioned, is north thirty-eight degrees fifty minutes, thence extending along the Atlantic and Gulf coast, some three thousand miles; but it has been found to do well north and south of these limits, as in Scotland and in Mexico, into which latter country, Humboldt says it was introduced before the invasion of the Spaniards; the noble tree in the garden of Montezuma is supposed to be more than four hundred years old. 
Taxodium sempervirens. This evergreen was discovered by Menzies on the north-west coast of North America; it will probably prove hardy as far north as Baltimore.

Taxodiumcapense is from the Cape of Good Hope; it requires the protection of a greenhouse in northern latitudes.

\section{JUNIPERS.}

Juniperus communis has many varieties of form and foliage. It is generally a bushy shrub, from three to five feet high, sometimes more. The variety Suëcia, is commonly cultivated; it is a native of Sweden, Denmark, and Norway. It is more erect than the common kind, and has larger berries. It grows to ten, twelve, or more feet high. Hardy.

Juniperus communis depressa, is a native of the Northern States; it does not grow more than a foot or two in height; but spreads its branches along the ground in every direction, forming a circle of fifteen or twenty feet in diameter; all of the spray rises gradually and regularly from the level of the ground at the circumference, to the greatest altitude, in the centre. These specimens, as they present themselves on the unfrequented margins of our Northern lakes, are often as regular and perfect as though they had been most carefully tended by the gardener. The Common Juniper, in its native habitat, is a low shrub, seldom rising more than three feet; but under cultivation it may be more fully developed; Loudon gives a portrait of a tree twenty feet high, and five feet eight inches in circumference. This plant is found in 
all the northern parts of Europe, and in very elevated situations in the southern countries; it grows in rocky places in Canada and the Northern States; but it is a question whether the Common Juniper has not been introduced. The variety, depressa, is undoubtedly a distinct species.

Juniperus oxycedrus is closely allied to the communis; it is a shrub from ten to twelve feet high, and feathered from the ground, but more tender, being a native of Spain, Portugal, and the South of France.

Juniperus macrocarpa is a native of Greece; it resembles the oxycedrus, but is a low, thick bush.

Juniperus drupacea is also a large-fruited species. The stem is erect, with spreading branches; it is a native of Syria.

Juniperus virginiana, or Red Cedar, is one of our own most valuable ever-green trees; nothing can exceed its value, for purposes of shelter, to the American agriculturist in the Middle States. It grows from forty to forty-five feet high; the branches spring horizontally and low down the tree. The wood is fragrant, compact, fine-grained, and light, though heavier and stronger than that of the White Cedar or Deciduous Cypress. Cedar Island, in Lake Champlain, lat. $44^{\circ} 25^{\prime}$, is its northern boundary, Cape Florida its southern; it is found along the Gulf of Mexico to beyond St. Bernard's Bay, making its range more than three thousand miles. It also grows in many spots upon the calcareous rocks of the Western States; and though not there a common plant, it is disseminated, directly, by man, as a planter, and indirectly, through 
his agency, by the birds-for in many places it is making its appearance in old fields, and even in the original forests where the seeds have been thus introduced. As an ornamental tree or large shrub it is of great value for grouping, and especially for shelter. This plant is highly esteemed in Europe, but quite too much neglected in our own country; perhaps, because it is so common: its growth is rapid, and it is very hardy. The shelter and food which this cedar affords to the feathered friends of man are a great recommendation to it, and should induce every farmer to plant the tree. The wood is red, fragrant, soft, and fine-grained, and often used in architecture and the domestic arts; but the frequent knots impair its usefulness for some purposes. There are several varieties of this species, among which that called humitis is remarkable for its prostrate character, if indeed the plants on Lake Huron be not a variety of Savin. The trees in Maryland, between Baltimore and Washington, assume an exceedingly regular, pyramidal shape, and remind the observer of the Cupressus sempervirens.

Having said thus much in regard to a favorite tree, while urging my fellow-countrymen not to neglect the culture of this very useful and ornamental evergreen, a suggestion may here be allowed with regard to trimming-which, however, has been perhaps sufficiently urged in the general rernarks upon this subject.

The lowest branches should always be the longest. Never "trim up" an evergreen, unless the lower 
branches have become shabby from neglect or abuse. Extending upper branches should be shortened-in.

Juniperus bermudianc is a tall tree in the Bermudas. The wood is very fragrant. Tender in the North.

Juniperus sabina, or Savin, is a low shrub, but sometimes has an upright trunk, rising ten or twelve feet. The branches are nearly straight, and much ramified, forming a regular low pyramid. Savin is a native of Spain, Italy, part of France, and the Levant. Pallas also refer's it to the Tourian chersonesus. The upright Savin was formerly much used in topiarywork, as this kind of torture does not injure it; but it is hoped that this style of ornamentation will not be considered appropriate to modern ornamental or landscape gardening. In France, it and the Common Juniper are both used to cover walls and other objects that need to be concealed; to which end, the trailing varieties are peculiarly appropriate.

Juniperus daurica is a native of Siberia, a prostrate shrub, trailing upon the rocks.

Juniperus phoenicea is a pyramidal shrub: leaves very small. Loudon says it deserves to be more generally planted. It is from the Levant.

Juniperus lycia. Pallas says it is perfectly prostrate in Siberia, the Levant, and the South of Europe. This Juniper furnishes the Gum Olibanum, supposed to be the incense used by the ancients, and now employed in Roman Catholic churches. It is said to be hardy in England.

Juniperus thurifera, the Spanish or Incense Juniper, is a native of Spain and Portugal-a low, evergreen tree. 
Juniperus cacelsa, the Tall juniper, found in Siberia by Pallas, on the Rock Mountains by Lewis and Clarke, and also on the Himalarahs. This is a rert handsome and elegant tree, with an upright trunk, and slightly pendulous branches. Hardy.

Juniprewe squanata is a trailing shrab, called the Creeping Cedar or Scaled Juniper, found in Nepaulsupposed to be tender.

Juniperus reourva is another native of Nepad-a graceful bush, with pendulous habit.

Juniporus revifere is from Cape Horn, and is believed to be the only species in the Southern Hemisphere. It is a decumbent and much-branched shrub.

Juniperus banbadensis, the Barbadoes Juniper, is a native of the West Indies, and, according to Pursh, of Florida. It is a large timber-tree, with rery widelf-spreading branches. Tender.

Juniperus chinensis, the Ohinese Juniper, is a shrub of three feet in height, with twisted and rery spreading branches.

Taxus, bacouta, the Iew, is a smal bush or tree of great beanty, on account of its dark-green, lanceolate leares, and bright-scarlet coal-like berries. The Yew is indigenous to the most of Europe, to parts of Asia, and one species, the cunadensis, is found in America: this last is not verr well characterized as a distinct species; it is a trailing shrub, nerer rising much from the ground. Some of the rarieties of $\mathrm{YeN}$ are quite as distinct: the firstiginto, or Irish Yew, is remarkable for its upright figure. The Yew has been much planted in old church-yards, in some of which it is 



\section{PLATE XII.}



nै?

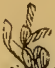

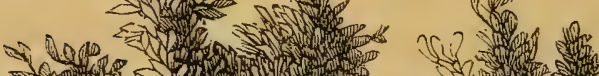

2)



3 -

ॠ

Uै

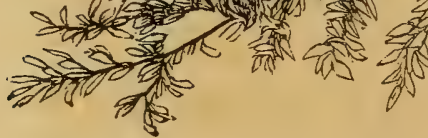

a

I

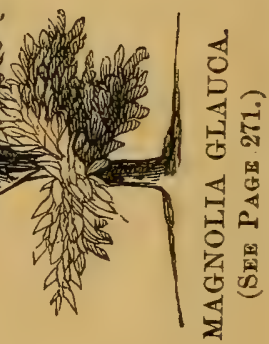

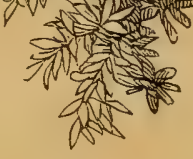

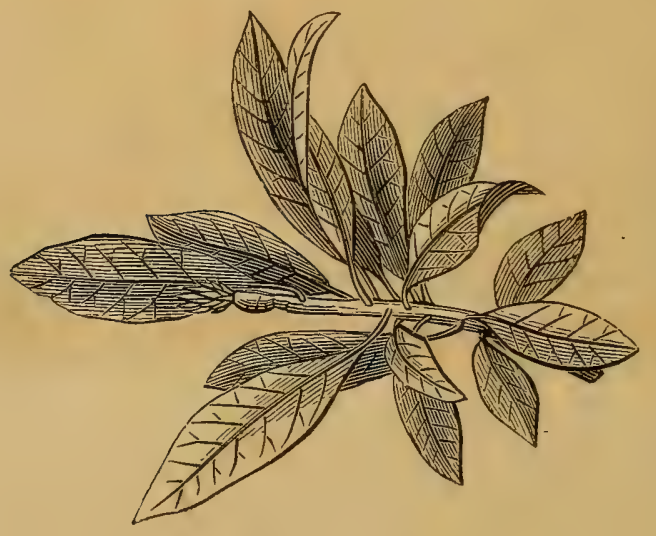

立 
questioned whether the trees or the church be the elder. Evelyn recommends the Yew for hedges, and for topiary ornaments.

\section{OTHER EVERGREENS, NOT TEREBINTHINATE.}

Magnolias.-The M. grandiflora (see Plate XII. A.) is one of the most beautiful evergreens of the Southern United States, rising to a height of from forty to sixty feet in favored localities; it forms a rounded pyramidal head, well covered with large coriaceous shining leaves of great size and beauty-among these, in fine contrast, the very large, pure-white flowers appear, and diffuse a delicious perfume that is almost oppressive at night, if the tree be planted too near a dwelling. This is deservedly a great favorite in the Southern States; but it is not sufficiently hardy to stand the climate of latitude forty degrees, though it has bloomed on that parallel; it is doubtful whether it will repay for cultivation north of thirty-five degrees. Its natural limits are still further south. Several varieties have been originated or disseminated in the European nurseries, among which the Exmouth is the most desirable.

The,M.glauca (see Plate XII., B.) is a smaller species, forming only a slender tree, sometimes attaining the height of fifteen feet. The leaves are smaller than those of $M$. grandiflora; they are of a glaucous green, and are partially deciduous; but, under favorable circumstances, this may be considered an evergreen. The flowers are creamy-white, and very sweet-scented: the natural habitat of the plant is low marshy ground, 
near the sea-coast; but, like many other swamp plants, it bears an elevated situation, if not too dry. There are varieties of this species, the result of accident, or possibly of hydridizing; some of which have a larger foliage than the true $M$. glauca. Thomson's is supposed to be a hybrid between $M$. glauca and the tripetala, a deciduous species. The range is extensive, being found in Massachusetts, and along the Atlantic coast to Florida; but most common in New Jersey and the Carolinas.

Mahonias.-M. aquifolium, or Holly-leaved Barberry, is one of the most beautifullow evergreens, peculiarly adapted for planting around and under a group of other trees. It produces an abundance of yellow flowers, in upright racemes, early in the Spring. As it belongs to the north-west coast of America, we should expect it to be perfectly hardy; but in the Middle States its beautiful leaves are often injured during the Winter. There are several varieties, and perhaps some other species, sold under this name.

The Pittosporum tobira is a half-hardy evergreen, with entire leaves, somewhat lanceolate. In its native country, it sometimes attains a height of twelve feet. The flowers are creamy-white, in clusters, appearing from March to August. In the Southern States, it may be treated as a hardy plant; in the Northern, it needs the protection of a glass-house.

Camellias.-The Camellia genus embraces elegant evergreen shrubs, with dark coriaceous shining leaves, that are remarkably persistent. The Camellia is characterized by the remarkable beauty of its flowers, which occur duringWinter. It is hardy in some of the Southern 
States. The varieties produced by culture are among the most beautiful flowering plants we possess. They need shelter, with very little heat, in the Northern States; but some have been found hardy, even in the south of Scotland. The C. japonica is the species cultivated; it was derived from China.

The Orange, Citrus, is a native of India, well known and much admired for its foliage and fruit. This tree has been cultivated in the Southern States, but has never become acclimated, and is occasionally cut to the ground by Winter frosts; it has many varieties. The limonia is from the Himalayahs, and grows at considerable elevations at Nepaul; but it is not more hardy than the Citrus.

Hollies.-The Holly, Ilex aquifolium, and other species, are among the most beautiful shrubs, sometimes becoming trees. In Europe, the Holly sometimes attains thirty feet elevation; in the Southern States, it is often twenty eight feet high. A great many varieties are sold by the gardeners - which are Fig. 12.

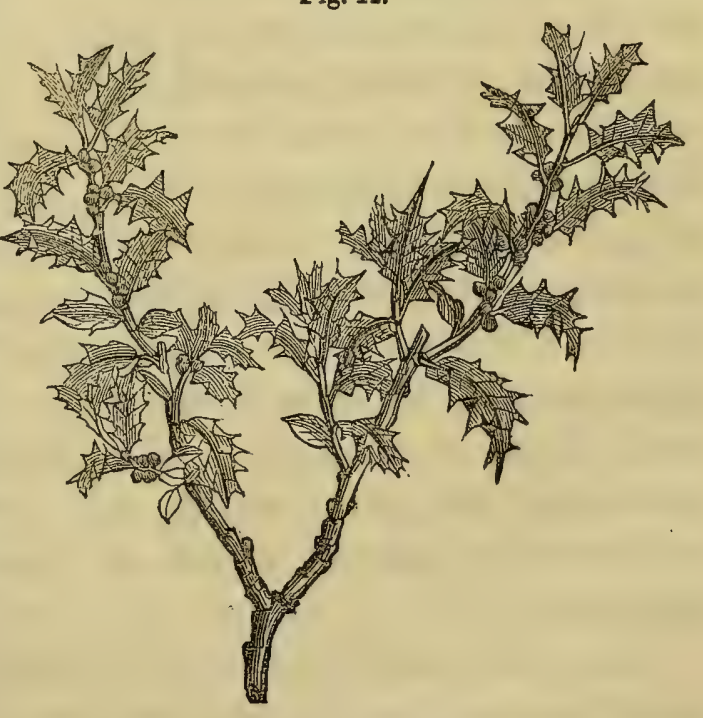
ILEX AQUTFOLIUM. often produced from sprouts; they are variegated, and 
have variously contorted leaves: none are so handsome as the original species, whether the European or American. For ornamenting grounds as single specimens, or for making evergreen hedges, few plants surpass the Holly, with its armed green leaves and bright-red berries. The Ilex aquifolium (see Fig. 12) is native in Middle and Southern Europe; the I. opaca (see Fig. 13), in the Middle and Southern States of the Union; they both prefer low grounds of a sandy character. The Holly has been celebrated in history and poetry, and hasmany associations of an agreeable character. Evelyn had a hedge of it four hundred feet long, nine feet high, and five in diameter, within the protection of which he could discourse with his loves, the trees. ILEX OPAOA-OPAQUT-LEAVED The Holly bears clipping remark-

Fig. 13.

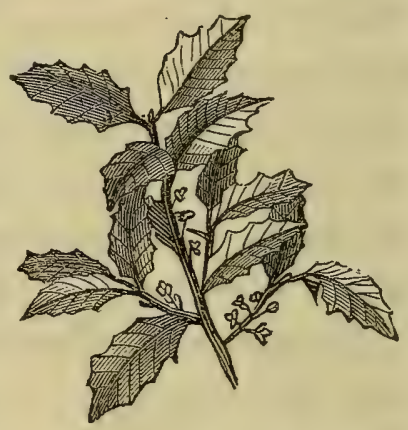
LAUREL.

ably well, and hence it has been a favorite tree with the old-fashioned gardeners, who exercised their artistic skill in carving animals, griffins, columns, and various figures-some of them of the most grotesque appearance-from these trees. This style of ornamental gardening has given way to a better taste, that can admire the natural forms of beauty everywhere prevalent.

The Holly makes the most impenetrable hedge, and also the most durable, as it is a long-lived tree. It is seldom attacked by insects-as most deciduous trees are. The great objection to the Holly for this purpose 
is, that it is .' very slow growth; but its durability and excellence may be urged as an offset. There are holly hedges in France that are two centuries old. As an ornamental tree, it has few superiors. The soil best adapted to this plant is sand, or sandy loam, and we find that it does not succeed well in the stiff limestone clays that abound in many parts of the country. Neither does it bear transplanting as well as some other speries.

Cassine-Ilex Cassine is a low, evergreen tree, of Carolina and Florida, and some other Southern States; it is planted about Mobile-as I learn from Mr. De Forest Holley, an ardent admirer, and successful propagator, of our American evergreens. The leaves are small, like the Arbutus; but the berries are large in proportion, red and persistent during the Winter-as they are not eaten by the birds, they produce a pretty effect. Other species of Ilex are found in the Sonthern States, some of which have merit; but they are not so well known.

The Prinos glaber, or Winter-Berry, is a handsome shrub, growing three or four feet high, and bearing black berries, called ink-berries. It is densely covered with shining green leaves.

The Ulex, or Furze, is a branchy evergreen and spiny shrub, native of Europe, and growing on dry soils. The $U$. europea is that commonly cultivatedit has not obtained much favor in the United States, as it is often killed in the Winter, though it grows well in Scotland, even on the elevated moors.

The Spartium junceum, or Spanish Broom, is a shrub with green twigs, and a few lanceolate leaves 
that drop off: its flowers are papilionaceous and yellow. This plant is very much admired, though only a sort of half-evergreen. The Genistes, hispanica, anglica, and other species, are closely allied, and are also known as the broom, being characterized by their branches and flowers-they are all sub-evergreens.

Cratcegus pyracanthus, or Fiery Thorn, is an evergreen with dark foliage and bright-red berries, which occur in great profusion. It is a native of the South of Europe, and is particularly prized for covering naked walls. It needs a dry soil, as in damp clayey lands about Cincinnati it has sometimes been Winterkilled.

The Photinia serrulate is a small ever-green tree from China. The leaves fall off in May, when they are of a dark and deep red, contrasting with the young foliage very beautifully.

The Myrtle, Myrtus communis, is a common evergreen shrub in the South of Europe, about Marseilles, in France, and in Italy. Among the ancients, it was sacred to Venus. It is cultivated with success in the Southern States; but in the Middle and Northern, it needs the protection of glass. It is always a favorite evergreen wherever known, and much used in the ornamenting of temples and churches where attainable. The Jews, at their festivals, especially, esteem that variety of the broad-leaved Myrtle which has three leaves in a whorl.

The Ivy, Hedera helix, is an ever-green climber, which supports itself by rootlets. This is a universal favorite, and peculiarly appropriate to old ruins, walls, ancient trees, and cemeteries. The ruined towers and 
antique monasteries of England would lose half their charms for visitors were they bereft of their ornamental festoons of Ivy. This plant generally succeeds where it has been introduced into our country; but it bas been found to suffer much from frost in stiff soils, and should be planted on a northern aspect.

The Laurustinus, Viburnum tinus, is an evergreen with dark foliage and fragrant white corymbose flowers. It is a native of the South of Europe, hardy in Great Britain, but a green-house plant in the Northern and Middle States. It flowers from November till April. This plant is used for forming low hedges in flower-gardens, where hardy.

The Rhododendrons are a class of shrubs, usually evergreen, that are characterized by the great beauty of their flowers, and by often having fine foliage. They must have a sandy, peaty soil. The $R$. ponticum and its many varieties attract universal admiration as flowering shrubs. The $R$. maximum is the Bay of our own comntry, where it is also known as the Largeleaved Laurel - it grows in mountainous places, from Canada to Carolina and Alabama. The R. catawbiense, from Carolina (see Fig. 14), has been much used to produce hybrids with the ponticum, which

Fig. 14.

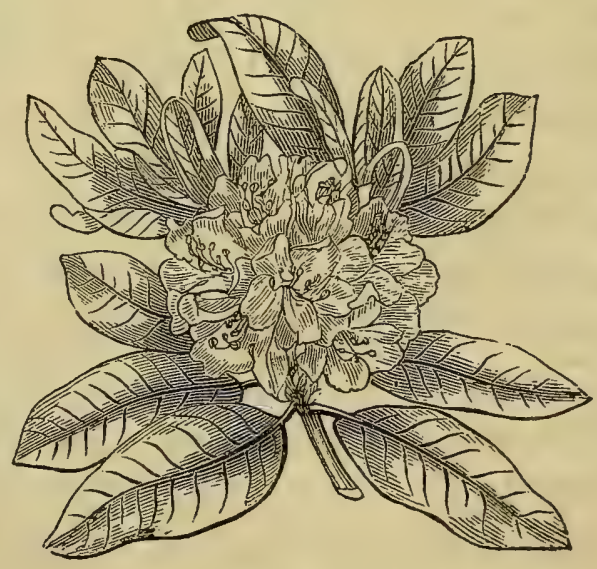

BHODODENDBON OATAWBIENSE. 
are more hardy than the Asiatic species. Rhododendrons flourish best in shady situations, where decaying vegetable matter abounds.

The Kalmias constitute a genus nearly allied to the Rhododendrons. They are low evergreens, and generally known in this country as Laurels. They are found in peaty and sandy soils, and are much prized for their beautiful blossoms and bright evergreen leaves. The $K$. latifotia (see Fig. 15 ) forms one of the greatest ornaments of the mountain forests. It is fond of elevated regions of poor soil, and often grows near the water. The $K$. angustifolia, a small shrub, with dull foliage and very pretty leaves, and other species, are of less value for planting than the latifotia: this, however, like the Rhododendrons, must have a soil that is adapted to its wants-nor will it thrive in

Fig. 15.

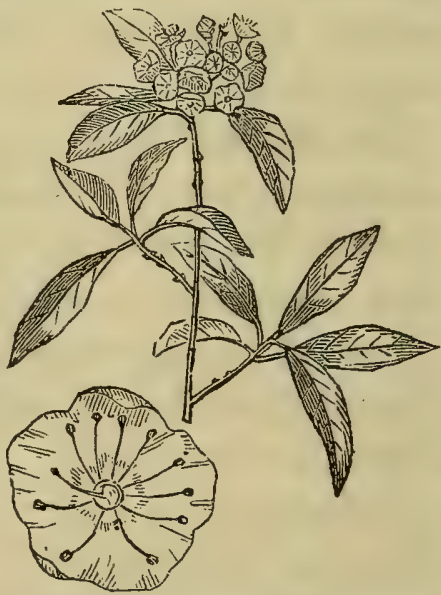
lime-stone clays; though it maLMia LATIFOLIA-BROAD-IFAVED may survive, and even bloom KALMIA.

a few years, it soon dwindles and dies. A soil composed in large part of mould from the woods, or of rotten wood, is peculiarlyadapted to these plants.

The Laurel - Laurus nobilis - or Laurel Bay. This is a large evergreen shrub; it has large, firm leaves that are very aromatic. The flowers are yellow, particularly those upon the male tree. It is a native of the south of Europe and the north of 
Africa, where it attains the height of thirty feet; but in England, it is generally a rambling bush, abounding in suckers. In this country, it is apt to be frostbitten north of latitude forty degrees, and therefore is less of a favorite here than in Europe.

The L. carolinensis, or Carolina Laurel, is a native evergreen, found from Virginia to Louisiana-it sometimes attains considerable height in the South, but never forms a handsome tree. The leaves are six inches long, glaucous, and evergreen. The swamps are its favorite habitat, and it is more beautiful further south than in Virginia.

The Box, Buxus sempervirens, is a well-known evergreen shrub, of great beauty. There are several varieties, belonging to the greater or tree sort, and the less or dwarf. The principal plants representing these classes are: $B$. sempervirens, var. arborescens and suffenticosa. The Box is much admired as an ornamental shrub. The larger kind seldom exceeds twelve or twenty-five feet in height, with a trunk of six or eight inches diameter, furnishing the boxwood for engraving and other purposes in the arts. The small, coriaceous, bright-green and shining leaves, are very persistent, and make this a beautiful evergreen. As the Box-tree bears clipping very well, the smaller is adapted to garden-edging, and the larger to hedges, particularly to subdivisions in cemeteries. This plant has furnished occupation and delight to the old-fashioned gardeners, who carved from it all sorts of verdant architectural and other designs. It is of very slow growth, but of great duration. The Box is native in Europe and Asia; it is abundant in Turkey. 
The Box was much used in the geometrical style of gardening that formerly prevailed. Topiary-work, or the art of cutting trees into artificial forms, was much practiced among the Romans: Pliny uses the word topiarius as a synonym for gardener, showing the importance of this accomplishment to the horticulturist of that day. Verdant architecture and sculpture was much pursued in the seventeenth century.

B. balearicus, the Balearic or Minorca Box, has paler and larger foliage of a less coriaceous character than the sempervirens; but in the shade, its color is deep-green. This plant is common in Turkey; it is hardy in Europe-but in the Northern States, it can scarcely be so considered, though it lives ont of doors. In the Southern States, it thrives admirably. One variety has striped leaves. This sport often produces branches with green leaves.

EvERGReen OAKS-are found in Europe as well as this country, where the Live-Oak and Water-Oaks lend such a charm to the Winter-landscape in the Southern States. The Quercus cerris, or Turkey Oak, in several varieties, as the Fulham and the Lucombe Oaks, are half-evergreen-from the latter, several sub-varieties have been produced that are more persistently evergreen than the parent variety.

The Quercus ilex, Holen or Holly Oak, is an evergreen shrub or small tree in Southern Europe, Africa, and Cochin China. There are numerous varieties, produced from seed. Some others are more or less evergreen.

The Quercus virens, Green or Live Oak, is a magniticent American species, of great size and beauty. 
The timber is exceedingly valuable for ship-building, being very durable. The tree, familiar to all voyagers on the Lower Mississippi, when growing separate, or in small clusters, has a wide tufted summit; Michaux says they attain forty-five or fifty feet. The leaves are oval, coriaceous, dark-green above, and whitish beneath. They are entire in old trees; but in young specimens, often toothed and lobed. This species is confined to the maritime portions of the Southern States. It is found as far north as Norfolk, Virginia. The acorns are sweet, and were used by the aborigines as an article of diet. Michaux says the wood is stronger and more durable than the White-Oak, or any other sort-hence its value for ship-building. The Live-Oak will not make a fine tree in the Northern States; but may be grown, in favorable localities, as a beautiful ornamental straggling evergreen shrub.

Ceratolia ericoides is a small, heath-like evergreen shrub, found in North America, and cultivated in British gardens.

Smilax aspera is an evergreen climbing shrub, with numerous slender, angular stems, armed with short crooked spines, and furnished with tendrils. It is a native of the south of Europe, Asia Minor, and Africa.

Smitax excelsa is a climbing shrub, a native of Syria.

Smilax rubens is a native of North America; it is ornamental, from the contrast between the brightgreen leaves of the red spiral tendrils that accompany them.

Ruscus aculeatus, the Butcher's Broom, is a biennial, that holds its sharp-pointed leaves during the 
Winter. This suffruticose plant has stiff stems, from one and a half to three feet high. The flowers appear on the upper surface of the leaf; but they really spring from the stem, being sheathed by the leaf. It is a native of Europe. It is used for brooms by the butchers. Its use in ornamental planting depends upon its power of growing in the shade, like the Mahonias; and it may be planted under trees with good effect.

Yucca gloriosa.-This kind of Adam's Needle is native of the Southern States and the West Indies. Though hardy in the climate of London, it can scarcely be so considered in the Northern States. The flowers are white, bell-shaped, and beautiful, though scentless. The fibres of the leaves are used by the Indians for making cloth and strings. This species, and some others of the genus, have been cultivated in Florida for the production of cordage.

Yucca superba has a more aborescent stem, and greater whiteness and density of the inflorescence.

Yucca aloifolia is a palm-like tree-stem ten or twelve feet high, with a tuft of stiff narrow, lightgreen leaves ; slightly serrated, and having very sharp spines at their ends. This species is from South America ; it is more tender than the gloriosa.

Yucca draconis has narrow leaves of a dark-green, and pendant; it is a native of South Carolina: the flower-stem is sometimes ten feet high. It is hardy in England.

Yucca stricta, the Upright Yucca, is found in Carolina-leaves narrow and long.

Yucca recurvifotia was found on the sandy shores 
of Georgia by Le Comte-the stem is about three feet high.

Yucca filamentosa, the Bear-grass, has its leaves serrated and thready, without spines. The branching flower-stem rises five or six feet, and is covered with large white blossoms most of its length. This plant is native of Virginia and Kentucky, and is hardy much further north. It has been recommended as an ornamental border to carriage drives, where it will answer as a sort of guard, as it is sessile, the leaves resting upon the ground.

Yucca angustifolia has very narrow leaves. This is also stemless. It was found by Nuttall on the banks of the Missouri.

Chamoerops humitis.-This palm-like plant is not a dwarf, as it grows to thirty or forty feet. It is a native of the south of Europe; but is not hardy, except in the Southern States.

Chamcrops palmetto, the Cabbage Tree, grows forty to fifty feet high-the stem has a uniform diameter, crowned with a regular and tufted head, composed of leaves of brilliant green, palmated and supported by large petioles that are triangular. The leaves are from one to five feet in diameter. They are folded like a fan before their development; and while white and tender, are eaten as a salad. The Palmetto grows on the coast of Carolina and Florida, and the wood is used for making wharves, as it resists the attacks of sea-worms; when submerged, it is durable, though very porous. For the construction of forts or block-houses, it was found that this porous tissue yielded to the cannon balls, and closing after 
them left no rents. The leaves make cheap and light fans and hats.

Arundinaria macrosperma.-The Cane is, in its native State, a very beautiful evergreen upon the sandy bottoms and islands of our southern rivers, and well worthy of culture as an ornamental plant, in soils and situations adapted to it. This plant has rapidly disappeared from many places where it once flourished, as on the banks of the Ohio and many of its lower tributaries; and is also less abundant even on the Mississippi, in consequence of the planters selecting cane lands for their productiveness under tillage.

Agave Americana, or American Aloe, is native of the tropical parts of South America. It has been introduced into the warmer parts of the Old World, where fences are made of it. Its leaves furnish a thready fibre, and a juice that is fermented-also a substance analogous to soap. It has stood the climate of Devonshire, England, and blossomed. The plant there attained its full dimensions-eleven feet in height, and sixteen feet in diameter-in twenty years, when it threw up a flower-stem twenty-seven feet high, and bore sixteen thousand blossoms. The Aloe develops itself grandly in the Southern States; but in . the Northern, must be kept in a conservatory. 
LIST OF DESIRABLE' EVERGREEN TREES AND SHRUBS.






\section{(CONTINUED.)}

\begin{tabular}{|c|c|c|}
\hline NAME. & $\begin{array}{c}\text { Feet high } \\
\text { when full } \\
\text { grown. }\end{array}$ & REMARKS. \\
\hline 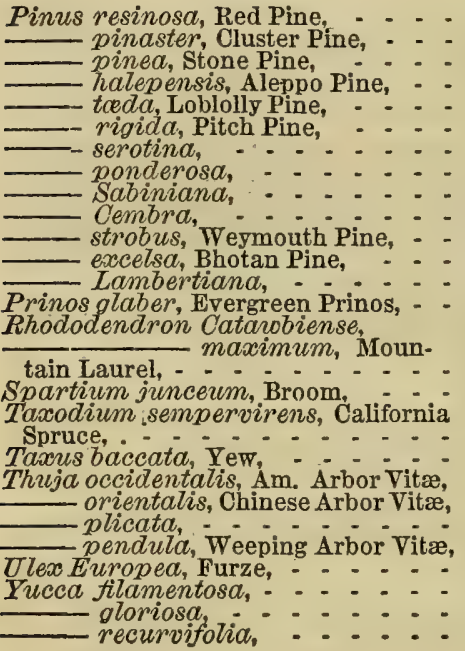 & \begin{tabular}{|c|}
70 to 80 \\
40 to 60 \\
50 to 60 \\
30 to 50 \\
80 \\
70 to 80 \\
35 to 40 \\
60 \\
100 to 130 \\
50 \\
100 to 180 \\
90 to 100 \\
150 to 200 \\
6 \\
8 \\
12 \\
12 \\
100 \\
20 \\
40 to 50 \\
18 to 20 \\
30 \\
20 \\
12 \\
3 \\
4 \\
5
\end{tabular} & $\begin{array}{l}\text { N. Amer., hardy, dark green foliage. } \\
\text { Europe \& Asia, pyr., rapid growth, hardy. } \\
\text { south of Europe, slow growth, hardy. } \\
\text { rapid growth, sprdg. head, tender at N.Y. } \\
\text { N. Amer., rapid growth. } \\
\text { "6 hardy. } \\
\text { "6 hardy } \\
\text { California. } \\
\text { slow growth, hardy. } \\
\text { N. Amer., vigorous growth, hardy. } \\
\text { Himalayas, handsome pyr., hardy. } \\
\text { N. Amer., branches pendulous, hardy } \\
\text { N. Amer., hardy. }\end{array}$ \\
\hline
\end{tabular}




\section{I $\mathrm{N} \quad \mathrm{D} \quad \mathrm{E} \quad \mathrm{X}$.}



Abietinæ; characteristics of. .........244

Agave, hedges of. ................242

Agave americana...............284

Alabama, laws regarding fences......154

Althea..........................46

Aloe, hedges of ....................242

Aleppo Pine....................247

Andalusia, hedges of. ...............242

American Aloe................284, 241

American Arbor Vitæ...........42, 240

American Red Spruce............... 43

American Black Spruce............. 43

American White Spruce.............253

American Silver Fir..............256

Appendix........................169

Arancarias ......................259

Araucaria imbricata.............259

" $\quad \begin{aligned} & \text { "raziliana..............259 } \\ & \text { " } \\ & \text { Cunninghanii..........260 }\end{aligned}$

Arboretum britannicum............243

Arandinaria macrosperma.........284

Arbor Vitæ, Weeping..............262



" Chinese.............42, 261

" American...........42, 240

Austrian Pine..................247

Banksiana ................... 46

Barberry ..................... 45

Barbadoes Junipera.................270

Barry, P., quoted.................... 49

Balm of Gilead. ...................256

Berberis vulgaris .... .......... 45



Bhotan Cypress..................264
PAGE

Birch....................... 48

Bill-hooks ..................... 98

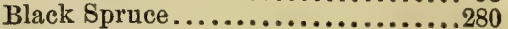

Bourault Rose...................4 47

Bodark (Bois d'arc)................. 32

Browne, D. J., quoted..................... 40

Broad-leaved Kalmia..............278

Buckthorn .....................25, 30

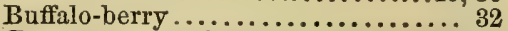

Buxus sempervirens ...........43, 279

"6 balearicus..................280

Butchers' Broom....................281

Cahbage Tree.....................283

Cactus, hedges of........................242

Calabrian Pine.................... 249

California, laws regarding fences.....164

Calitris quadrivalvis .............263

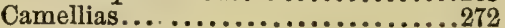

Carolina Rose..................... 33

Castor Beans to keep away moles.... 61

Catalogue of Evergreens........243

Cedars ..........................258

Cedrus libani...................258

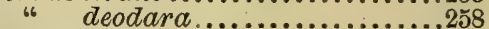

Cedar, Portugese....................... 264

Cedar, Red..............240, 267, 269

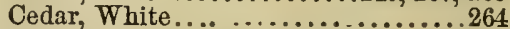

Cephalonian Spruce Fir .........255

Ceratolia ericoides...............281

Cerasus Caroliniana..............44

Chamoerops humilis .................283

Cherokee Rose................. $33,46,240$

Chinese Arbor Vitæ..............42, 261

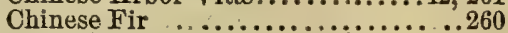

Chinese Juniper....................270

Chinese Multiflora.................46,49

Cincinnati Horticultural Society, Re-

port to.....................215

Citrus ........................273

Cluster pine .....................248

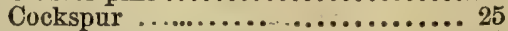

Coniferous Evergreens .............243

Corsican Pine.....................247

Connecticut laws regarding fences..... 147 
Cost of hedging ...............108, 111

Cost of fences................121, 172

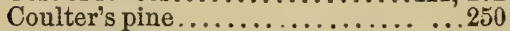

Crab Apple.................... 26

Cratcegus oxycanthus ............ 24

$$
\text { " pyracanthus.........49, } 276
$$

crus-galli.............25

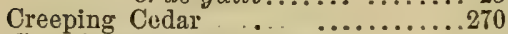

Cunninghamia Sinensis............260

Cultivation of hedges, 1 st year....79, 217

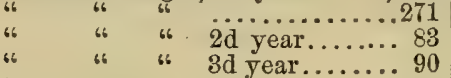

"6 "6 6 4 4th year.......99 90

Cupressinæ.....................244

Cupressus sempervirens...........263

"6 $\quad$ thyoides ..............263

torulosa...............264

Cydonia pendula ............264

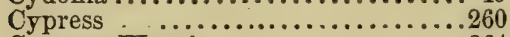

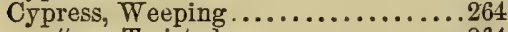

"6 Twisted...............264

"6 Bhotan.................264

6. Evergreen..............263

Dammara orientalis ............260

" occidentalis............260

Deodar Cedar ..................258

Defects in hedges.................116

Dibble ........................ 97

Distance of setting plants, $74,79,188$, $240,217,218$

Dwarf Box.................. 44

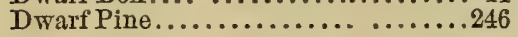

Economy of Hedges............. 17 English Hawthorn . . . . . . . . . . . 24

English $Y e w \ldots . . . . . . . . . . . . .44$

Ernst, A. H., quoted......29, 39, 186, 203

European hedging.................130

European Silver Fir..............255

Euonymus. .....................240

Evergreen Oaks .................280

Evergreen Hedges.................240

Evergreen Cypress................263

Evergreens, Catalogue oF.......243

Evergreens, transplanting .........228

"6 distance to plant.......240

" essay upon.............223

"6 as an ornament.......2283

"6 for shelter .........227

(6 economy of planting...226

"6 root-pruning of........229

"6 time to transplant... . .2232

6 landscape effect of......233

". . "trimming up".........234

"s grouping .............234

"6 for the South .........235

"6 pruning ...........235, 241

6. manure for...........231

" terebinthinate.........243

. not terebintbinato......271
PAGE

Fagus sylvatica $\quad \ldots . . . \ldots \ldots \ldots 48$

Failure of hedges. . . . . . . . . . . . 50, 204

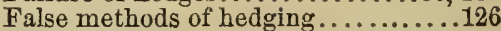

Fences, laws of the different States regarding .................. 143

Finishing hedge..................95, 105

Fiery Thorn...................276

Firs........................275

Fir, American Silver.............256

Fir, European Silver. . . . . . . . . . . . 258

Florida laws regarding fencing.......155

Frankincense Pine................249

Furze.....................275

Gano, Daniel, letter from..........202

" introduced the Maclura at Cincinnati................. 40

Georgia laws regarding fences....... 154

Gleditschia tricanthus............27

Glory of Rosamenes............... 47

Grouping Evergreens...............234

Hawthorn, English ............ 24

Hedge-making. . . . . . . . . . . . . . 67

Hedge, setting..........66, 69, 182, 217

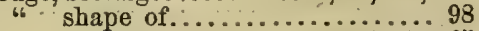

6. . replanting................. $83,73,65$

Hedges in the West.............. 14

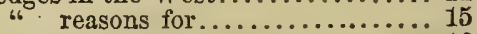

6. in the Bible............... 16

6) among the ancients.......... 16

"6 economy of................. 17

"6 cost of ...........................

" beauty of.................... 18

"6 for protection............. 19, 23

6. 6 ornament $\ldots \ldots \ldots \ldots \ldots \ldots . \ldots . \ldots . \ldots, 45$

"6 "shelter............23, 19, 41

s6 effect on climate............. 19

6. morality of................ 21

6. choice of plants for............. 23

" for the South.............. 44

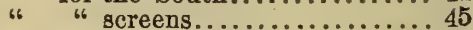

" Prickly Pear for................241

" of the Cherokee Rose.......... 34



Hemlock................43, 240, 254

Hibiscus syriacus................... 46

Holly.................... $240,240,273$

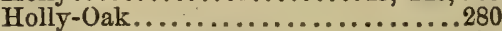

Holly-leaved Barberry...............272

Honey-Locust. . . . ............27, 80

Horse-power for trimming . . . . . . . . . 98

Horticulturist quoted...........28, 125

Ilew opaca................43, 274

"6 aquifolium......................273

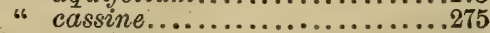

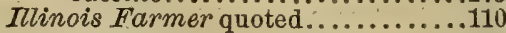

Illinois laws regarding fences.........160

Implements..................... 95

Incense Juniper.......................269

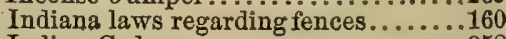

Indian Cedar ....................258

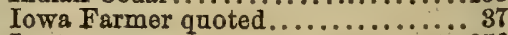

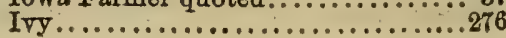


Jersey Pine.................... 245

Junipers.....................266

Juniperus virginiana........41, 267 suecica.............. 43 communis .............266 depressa.............266 oxycedrus .............267 macrocarpa...........267 drupacea.............267 bermudiana...........269 Sabina .................269 daurica ..............269 Phcenicea.............269 lycea ................269 thurifera..............269 excelsa ................270 squaniata..............270 barbadensis ...........270 chinensis..............270

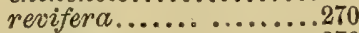
recurva..............270

Jurisprudence of fences............. 143

Kalmia angustifolia

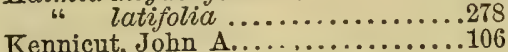

.278

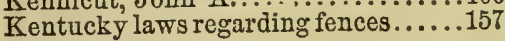

Labrador Pine...............245

Landreth, D., quoted ................243

Landscape effect of Evergreens......233

Larch Pine ...................247

Laurel, Opaque-leaved.............274

"6, Carolina.................279

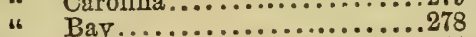

Laura Davoust................... 46

Lauri Mundi .....................240

Laurus nobilis.................278

"6. carolinensis ............279

Laurustinus ..............44, 277

Laws on fencing...................148

Leader, remedy for loss of. . . . . .236, 244

Ligustrum vulgare.............. 45

Live-Oak......................280

Live-fences, history of............ 13

Lilac ....................... 46

List of Plates and Engravings.........

shrubs...................285, 286

Loudon, J. C., quoted.................243

Louisiana laws regarding fences........ 156

Maclura auriantica.....32, 35, 173, 215

Maclurn Hedge................ 50

Maclura, nativity of..............216

Magnolia grandiflora..............271



McGrew, James..............52, 66, 170

Mahonia aquifolium...............272

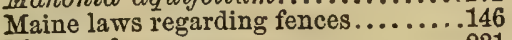

Manure for evergreens.............231

Maryland laws on fences ............ 142

Michaux ......................243

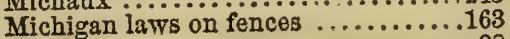

Miller, $\mathbf{E}$.
Mississippi laws on fences............158

Missouri laws on fences.............156

Mock Orange . ............. 46

Moles, to avoid the attacks of......61, 74

Mountain Pine................ 245

Mulching.............. $44,60,80,93,94$

Myrtle ....................276

Ifyrtus communis...............276

New Hampshire laws on fences. .....147

New Jersey laws on fences...........149

New York laws on fences............ 148

Noble Silver Fir ...............257

North Carolina laws on fences..........153

Norfolk Island Pine.............. 259

Norway spruce ...............42, 240

Nursery, hedge-plants in.......62, 181

Oaks, Evergreen................44

Objections to hedges.............. 120

Ohio laws on fences...........158, 182

Old hedges made valuable.......... 214

Opaque-leared Laurel............. .274

Orange, Wild.................. 44

Osage Orange...32, 35, 36, 107, 173, 194, 215

Osage Orange hedges, value of. ......174

Overman, C. R.....36, 50, 58, 65, 106, 118

Palmetto ......................283

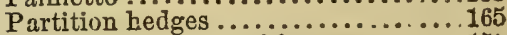

Pennsylvania laws of fences ......... 150

Philadelphus grandifiora......... 46

Photinia serulate................276

Picea pectinata.................255

6. pichta .....................256

. balsamea..................256

" Fraseri...............256

"grandis....................256

" amabilis...................256

s nobilis....................257

"Webbiana...............257

" Pindrow...................257

" bracteata.................257

"6 religiosa....................257

Pines with two leaves in a sheath...245

Pines with three leaves in a sheath. .249

Pine, Red........................247

${ }_{66}$ Austrian....................247

" White....................247

" Aleppo....................246

"4 Jersey.....................249

6. Pitch......................247

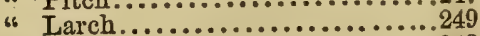

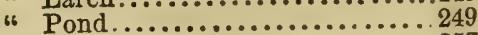

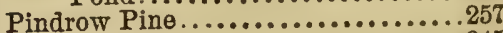

Pinus sylvestris...................245

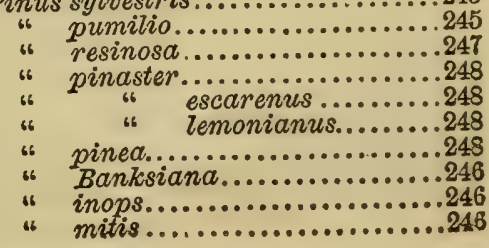




\begin{tabular}{|c|c|}
\hline & PAC \\
\hline Pinul & pungens. \\
\hline & laricio..... \\
\hline 66 & "6 austriaca........ \\
\hline แ & Pallasiana....... \\
\hline 66 & halepensis.............. \\
\hline 66 & brutia... \\
\hline 66 & toeda. \\
\hline 66 & rigida................ \\
\hline 6 & 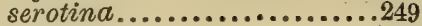 \\
\hline "6 & ponderosa............. \\
\hline 66 & Sabiniana........... \\
\hline 46 & coulteri. \\
\hline 66 & Gerardiana........ \\
\hline 66 & australis ................250 \\
\hline 66 & 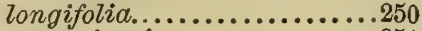 \\
\hline 6 & 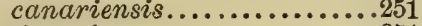 \\
\hline " & sinensis. \\
\hline 66 & insignis .................. \\
\hline 6 & teocote................... \\
\hline 66 & 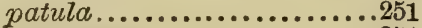 \\
\hline 66 & Zlaveana................ \\
\hline 6 & californiana.... \\
\hline 6 & occidentalis... \\
\hline 66 & Zeiophylla....... \\
\hline 6 & cembra.... \\
\hline "6 & strobus. \\
\hline 6 & excelsa \\
\hline "6 & Lambertiana... \\
\hline " & monticola.............. \\
\hline
\end{tabular}

Photinia serulate.................276

Pittosporum tobira...............272

Pitch Pine......................249

Pitch Silver Fir...................256

Planting seed of Osage Orange.......216

Plashing................105, 118, 192

Plicate Arbor Vitæ...............261

Pond Pine...................... 249

Portugmese Cedar..................264

Prairie, hedges for................. 37

Prairie Farmer.........20, 21, 80, 197

Prairie Rose.................... 49

Preface........................... 5

Preparation of hedge-row.........667

Prickly Pear, hedges of .........241, 242

Prickly Cone Pine................250

Prinos glaber......................275

Privet......................29,45

Pruning ....... $79,8499,183,206,217,235$

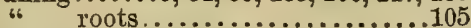

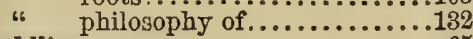

Paddling.....................65

Pyrus coronaria................ 26

" japonica..................... 49

Pyramidal shape for hedges.......... 98

Quercus cerris..................280

" ilev...................280

virens..................280

Red Cedar .....................267

Red Pine.....................247

Reid, William, opinion quoted.......28

Replanting hedge..............66, 83

Rhamnus catharticus................ 25

Rhododendron ponticum..........277

$$
\text { " mavimum }
$$

Rhododendron catarobiense .......277

Root-pruning...................... 229

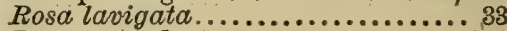

Ruscus aculeatus.................281

Savin........................269

Scotch Pine...................245

Setting the hedge...........66, 182,217

Seeds, selection of................ 55

"6 sprouting...............55, 179

"6 planting............59, 180, 216

Shepardia eleagnoides............. 32

Shears......................... 98

Siberian Crab-Apple.............. 48

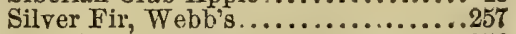

American.............256

"6 $\quad$ American...................256

Smilaw aspera......................281

"6 excelsa...................281

rubens.................281

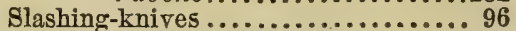

Sleeper \& Lindley, letter from......215

Sorting the hedge-plants........... 65

South Carolina laws on fences.........153

Southern Pine...................250

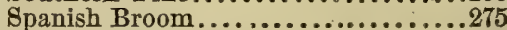

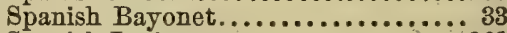

Spanish Juniper. . . . . . . . . . . . . . 269

Spartium junceum...............275

Spring Grove Cemetery Hedge......217

Stone Pine......................248

Summer-pruning hedges.........91,92

Swedish Juniper.................76, 43

Sylva Americana.................243

Table Mountain Pine..............247

Tartary Pine....................247

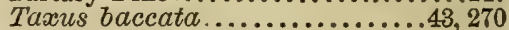

Taxodium distichum..............264

"6 sempervirens.............266

"6 capense................266

Terebinthinate Evergreens..........243

Tennessee laws on fences........... 157

Texas laws on fences.............162, 270

Thuja occidentalis..............42, 260

6 orientalis...............42, 261

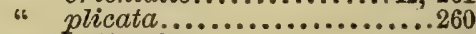

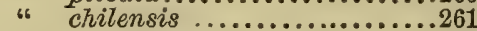

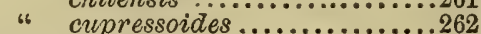

" pensitis...................262

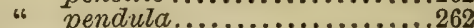

Transplanting evergreens...............228

Transplanting hedge-plants.........63, 66

Tree, Box...................... 44

Trenching-in the hedge-plants.......65

Trimming evergreen hedges.........241

"Trimming up" Evergreens..... 234, 269

Trowel for transplanting ............ 98

Turkey Oak........................2s0

Turner, J. D., quoted............... 111, 197, 200

Twisted Cypress.................264

Otex eùropsa...................275

Valley Farmer quoted. . 255 
PAGE

Vormont laws on fences

Viburnum tinus............ 44.147

Washington Thorn

Water Oak.....................280

Webb's Silver Fir.................257

Weeping Arbor Vitæ..............262

Weeping Cypress...................264

Weymouth Pine..................252

Western Horticultural Revievo... . 29, 74

White Cedar......................264

White Thorn..................... 29

Wild Orange.................... 44

Willard, J. F., quoted...............121
Winter-berry .....................

Wintering the hedge-plants. ........ 64 Wisconsin laws on fences.............161

Yellow Pine ...........245

Yew......................... 43,270

Yucca an gustifotia..............283

"6 aloifolia.................33, 282

"6 gloriosa ..................282

"s superba.................282

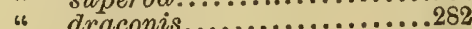

"s stricta ..................282



"6 filamentosa...............288 


$$
\because
$$$$
\text { "F } 909^{\circ}
$$ 




\section{LIBRARY OF CONGRESS

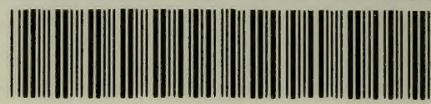

00009108609 